University of Louisville

ThinkIR: The University of Louisville's Institutional Repository

$5-2018$

\title{
An examination of individual teacher engagement and school climate characteristics that influence highly effective veteran teachers to remain teaching in low-performing schools.
}

Terrie Elizabeth Blackman

University of Louisville

Follow this and additional works at: https://ir.library.louisville.edu/etd

Part of the Educational Leadership Commons

\section{Recommended Citation}

Blackman, Terrie Elizabeth, "An examination of individual teacher engagement and school climate characteristics that influence highly effective veteran teachers to remain teaching in low-performing schools." (2018). Electronic Theses and Dissertations. Paper 2929.

https://doi.org/10.18297/etd/2929

This Doctoral Dissertation is brought to you for free and open access by ThinkIR: The University of Louisville's Institutional Repository. It has been accepted for inclusion in Electronic Theses and Dissertations by an authorized administrator of ThinkIR: The University of Louisville's Institutional Repository. This title appears here courtesy of the author, who has retained all other copyrights. For more information, please contact thinkir@louisville.edu. 


\title{
AN EXAMINATION OF INDIVIDUAL TEACHER ENGAGEMENT AND SCHOOL CLIMATE CHARACTERISTICS THAT INFLUENCE HIGHLY EFFECTIVE VETERAN TEACHERS TO REMAIN TEACHING IN LOW-PERFORMING SCHOOLS
}

\author{
By \\ Terrie Elizabeth Blackman \\ B.A., University of the West Indies, 1995 \\ M.Ed., University of Louisville, 2007

\begin{abstract}
A Dissertation
Submitted to the Faculty of the

College of Education and Human Development of the University of Louisville in Partial Fulfillment of the Requirements

for the Degree of

Doctor of Education

In Educational Leadership and Organizational Development
\end{abstract}

Department of Educational Leadership and Organizational Development

University of Louisville

Louisville, Kentucky

May 2018 
Copyright 2018 by Terrie Elizabeth Blackman

All rights reserved 



\title{
AN EXAMINATION OF INDIVIDUAL TEACHER ENGAGEMENT AND SCHOOL CLIMATE CHARACTERISTICS THAT INFLUENCE HIGHLY EFFECTIVE VETERAN TEACHERS TO REMAIN TEACHING IN LOW-PERFORMING SCHOOLS
}

\author{
By \\ Terrie Elizabeth Blackman \\ B.A., University of the West Indies, 1995 \\ M.Ed., University of Louisville, 2007
}

A Dissertation Approved on

April 26, 2018

By the following Dissertation Committee:

Dr. William Ingle (Co-Chair)

Dr. Brad Shuck (Co-Chair)

Dr. Blake Haselton

Dr. Georgia Hampton 


\section{DEDICATION}

This dissertation is dedicated to my husband Orville and my daughter Robyn. Thank you

for the physical, emotional, and spiritual support you gave throughout my studies. I could not have done it without you. I love you both, very much. I would also like to dedicate this study to "Ma" my grandmother for instilling in me determination and faith in God. Mum, thank you for encouraging me when I was tired and it was hard to see the end. You told me you knew I could do it. I dedicate this study to the hundreds of veteran teachers who make a difference in the classroom every day. This study is your voice. Finally, I dedicate this study to my Heavenly Father. "Lord, use it as you will and for your purpose.” 


\section{ACKNOWLEDGEMENTS}

I would like to thank my dissertation chairs, Dr. William Ingle and Dr. Brad Shuck for their guidance and dedication in helping me think through all of the critical factors needed to make this study applicable to the school environment. Thank you for the critical feedback and encouragement to stay focused on my personal goals. I would also like to thank Dr. Blake Haselton for his invaluable guidance and support and Dr. Hampton, who encouraged me and helped to add relevance to the information in this study.

I would also like to thank my husband, Orville for his strength, encouragement, patience, and understanding from the very beginning of this process. I could not have done it without your constant prayers, words of inspiration, and suggestions, especially when I felt tired and discouraged. Robyn, your words of encouragement and belief in me inspired me to run the course. Thanks to my dear friends Gregory, Sandra, and Liz who have supported me in so many ways. Thanks to my colleagues Darlene, Geena, Chelsea, Natalie, and Dana who "filled the gap" in my times of need.

Most of all, eternal thanks to my Heavenly Father who assured me that I was not

alone in this process. Father, you were with me every step of the way, "Thank you, God for your faithfulness!” 


\title{
ABSTRACT \\ AN EXAMINATION OF INDIVIDUAL TEACHER ENGAGEMENT AND SCHOOL CLIMATE CHARACTERISTICS THAT INFLUENCE HIGHLY EFFECTIVE VETERAN TEACHERS TO REMAIN TEACHING IN LOW-PERFORMING SCHOOLS
}

\author{
Terrie Elizabeth Blackman
}

April 27, 2018

It has been established that attrition of both novice and veteran teachers, but particularly novice teachers, is an ongoing challenge in the United States. The literature confirms that teacher attrition is most prevalent in schools that are hard to staff. Researchers described these schools as urban schools serving high numbers of underprivileged, minority students typically taught by new, inexperienced, and often ineffective teachers. Having large numbers of beginning teachers and increasing numbers of veteran teachers exiting teaching is disruptive to the social, emotional, and academic well-being of the students and prevents schools and school districts from reaching statemandated student academic goals. A large percentage of beginning teachers typically leave teaching within three to five years after beginning the job.

Empirical literature attests to teachers becoming more effective with experience. Beginning teachers leave before they acquire the knowledge and skills needed to become effective teachers. It is therefore critical to retain highly skilled and knowledgeable veteran teachers who can lead in the turnaround process. This research proposes that there are still pockets of highly effective veteran teachers who still teach in low- 
performing schools, who are experts in their field and therefore possess the skills and knowledge to lead in the turnaround process. It is critical for schools and school districts to find ways to retain these teachers.

In this qualitative single instrument case study, I used semi-structured open-ended questions to gain information, hear and interpret participants' understanding of three main factors. First, I sought to understand the characteristics of highly effective teachers as reported by principals, teachers-colleagues of highly effective veteran teachers, and highly effective veteran teachers. Second, the ways in which highly effective veteran teachers engage in low-performing schools as reported by principal, teacher-colleagues of highly effective veteran teachers, and highly effective veteran teachers. Third, the perspectives of highly effective veteran teachers on engagement and how engagement contributes to their commitment to continue teaching in low-performing schools. Finally, implications for practice and future research were discussed. 


\section{TABLE OF CONTENTS}

PAGE

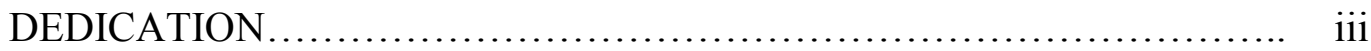

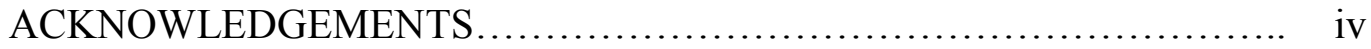

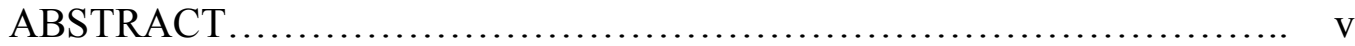

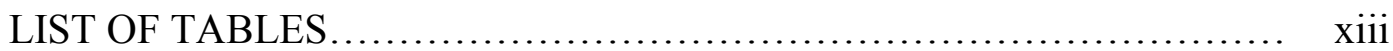

LIST OF FIGURES ................................................. xiv

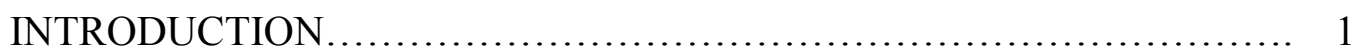

Background to the Problem.......................................... 3

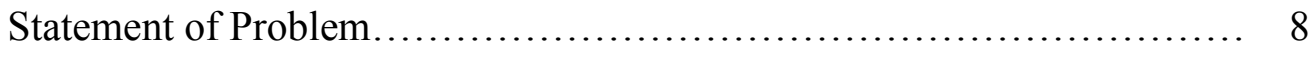

Research Questions............................................. 10

Conceptual Framework........................................... 11

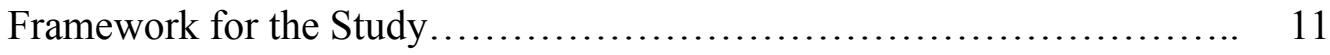

Assumptions of the Study .......................................... 16

Delimitations.......................................................... 17

Limitations........................................................... 18

Definition of Terms................................................... 20

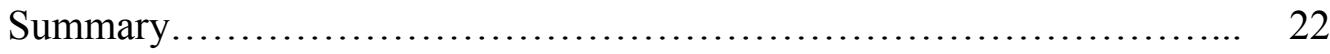

LITERATURE REVIEW ................................................... 23

Employee Engagement............................................ 25

Antecedents to Employee Engagement.......................... 30

Measurement of Teacher Engagement............................ 32 
Employee Engagement Framework............................ 34

Factors Related to Teacher Attrition............................... 38

School Climate............................................. 38

School-Level Characteristics.............................. 39

Classroom Characteristics.................................... 45

Teacher Characteristics.................................. 51

Teacher Experience and Teacher Effectiveness................. 54

Teacher Quality and Attrition................................. 61

Gender................................................ 65

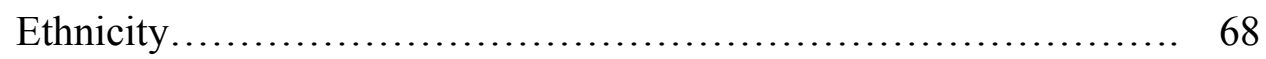

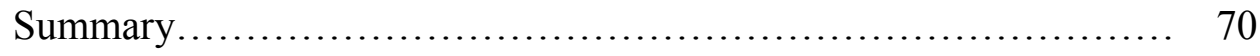

Why Do Veteran Teachers Remain Teaching in Low-Performing

Schools? .................................................................................... 71

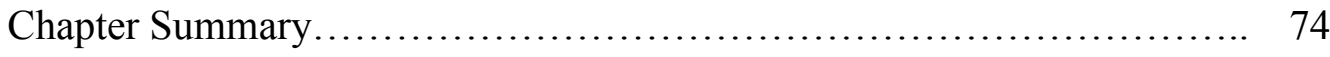

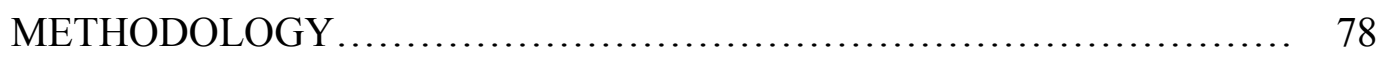

Research Questions........................................... 78

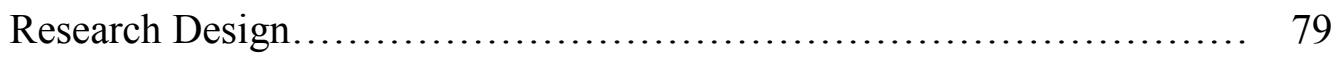

Context of the Study......................................... 82

Data Collection.............................................. 85

Data Sources.............................................. 88

Institutional Review Board Approval and Ethical Considerations......... 90

Data Analysis.............................................. 90

Validity and Reliability $\ldots \ldots \ldots \ldots \ldots \ldots \ldots \ldots \ldots \ldots \ldots \ldots \ldots \ldots, 93$ 
Researcher's Positionality ........................................... 97

Chapter Summary ..................................................... 99

FINDINGS...................................................... 101

Profiles of Participants and Their School............................... 103

Findings from Interviews in Response to Research Question 1.......... 105

Findings from Participants' Interviews............................ 105

Building Relationships with Students........................... 107

Planning and Instruction......................................... 109

Professional Responsibilities.................................... 113

Self-Reflecting and Record-Keeping.............................. 113

Communicating with Parents and Other Stakeholders................ 115

Findings from Interviews with Highly Effective Veteran Teachers........ 117

Profiles of Participants........................................... 117

Building Relationships with Students............................. 119

Planning and Instruction...................................... 123

Professional Responsibilities................................... 126

Self-Reflection.............................................. 127

Communicating with Parents and Record-Keeping.................. 128

Findings from Interviews with Teacher-Colleagues of the Highly

Effective Veteran Teachers............................................. 129

Profiles of the Teacher-Colleague Participants..................... 130

Building Relationships with Students............................. 131

Planning and Instruction....................................... 135 
Professional Responsibilities................................... 138

Self-Reflection.............................................. 138

Communicating with Parents.................................... 139

Record-Keeping ............................................ 140

Findings from Interviews in Response to Research Question 2.......... 142

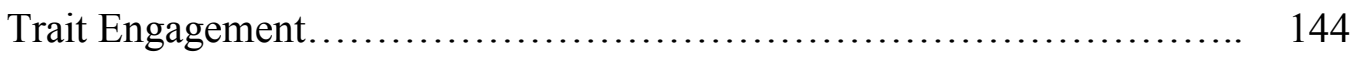

Findings from Interviews with Principal Participants................ 144

Findings from Interviews with Highly Effective Veteran Teachers.... 146

Findings from Interviews with Teacher-Colleagues of the Highly

Effective Veteran Teachers........................................ 149

State Engagement.............................................. 150

Findings from Interviews with Principal Participants................ 151

School Safety ................................................... 153

Concerns about Limited Time and Resources........................ 154

Findings from Interviews with Highly Effective Veteran Teachers.... 154

School Safety .................................................. 155

Trust in Administrators Lead to Sense of Security.................. 156

Concerns about Limited Time and Resources....................... 157

Findings from Interviews with Teacher-Colleagues of the Highly

Effective Veteran Teachers..................................... 158

Behavior Engagement............................................ 161

Findings from Interviews with Principal Participants................ 161

Involvement in School Activities.................................. 161 
Creating a Positive Classroom Environment........................ 162

Findings from Interviews with Highly Effective Veteran Teachers.... 163

Involvement in School Activities..................................... 163

Creating a Positive Classroom Environment........................ 164

Findings from Interviews with Teacher-Colleagues of Highly Effective

Veteran Teachers................................................. 166

Involvement in School.......................................... 166

Creating a Positive Classroom Environment......................... 167

Findings from Interviews in Response to Question 3................... 169

Findings from Interviews with Highly Effective Veteran Teachers.... 170

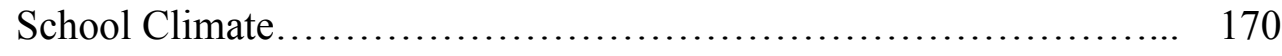

Relationships with the Schools' Administration....................... 173

Chapter Summary ................................................. 176

SUMMARY AND CONCLUSION................................... 179

Introduction..................................................... 179

Statement of the Problem........................................... 180

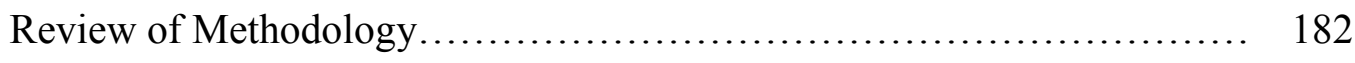

Summary of Results and Discussion................................ 185

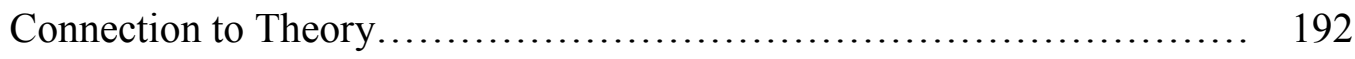

Limitation to the Study .......................................... 196

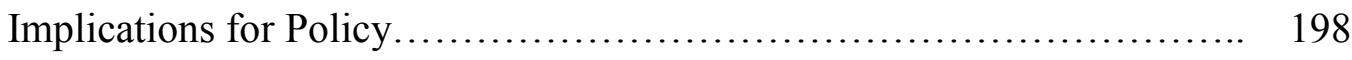

Implications for Practice .......................................... 202

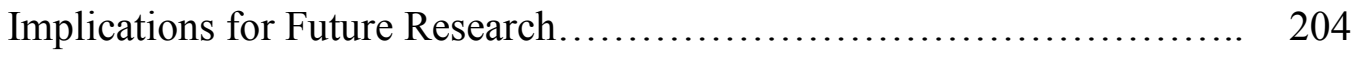


Summary................................................. 205

REFERENCES.................................................... 209

APPENDIX A: SUMMATIVE TEACHER EVALUATION (FORM D).... 232

APPENDIX B: RETENTION OF HIGHLY EFFECTIVE VETERAN

TEACHERS: SUBJECT INFORMED CONSENT DOCUMENT ........... 240

APPENDIX C: INTERVIEW PROTOCOL FOR DISSERTATION STUDY

INTERVIEWEES: HIGHLY EFFECTIVE VETERAN TEACHERS........ 245

APPENDIX D: INTERVIEW PROTOCOL FOR DISSERTATION STUDY

INTERVIEWEES: PRINCIPALS AND TEACHER COLLEAGUES....... 256

CURRICULUM VITAE ............................................ 267 


\section{LIST OF TABLES}

$\begin{array}{ll}\text { TABLE } & \text { PAGE }\end{array}$

3.1 Comparison of Percentage of Teachers and Students Participation

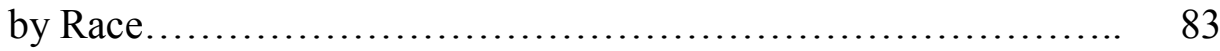

3.2 Research Questions and Data Sources........................ 87

3.3 Deductive Codes: Principal, Teacher-Colleagues and Highly Effective Veteran Teacher Protocols............................. 91

4.1 Demographic Information for Secondary Schools Participating in

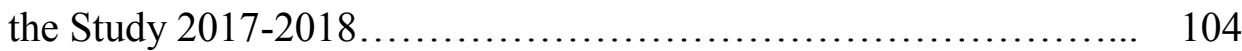

4.2 Demographic Information of Leaders of Secondary School......... 106

4.3 Demographic Information for Highly Effective Veteran Teachers... 119

4.4 Demographic Information for Teacher-Colleagues of Highly

Effective Veteran Teachers.................................. 


\section{LIST OF FIGURES}

$\begin{array}{ll}\text { FIGURE } & \text { PAGE }\end{array}$

1.1 Macey and Schneider's (2008) framework for understanding the

elements of employee engagement........................... 13 


\section{CHAPTER I}

\section{INTRODUCTION}

Retaining teachers in our nations' schools is a challenge for national, state, and local boards of education. Although the rate of teacher turnover is comparable to that of police officers it is higher than the turnover rate in other highly regarded professions such as nursing, law, architecture, engineering, and academia (Ingersoll \& Perda, 2012). While adequate numbers of teachers are being produced and hired, an even larger number vacate the profession every year for reasons other than retirement (Ingersoll, 2001, 2003). Recent research indicates that 41 percent of beginning teachers leave the profession within five years of beginning their careers (Perda, 2013). Moreover, many of the new inexperienced hires are recruited to teach in low-performing urban schools that serve poor, non-white students who speak limited English. Attempts by states and districts to retain these new teachers have only achieved pockets of success as novice teachers generally leave the profession within three to five years. These teachers often leave jobs in low performing schools seeking jobs in higher-performing schools or leaving the profession altogether (Ingersoll, 2001, 2011; Ingersoll \& Merrill, 2013). The most vulnerable schools continue to lose teachers as the majority of teachers seek assignments in schools where students are easy to teach (Clotfelter, Ladd, Vigdor, \& Aliago-Diaz, 2004; Ingersoll, 2011). However, despite the challenge of high teacher turn over, there is a cadre of teachers who are motivated to pursue opportunities teaching students who have “serious educational challenges" (Clotfelter et al., 2004, p. 252). 
Although turnover rates vary widely from school to school and district to district, the research literature indicates that turnover rates are higher in urban schools and schools with less-wealthy student populations. Data from 1998 to 2008 indicated that teacher attrition increased by 41 percent particularly in poor, urban schools that served high populations of minority students (Ingersoll, 2001, 2011; Ingersoll \& Merrill, 2013). While extensive research has been done on recruitment and retention of beginning teachers in low-performing schools, there is a paucity of information on highly effective veteran teachers who continue to teach in low-performing schools. Teaching experience does not guarantee quality instruction, but studies show that experienced teachers are more effective than inexperienced, beginning teachers (Ingersoll \& Merrill, 2013). Researchers have also suggested that inexperienced teachers' interaction with veteran teachers may influence beginning teachers to remain teaching in low-performing schools thereby helping to stem the teacher carousel (Ingersoll \& Merrill, 2013).

The experiences of Paul Barnwell, a Jefferson County Public Schools (JCPS) teacher (now in his thirteenth-year of teaching), were featured recently in the Atlantic Monthly. Barnwell described his experiences in an eighth-grade classroom in a lowperforming middle school in Kentucky. He credited his eventual decision to remain in the teaching profession to the efforts of "an effective, veteran staff member" (Barnwell, 2015, para. 8). Experienced teachers were more effective at working with difficult student populations, providing quality classroom instruction that often resulted in higher student achievement outcomes (Ladd \& Sorensen, 2017; Sawchuk, 2015). A description of his experiences follows:

Standing in front of my eighth-grade class, my heart palpitated to near-panicattack speed as I watched the second hand of the clock. Please bell—ring early, I 
prayed. It was my second day of teaching, and some of my middle-school male students were putting me to the test...I was 22 years old and had been placed as a beginning teacher in one of Kentucky's most troubled, underperforming, and dysfunctional middle schools. I had no prior teaching experience, nor had I studied education as an undergraduate... I wasn't ready for the stress, the culture shock, or the pressure to increase student reading scores. I resigned from the position before Christmas. I hadn't even gotten my certification. (Barnwell, 2015, para.1).

In the following section, I examined the background to the problem of teacher attrition. Several factors are highlighted in the literature that have been shown to influence school success. These factors include school climate features such as: school characteristics, classroom characteristics, and teacher characteristics. Additionally, one researcher suggests examining the issue of teacher attrition from a positive psychological perspective. Therefore, I also explored teacher engagement as a factor that influences teacher attrition.

\section{Background to the Problem}

There is compelling evidence that retention of quality teachers and school leaders are important to successful schools (Chetty, Friedman, \& Rockoff, 2014; Clotfelter, Ladd, Vigdor, \& Wheeler, 2007; Kraft, Marinell, \& Yee, 2016; Pogodzinski, Youngs, Frank \& Belman, 2012). Research reveals that teachers' daily preparation, instruction, and interactions with students in the classroom are critical to yielding student achievement gains (Chetty et al., 2014; Clotfelter et al., 2007; Rivkin, Hanushek \& Kain, 2005). Research asserts that any recognition and support extended to teachers by leadership would enhance teachers' intent to remain teaching (Boyd et al., 2011; Cherng \& Halpin, 2016; Pogodzinski et al., 2012). The Interstate School Leadership Licensure Consortium (ISLLC) standards and Professional Standards for Educational Leaders (PSEL) state explicit standards for school leaders to "maximize student learning and 
instruction" (Fuller, Williams, Nash, \& Young, 2016, p. 19). Transformative school leaders' numerous responsibilities are as follows: (1) To create a shared mission, vision, and core values; (2) To support instruction and assessment; (3) To manage and provide professional development opportunities for staff; (4) To cultivate a caring and inclusive school community; (5) To provide resources, time, and structures to facilitate staff needs; (6) To engage families and the wider community; (7) To administer and manage school operations (Fuller et al., 2016, p. 19). Additionally, PSEL emphasized cultural responsiveness and equitable treatment of all stakeholders (Fuller et al., 2016, p. 21).

School and district accountability are defined by their ability to raise students' achievement scores at the aggregate level and by student subpopulations (Chetty et al., 2014; Hanushek \& Rivkin, 2007 Ronfeldt, Loeb, \& Wyckoff, 2013). This issue is compounded by the 41 percent of new teachers who typically leave teaching within the first five years (Perda, 2013). Teacher attrition is reliably 50 percent higher in lowperforming schools when compared to affluent schools (Darling-Hammond \& Sykes, 2003; Ingersoll, 2001, 2003). Researchers described this high rate as a particularly alarming situation (Darling-Hammond \& Sykes, 2003; Ingersoll, 2001, 2003).

Retention of effective veteran teachers who possess experience and a repertoire of specialized skills required to work in low-performing schools may be essential to increase student achievement and turnaround in low-performing schools. As important as it is in meeting state and federal accountability targets, retaining high quality teachers is also important for mitigating costs associated with teacher attrition and human resource functions in education (Ingle, 2009). Effective teachers play a crucial role in students' academic and emotional success, particularly poor, minority, students (Strecher et al., 
2016). It takes several years of preparation for teachers to develop from being novice to experienced teachers. Educational experts propose that teachers go through different stages of development to become effective veteran teachers (Darling-Hammond \& Baratz-Snowden, 2007; Dreyfus, 2004). Teachers who are hired to teach in lowperforming schools are generally new, inexperienced, less qualified, and not as effective as their more experienced counterparts (Clotfelter et al., 2004; Hanushek, Kain, \& Rivkin, 2004). Research indicates that retaining effective experienced teachers would help schools to be more successful (Ingersoll \& Merrill, 2013). However, only one study examined factors motivating highly effective veteran teachers to remain teaching. This study was undertaken in the context of Australia (Ashiedu \& Scott-Ladd, 2012). The findings highlighted intrinsic motivators as key to retaining highly effective veteran teachers in public schools in Australia.

In the United States, K-12 teachers represent 4 percent of the national workforce. This number exceeds the national population of other professionals such as nurses, lawyers, and professors (Ingersoll, 2003). The size of the teaching population coupled with the number of teachers exiting the profession has created a "revolving door" effect (Ingersoll, 2001). Teachers leave the teaching profession for several reasons other than retirement (Ingersoll 2001, 2003). Some research concluded that the working conditions in schools predicted teachers' decisions to remain or leave teaching (Boyd et al., 2011). School characteristics such as job dissatisfaction in the context of salaries, administration support, student behavior and lack of teacher input in decision-making were identified as influencers of teacher attrition (Boyd, Lankford, Loeb, \& Wyckoff, 2008; Ingersoll \& Smith, 2003). Although researchers proposed that higher salaries influenced teachers to 
remain teaching (Hughes, 2012; Imazeki, 2005; Loeb \& Page, 2000), other research challenged these findings (Grissom \& Strunk, 2012). Since the same salary schedule is likely to apply to most teachers with the same level of experience and expertise regardless of schools where they taught, salary was unlikely to be an important factor (Grissom \& Strunk, 2012). Instead, salaries were mainly important to attract and retain novice teachers for first four or five years of their careers (Grissom \& Strunk, 2012). The lure of salary was less appealing to veteran teachers in their sixth to eight years of teaching (Grissom \& Strunk, 2012). Rather, school climate and culture that influenced the quality of work a teacher produced were more likely to influence a teacher's intent to remain in or leave teaching in a school (Clotfelter et al., 2007).

Teacher characteristics such as age and gender were also contributors to teacher attrition (Grissmer \& Kirby, 1994; Ingersoll, 2001; Henke, Chen, Geis, \& Knepper, 2000; Hughes, 2012). The research showed that attrition was more prevalent amongst young beginning teachers than middle-aged teachers (Bidwell, 2014; Grissmer \& Kirby, 1987; Murnane, Singer, \& Willett, 1989). Research also revealed that there were more female than male teachers (Ingersoll \& Merrill, 2013). Although female teachers were more committed than male teachers to teaching, some researchers proposed female teachers were also more likely to exit the profession than male teachers (Adams, 1996; Gritz \& Theobald, 1996; Ingersoll, 2001; Ingersoll \& Alsalam, 1997). Heyns (1988) found this to be consistent at both elementary and secondary levels. However, Ingersoll and Merrill (2013) found that attrition was more prevalent amongst male teachers than female teachers. Other literature indicated that age was not a predictor of a teacher's intent to remain in teaching (Perrachione, Rosser, \& Petersen, 2008). Rather, teachers' intent to 
remain in the profession was more influenced by intrinsic motivators such as the satisfaction of working with students, satisfaction with the job of teaching, and high teacher efficacy (Hughes, 2012; Perrachione et al., 2008). Extrinsic factors influencing retention were related to teachers' work environment, such as retirement, time-off, and work schedule (Ashiedu \& Scott-Ladd, 2012; Futernick, 2007; Perrachione et al., 2008; Petty, O’Connor, \& Dagenhart, 2011).

Additional teacher characteristics that are salient to stemming teacher attrition include teachers' perceptions of school leaders, and the relationship between novice teachers and school leaders which were also highlighted as strong predictors of a teacher's intent to remain or leave the profession, particularly in low-performing schools (Pogodzinski et al., 2012). Further, predictors of teachers' intent to remain teaching in low-performing schools were the level to which they felt recognized by school leaders, felt safe in the school environment, and experienced collegiality with peers (Boyd et al., 2011; Kraft, Marinell, \& Yee, 2016; Pogodzinski et al., 2012).

Using a positive psychological perspective which focused on the concept of teacher engagement, De Stercke, Goyette, and Robertson (2015) proposed that teachers who were engaged in the work environment were more likely to remain in teaching for longer periods than teachers who were disengaged with the work environment. This begs the question "What is an engaged teacher?" There is limited research on teacher engagement. For the purpose of this research, I will use the term "employee engagement" (EE) as a proxy for understanding "teacher engagement" (TE). Shuck and Wollard (2010) defined EE as "an individual's cognitive, emotional, and behavioral state directed toward a desired organizational outcome" (p. 103). In more recent work, EE was defined as an 
active, work-related positive psychological state operationalized by the intensity and direction of cognitive, emotional, and behavioral energy (Shuck, Adelson, \& Reio, 2016 Shuck, Nimon, \& Zigarmi, 2017).

The tenets of EE are meaningfulness, safety, and availability. Teachers are willing to invest their physical, cognitive, and emotional selves in their jobs when the work is meaningful, in a safe environment, with resources readily available to do the job (Kahn, 1990). Creating a safe work environment and providing resources is part of the role of the school leader (Fuller et al., 2016; Pogodzinski et al., 2012). Based on Macey and Schneider's (2008) engagement framework, teachers who trust their leaders to take care of their needs will be willing to invest their physical, cognitive, and emotional selves into the job (Christian, Garza, \& Slaughter 2011; Macey \& Schneider, 2008). Similar to engaged employees outside the K-12 environment engaged teachers who perceive their work as a meaningful experience are more likely to be happy with their working conditions and work experience. They are therefore more likely to remain teaching (De Stercke et al., 2015). It is believed that a lack of perceived meaningfulness results in burnout and departure from teaching (Chang \& Davis, 2009; Kyriacou \& Sutcliffe, 1978; Maslach, Schaufeli, \& Leiter, 2001).

\section{Statement of Problem}

Retaining teachers in public schools is a national challenge. The schools mostly

affected by high teacher attrition are often low-performing, urban schools that serve poor, minority students (Alliance for Excellence, 2014; Boyd, Langford, Loeb, \& Wyckoff, 2005; Clotfelter et al., 2004; Lee \& Orfield, 2006). Over 41 percent of teachers hired to teach in these schools are beginning teachers who leave within three to five years of 
beginning their careers (Ingersoll, 2001, 2003; Perda, 2013). Veteran teachers often leave to teach in more affluent schools that serve higher-performing students (Alliance for Excellence, 2014; Rivkin et al., 2005). Not only does this constant movement of teachers in low-performing schools have a negative influence on students' social, emotional, and academic growth (Stecher et al., 2016), but schools and school districts are penalized for students' failure to meet academic goals in state mandated tests.

Ingersoll and Merrill (2013) established "having an increasingly larger number of beginners, along with an increasingly smaller number of veterans in a school could only have a negative impact [on student achievement]" (p. 10). In addition to influencing increases in student achievement, effective veteran teachers also bring a wealth of experience to the classroom and can serve as mentoring resources for beginning teachers (Ingersoll \& Strong, 2011). Moreover, highly effective veteran teachers are well versed in working through student behavior issues and often know how to work with a culturally diverse student population (Ingersoll et al., 2014). Additionally, veteran teachers have experience with interacting and communicating with parents, encouraging self-efficacy, and inspiring a good work ethic in students (Ingersoll et al. 2014). Despite the large number of teachers exiting the workforce to work in richer, higher-performing schools, there is a cadre of highly effective veteran teachers who remain teaching in lowperforming schools (Clotfelter et al., 2004).

In my study, I focus on Wimsel Public Schools (WPS), a large urban school district located in a southeastern city in the United States. Recent district data sources indicated that the teacher retention rate in WPS is 87 percent. The teacher retention rate for low-performing schools in this study ranged from 46 percent to 96 percent. The 
teacher retention rate for all high schools in WPS ranged from 77 percent to 94 percent for the same period. The teacher retention rates for all middle schools for the same period ranged from 46 to 98 percent. The data showed that the teacher retention rate for middle school is more variable than the retention rate for high schools. The turnover population includes veteran teachers who possess the knowledge, skills, dispositions, and experience that are required to assist principals lead the turnaround process in low-performing schools. As a result of the movement of veteran teachers, schools continue to lose traction that contribute to student instructional development, student socialization, effective behavior management, and ongoing dialogue that influences effective change. It is therefore incumbent on the schools and school district to find ways to retain highly effective veteran teachers who would form the core of teacher leaders who are essential to leading the turnaround process in low-performing schools.

\section{Research Questions}

This research examined individual teacher engagement and school climate characteristics that influence highly effective veteran teachers to remain teaching in the low-performing schools. The research questions were as follow:

1. What are the characteristics of highly effective veteran teachers who remain teaching in low-performing schools as reported by principals and teacher colleagues?

2. In what ways are highly effective veteran teachers engaged in low-performing schools?

3. How do highly effective veteran teachers perceive their engagement as contributing to their commitment to remain teaching in low-performing schools? 


\section{Conceptual Framework}

In this qualitative research, I examined factors that influenced highly effective veteran teachers to remain in low-performing schools. The data show that while 25 percent of active teachers nationwide are veteran teachers, increasingly large numbers of inexperienced teachers are joining the profession (Ingersoll \& Merrill, 2013; Metlife, 2012). These findings suggest that the majority of the nations' teachers are beginning teachers with little teaching experience (Ingersoll et al., 2014). They are often hired to teach in some of the nation's poorest and low-performing urban schools that serve poor, minority students and limited English-speaking students (Alliance for Excellent, 2014; Boyd et al., 2005; Clotfelter et al., 2004; Lee \& Orfield, 2006). These teachers often leave within three to five years of taking the job (Ingersoll 2001, 2003; Perda, 2013). Ingersoll and Merrill (2013) emphasized "having an increasingly larger number of beginners, along with an increasingly smaller number of veterans in a school could only have a negative impact [on student achievement]" (p. 10). Highly effective veteran teachers possess the experience, knowledge, and skills needed to increase student achievement, while positively influencing instructional practices of beginning teachers and beginning teachers' ability to improve student academic achievement (Ingersoll \& Merrill, 2013). Therefore, it is critical for schools and school districts to find ways to retain highly effective veteran teachers to teach in low-performing schools.

\section{Framework for the Study}

In this study, I used EE as a proxy for Teacher Engagement (TE). In this regard, engaged teachers (like engaged employees) are inclined to view the world from a perspective classified as a psychological state of engagement (Shuck et al., 2016). The 
psychological state of engagement is preceded by antecedents to behavioral engagement that motivate employee to perform (Macey \& Schneider, 2008). The employee has an "I feel, therefore I do" mindset (Macey \& Schneider, 2008, p. 5). Engagement is a psychological concept that incorporates enthusiasm, commitment, involvement, purpose, and passion that influence attitudes and behaviors (Macey \& Schneider, 2008). According to Erikson (2005), engagement goes "above and beyond simple satisfaction with the employment arrangement or basic loyalty to the employer...Engagement...is about passion and commitment - the willingness to invest oneself and expend one's discretionary effort to help the employer succeed" (p.14). Christian et al. (2011) explicated engagement as employees "bringing their personal selves during work role performances, investing personal energy and experiencing emotional connection to their work" (p. 91).

I utilized Macey and Schneider's (2008) theory of engagement (see Figure 1.1) as the guiding theoretical framework for my study. According to Meyer and Gagné (2008), Macey and Schneider's (2008) engagement framework provides a better understanding of the key components of engagement. Employee engagement (EE) is an emerging concept generally linked to human resource development (Macey \& Schneider, 2008; Shuck, 2011). Explanation of the framework follows in subsequent paragraphs in this section. 
Trait Engagement (Positives views of life and work)

Proactive Personality

Autotelic Personality

Trait Positive Affect

Conscientiousness

State Engagement
(Feelings of energy, Absorption)
Satisfaction (Affective)
Involvement
Commitment
Empowerment

State Engagement

Behavioral Engagement

(Extra-role behavior)

Organizational Citizenship

Behavior (OCB)

Proactive/Personal Initiative

Role Expansion

Adaptive

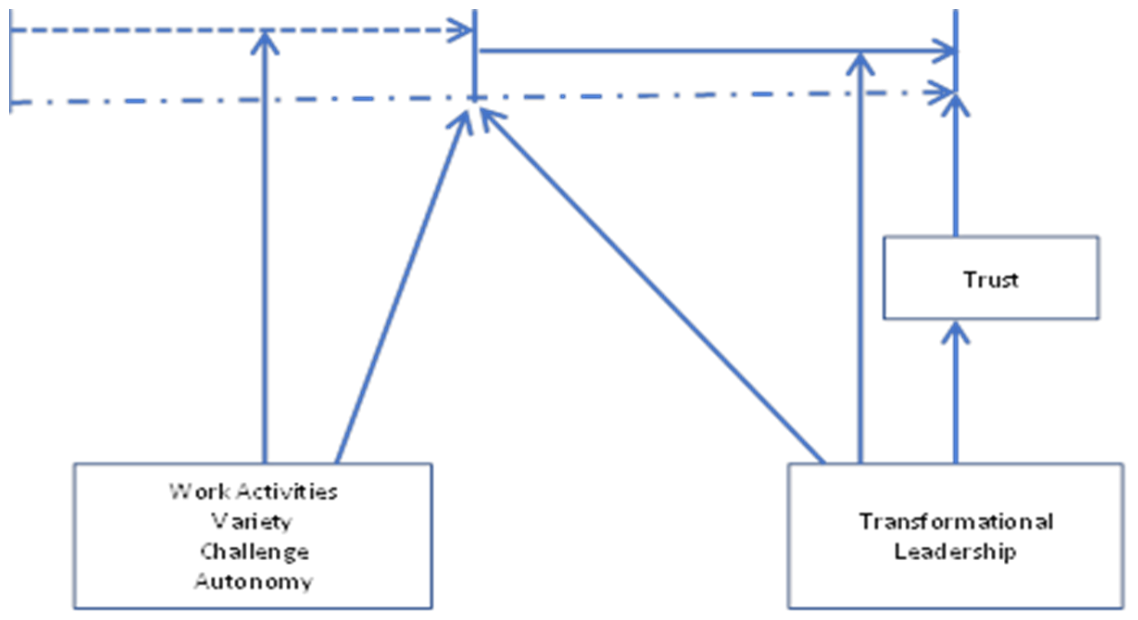

Figure 1.1. Macey and Schneider's (2008) Framework for understanding the elements of employee engagement (p. 6).

Macey and Schneider's framework explicates engagement as a "disposition, [that is,] an inclination or orientation to experience the world from a particular vantage point" (p. 5). Figure 1.1 highlights three facets of EE: (a) Trait Engagement (mindset); (b) State Engagement (feelings/emotions); and (c) Behavioral Engagement (work attitude). Trait engagement is an employee's worldview or disposition. It is defined as a positive perspective on life and work. Employees with proactive personalities are resourceful and conscientious workers. Employees with autotelic personalities work for self-gratification rather than for incentives or rewards. Employees whose work experiences are positive and stimulating are more likely to put forth optimum effort to get the job done. They are also more likely to engage in the job and "go beyond what is necessary [to initiate] 
change to facilitate organizationally relevant outcomes" (Macey \& Schneider, 2008, p. 21).

The framework shows that one's job and work directly influence one's pride in the occupation, the amount of energy, enthusiasm, perseverance, and the effort one exerts in doing the job, (State Engagement) (Macey \& Schneider, 2008). That is, work influences the level of job satisfaction, involvement, commitment, and feeling of empowerment for the employee. State engagement is an antecedent to behavioral engagement. Employees who are behaviorally engaged identify with the job by being "focused, connected, and integrated" in the jobs (p. 12). They use their skills, abilities, and available resources to get the job done (Kahn, 1992). Work conditions both directly and indirectly influence employees' feelings and attitudes towards their work. Work conditions are identified as: nature of the tasks, how stimulating the tasks are, and the amount of autonomy afforded to get the tasks completed. Additionally, work indirectly influences or moderates the relationship between trait engagement and state engagement. In summary, work conditions have a direct and indirect influence on one's feelings towards one's job and one's attitude and on-the-job behavior.

Figure 1.1 also highlights the importance of transformational leadership and the importance of leadership in creating and sustaining a positive work environment and a rewarding work experience. Transformational leadership directly influences state engagement and indirectly influences the relationship between state and behavioral engagement. This is supported by empirical research. The literature highlights transformational leaders as visionaries who inspire their supports to extraordinary levels of performance (Bass \& Riggio, 2006; Rao, 2014). Moreover, transformational leaders 
empower and inspire supporters to grow as leaders. As a result, supporters reach higher levels of personal satisfaction and are more committed to their colleagues and organizations. Bass (1999) posited that failure to evoke self-worth and confidence in employees may result in less commitment to achieving goals set by leaders. On the other hand, transformational leaders affirming employees' self-worth will influence higher levels of commitment and greater outcomes. Essentially, an employee's commitment to an organization that extends beyond basic job satisfaction and traditional loyalty to the employer is influenced by leadership style.

Griffith (2004) established a relationship between transformational leadership in schools and teacher satisfaction in his study "Relation of Principal Transformational Leadership to School Staff, Job satisfaction, Staff Turnover, and School Performance.” The research highlighted three characteristics of principals who are transformational leaders. Principals who are transformational leaders are inspirational and charismatic, they provide individualized attention to teachers, and they stimulate teachers' intellectual abilities. Findings from this study suggested that transformational principals influenced higher levels of teacher satisfaction which had a positive influence on teachers' intent to remain in teaching. Further, schools that were led by principals who were transformational leaders were more likely to see decreasing gaps between minority and non-minority students' performances in achievement tests.

Macey and Schneider's (2008) framework is supported in this study by Kahn's (1990) needs-satisfying approach, which proposed that an employee's mindset is influenced by outside forces (Shuck, 2011). Employees are more willing to invest time, physical, and mental energy into the job if the job is meaningful, safe, and if the 
employee receives needed resources to get the job done. The need-satisfaction approach also suggested a strong association between employee engagement and employee retention (Shuck, 2011). Employees whose needs were being met by the organization were more likely to remain and make valued contributions to the organization.

In conclusion, I used Macey and Schneider's (2008) engagement model to investigate teacher engagement (TE) and school climate characteristics that influence highly effective veteran teachers to remain teaching in low-performing schools. This research suggests that highly effective veteran teachers who are cognitively, emotionally, and behaviorally connected to the job of teaching are more likely to remain in teaching. Further, school climate characteristics such as leadership, influence teachers' mindset, feelings of commitment, and attitudes toward the job of teaching. Teachers are more likely to be engaged and remain in teaching if they work in a supportive school environment that is intellectually stimulating, promotes autonomy, and empowers teachers. Further, teachers are more likely to be satisfied and committed to the job of teaching if school leaders are trustworthy, affirming, and supportive of teachers' efforts.

\section{Assumptions of the Study}

I undertook a qualitative case study. The objective of qualitative research is to "understand the meaning of an experience" (Merriam, 1988, p. 16). Qualitative case study research is inductive by nature, it focuses on process, understanding, and interpretation of the data. The researcher collects data in the hope that the theory will explain the data (Goetz \& LeCompte, 1984). Qualitative case study also assumes the existence of multiple realities. The researcher is interested in the meaning that people 
create out of their lives and experiences, and the implication this has on peoples' worldview (Merriam, 1988).

The researcher is the primary data collection instrument in case study (Merriam, 1988). Fieldwork is generally conducted in the natural setting for observation purposes (Yin, 2014). Data are primarily collected through interviews, observation, focus groups, and action research (Yin, 2014). The qualitative researcher explores the data, analyzes, and presents an authentic representation of the perspectives of the participants in the research to interested audiences (Merriam, 1988). In qualitative cases studies data are flexible, evolving, and emergent (Merriam, 1988).

Fieldwork in this case study was conducted in the participants' natural environment, I also interviewed participants by phone. I explored participants’ perspectives on engagement and school climate characteristics that influenced them to remain teaching in the low-performing schools in WPS. Questions were asked to uncover participants' personal experiences and how those experiences influenced their engagement. Differences in answers were due to participants' perspectives and experiences. The protocol was framed to facilitate easy interaction with participants. Data was analyzed and presented under the assumption that participants understood and honestly answered questions to the best of their abilities (Glesne, 2016; Yin, 2014).

\section{Delimitations}

This study was delimited to low-performing middle and high schools, also classified as secondary schools, in a large urban school district in the southeastern United States. Elementary schools have been excluded from this research because they were deemed to be more stable and have lower rates of teacher attrition (Krieg, 2006; Marinell 
\& Coca, 2013). There are 18 schools in WPS designated as low-performing or priority schools based on student performance scores on state-mandated tests. Of the 18 lowperforming schools, 16 schools are secondary schools. There are eight middle schools and eight high schools. Low-performing secondary schools were identified using online data from the school district.

\section{Limitations}

In the process of executing this research project, I encountered some challenges that limited its scope. There were limitations with the sampling and the schools that I was able to access due to restrictions by WPS district IRB committee. In the initial design I anticipated sampling from an equal number of middle schools and high schools, but the schools that I was permitted to access were mainly high schools. Thus, there was an imbalance between the number of middle and high schools from which information was drawn in my study.

A second consideration is the fact that I limited the selection of highly effective veteran teachers to people who have been teaching in the roles for five or more years but did not place a tenure limit on the principals under whom they served. Considering that the effect of leadership is a factor in the Macey \& Schneider (2008) model, an

opportunity to measure the leadership effect over the same time period may have yielded different results. All of the six principal participants and the one assistant principal participant had been in their current jobs for less five years. Feedback on the growth of the veteran teachers over the five-year period would have been helpful in establishing patterns that led to their growth and effectiveness. 
Third, the feedback from the colleagues of highly effective veteran teachers was limited to planning and activities outside the classroom. Considering that the teachers are on the same teaching schedules, there were no opportunities for the teacher-colleagues to observe the classroom instruction of the veteran teachers. Therefore, they had a limited perspective of what made the veteran teachers "highly effective."

Fourth, time and weather affected data collection. It was my intention to schedule face to face interviews with each of the participants. However, with the data collection phase occurring at the height of the winter, many teachers became unavailable for face to face interviews due to road conditions and school closings. Therefore, several interviews, especially with the teacher-colleagues of the highly effective veteran teachers were telephone interviews. The telephone interviews created a disadvantage of not being able to observe the participants' facial expressions and body language which help to contextualize some of the emotions that support what they were saying in response to the interview questions. In contrast, I observe the facial expressions and hand gestures of the other participants when they were giving feedback. I was able to capture the genuineness of Participant 10's account of her interaction with her students in my field notes. There was a smile of satisfaction on her face and she enthusiastically she moved her hands to mimic the activity in her classroom during the "academic enrichment sessions."

Finally, there was a high degree of confidence amongst the teachers and principals that the veteran teachers were indeed making a positive impact on the lives of the students. A more rounded perspective would have been garnered had past or present student of the teachers been interviewed also. This should therefore be considered for future study as we work to measure effectiveness and engagement. 


\section{Definition of Terms}

The following terms were used in this study:

Beginning or Novice teachers. Teachers who were teaching for less than five years. Employee Engagement (EE). This serves as proxy for "teacher engagement" (TE). EE is an active, work-related positive psychological state operationalized by the intensity and direction of cognitive, emotional, and behavioral energy (Shuck, Adelson, \& Reio, 2016; Shuck, Nimon, \& Zigarmi, 2017). It is the act of employees bringing "their personal selves during work role performances, investing personal energy and experiencing an emotional connection with their work" (Christian et al., 2011, p. 91). I will use the assumptions from these definitions to explicate "teacher engagement" in this study. Highly Effective Teachers. Highly effective teachers are measured using WPS Summative Evaluation - Teacher Form D (see Appendix A) and National Board-Certified Teachers (NBCTs). Using WPS Summative Evaluation - Form D, the measures on the teacher evaluation form range from (a) Ineffective; (b) Developing; (c) Accomplished; and (d) Exemplary. For the purpose of this study, teachers who are rated Exemplary are classified as "highly effective." Based on National Board requirement, highly effective teacher have at least bachelor's degree from an accredited university or institution, three years of teaching experience, and a valid teaching license. Highly effective teachers plan and prepare appropriate instruction. They are knowledgeable of content and pedagogy. They find multiple ways to assess and actively encourage students to reflect, and also engage in self-reflection. Highly effective teachers ensure a safe, positive, and culturally competent learning environment with high expectations that are clearly articulated to all students, provide instruction that is rigorous, and they actively engage students in 
learning. They assist students in connecting personal experiences and current events to the learning from text. Highly effective teachers engage in professional responsibilities and participate in professional learning communities. They communicate with families and maintain a high degree of professionalism (Goe, Bell, \& Little, 2008; National Board, 2018; Popp, Grant, \& Stronge, 2011; Stronge, 2007).

High Student Outcomes. Student achievement outcome is measured using Novice for the lowest achieving students, and Proficient or Distinguished for the higher academic performance. High achieving students score proficient or distinguished on state achievement tests. Achievement outcome parameters are based on the State Department of Education measures.

Low-Performing Schools or Priority Schools. Low-performing or failing schools are schools that have not met annual yearly progress (AYP) as required by State guidelines. Characteristics of low performing Schools include persistently low scores on standardized tests, low graduation and high dropout rates, inadequate resources and facilities, inability to attract sufficient numbers of highly qualified teachers, overcrowding, student disciplinary problems and frequent instances of low morale, low student expectations, and a disorganized learning environment (Quality Counts, 1999, 2003 as cited in Education Week, 2004).

Veteran Teachers. Veteran teachers are experienced teachers who have been teaching consistently for over five years (Berliner 2005; Lopez, 2007; Berry, 2008; Okas, Van der Schaaf, \& Krull, 2014). 


\section{Summary}

This chapter introduced three research questions that are related to teacher engagement and the factors that influence them to remain in low performing schools. The study is premised on Macey and Schneider's (2008) engagement model which is the framework for the study. This study provides insights that may be helpful in assisting in the retention of veteran teachers in low performing schools. Scholarly literature reveals that veteran teachers are more effective teachers than inexperienced, beginning teachers. This chapter also included the statement of the problem, purpose of the study, and research questions. It also included assumptions of the study, delimitations, limitations, and definitions of terms.

Here is a synopsis of subsequent chapters: Chapter II includes a review of current literature and trends in teacher retention and attrition. Chapter III includes the research methodology for this study, comprising the research design, research setting, research questions and data sources. Chapter IV presents findings and an analysis of the data. Chapter V presents the conclusion, limitations, and recommendations of this study. 


\section{CHAPTER II}

\section{LITERATURE REVIEW}

Retaining quality teachers to teach in the nations' public schools is an ongoing national and local challenge (Hughes, 2012; Ingersoll, 2001; Perrachione et al., 2008). There is considerable research on teacher mobility, including teacher retention and attrition (Gray \& Taie, 2015). Ongoing research focuses on school staffing problems and efforts to attract and recruit new teachers to the teaching profession and the results of these programs for example, Troops-to-Teachers and Teach for America (Ingersoll, 2001; Ingersoll, Merrill, \& Stuckey, 2014). Other research focused on teacher turnover, defined as teachers leaving the teaching service (Grissmer \& Kirby, 1987; Heyns, 1988; Murnane, Singer, \& Willett, 1988). Despite the negative statistics that illustrate a significant teacher attrition problem in low-performing schools, there is evidence that there are some veteran teachers who remain in low-performing schools for extended periods beyond the average five years (Clotfelter et al., 2004). Related literature supported that retaining highly effective veteran teachers would help schools to be more effective in the turnaround effort (Ingersoll \& Merrill, 2013; Ingersoll et al., 2014; Kraft et al., 2016). However, only one study has been identified that examined factors that influenced veteran teachers to remain in the teaching profession. The study was in the educational context of Australia (Ashiedu \& Scott-Ladd, 2012). 
In this qualitative case study, I examined individual teacher engagement and school climate characteristics that influence highly effective veteran teachers to remain teaching in low-performing schools. The research questions are as follows:

1. What are the characteristics of highly effective veteran teachers who remain teaching in low-performing schools as reported by principals and teacher colleagues?

2. In what ways are highly effective veteran teachers engaged in low-performing schools?

3. How do highly effective veteran teachers perceive their engagement as contributing to their commitment to remain teaching in low-performing schools?

This review of literature elucidate what existing literature says about factors influencing teacher attrition and retention. This chapter is divided into four main sections. First, the current study examined the concept of engagement. Employee engagement was used as a proxy for teacher engagement. Second, this review explored factors relating to teacher attrition. These included school climate characteristics such as school-level characteristics, classroom-level characteristics, and teacher-level characteristics. The third section of this review illuminated factors that influence veteran teachers to remain teaching in low-performing schools. The final section of this review of literature was the summary of literature review, highlighting trends in findings, trends in methods, and evidence of the need for future research to be undertaken. 


\section{Employee Engagement}

The concept of engagement is gaining attention in academia (Shuck, 2011). It is an evolving concept typically associated with business, management, industrial and organizational psychology, and human resource development (HRD) (Macey \& Schneider, 2008; Shuck, 2011). Literature on employee engagement highlights the difference between employee engagement and job or employee satisfaction. Macey and Schneider's (2008) engagement framework denotes engagement as a feeling of being focused, enthusiastic, and energetic, being proactive and persistent at completing tasks (Kahn, 1990; Rich, LePine, \& Crawford, 2010). Whereas, job satisfaction implies contentment and satisfaction rather than the energy that is associated with engagement (Erickson, 1986).

Kahn (1990), drawing from the work of Goffman (1961) and others, was the first to mention and research engagement in his published work the "Psychological Conditions of Personal Engagement and Disengagement at Work.” Kahn's (1990) work proposed that people demonstrated the ability to become attached and detached from work roles. In his ethnographic study, Kahn (1990) interviewed 16 camp counselors and 16 professionals who worked for an architectural firm, a total of 32 participants. The purpose of the study was to examine how fully the participants were psychologically present while performing work tasks. The study proposed the more engaged the worker, the more committed he or she was to the job, and better job performance was observed (De Stercke et al., 2015). Three psychological conditions emerged from Kahn's (1990) study: the concepts of "meaningfulness, safety, and availability" (p. 692). Kahn (1990) determined that varying degrees of a worker's physical, cognitive, and emotional selves 
were present at particular times when they performed work roles and that levels of engagement varied based on workers' perceptions of meaningfulness, safety, and availability. Taken together, these three characteristics shaped how individuals performed their roles.

Presenting the concept of engagement from a positive psychological lens (Attridge, 2009; Shuck, 2011; Rich et al., 2010), engagement is explicated as the act of employees bringing "their personal selves during work role performances, investing personal energy and experiencing an emotional connection with their work" (Christian et al., 2011, p. 91). In recent literature, Shuck et al. (2016) and Shuck et al. (2017) defined employee engagement (EE) as an active, work-related positive psychological state operationalized by intensity and direction of cognitive, emotional, and behavioral energy. Using an integrative literature review to examine emerging perspectives of employee engagement, Shuck (2011) explicated that extensive research, offering "reinterpretations" (p. 304) of the concept employee engagement. The purpose of Shuck's (2011) study was to synthesize academic literature on employee engagement. Shuck (2011) identified four emerging themes generally used to define approaches to understanding EE. (1) The needsatisfying approach (Kahn, 1990); (2) the burnout-antithesis approach (Maslach et al., 2001); (3) the satisfaction-engagement approach (Harter, Schmidt, \& Hayes, 2002); and (4) the multidimensional approach (Saks, 2006).

In his needs-satisfying approach, Kahn (1990) proposed that EE was "an internal state of being affected by forces external to the employee" (Shuck, 2011, p. 309). Examples of studies using Kahn's (1990) framework were researched by Shuck (2010) and Rich et al. (2010). Rich et al. (2010) conducted a correlation research on 245 firemen 
and their supervisors. The purpose of the study was to determine if engagement was the key factor mediating the relationships between the following antecedents: value congruence, perceived organizational support, and core self-evaluations. The dependent variables were task performance and organizational citizenship behavior. Engagement represented "investment of cognitive, affective, and physical energies" (p. 617) in performance of assigned roles. Value congruence, perceived organizational support, and core self-evaluations were linked to job-performance (Rich et al., 2010).

Findings from this study suggested a strong statistical significance between engagement and each antecedent and job performance. Rich et al. (2010) concluded that engagement explained the highest level of variance when compared to intrinsic motivation, job satisfaction, and job involvement. Workers who exhibited higher levels of engagement were found to be greater contributors to their organizations. They invested energy and time doing assigned individual tasks and voluntary tasks inside of the organization. The authors acknowledged a weakness of this study was it generalized to one group of employees in one organization. Studies in other settings might have generated different results. Additionally, antecedents and mediators were self-reported. However, this study was useful in clarifying and assessing EE.

Shuck (2010) conducted a non-experimental, correlation study examining the relationship between job fit, affective commitment, psychological climate, discretionary effort, and intent to turnover. The data were collected using surveys. The sample comprised 283 professionals. The results of this study suggested a statistically significant relationship between job-fit, affective commitment, and psychological climate and 
employee engagement. The findings also showed strong associations between employee engagement and discretionary effort and intent to turn over.

The need-satisfaction approach proposed associations between EE and employee retention. Shuck et al. (2017) maintained that job satisfaction was an important component of engagement and that job satisfaction was a contributing factor to predicting engagement. Alongside engagement, job satisfaction also predicted how much employees were willing to contribute to the organization. Employees whose needs were being met by the organization were more likely to remain in that organization. Employees who were the most engaged would contribute most to the organization.

Conversely, Maslach et al. (2001) presented EE as the positive antithesis to burnout (Shuck, 2011). Engagement was explicated as a chronically positive emotional state of mind symbolized by extreme pleasure and activity (Shuck, 2011). Workers feeling the effect of burnout experienced fatigue, and/or cynicism, may feel ineffective, and focus more on the challenges of the job (Hakanen, Bakker, \& Schaufeli, 2006; Maslach et al., 2001). What was once meaningful, challenging work had now become mundane, unfulfilling, and meaningless (Maslach et al., 2001).

Researchers tested Maslach et al.'s (2001) theory. Schaufeli, Salanova, GonzálezRoma, and Bakker (2002) carried out a study on the relationship between burnout and engagement. Engagement was characterized as "vigor, dedication, and absorption" (Schaufeli et al., 2002, p. 74-75). The sample comprised 314 undergraduate students from the University of Castleton, Spain. Burnout was measured using the Maslach-Burnout Inventory-General Survey (MBI-GS). The results of this study showed a negative association between burnout and work engagement. 
Unlike Kahn's (1990) needs-satisfying theory, and Maslach et al.'s (2001) burnout theory, Harter et al. (2002) utilized the satisfaction - engagement approach to examine employee engagement. Harter et al. (2002) used a meta-analysis based on 7,939 business units in 36 companies to examine the relationship between employee engagement operationalized as employee satisfaction, and business outcomes operationalized as customer satisfaction, productivity, profit, employee turnover, and accidents. The instrumentation used to measure the data was the Gallup Workplace Audit (GWA). The results of this study suggested a positive relationship between employee engagement and business outcomes such as, customer satisfaction, turnover, safety, productivity, and profitability (Harter et al., 2002).

Finally, Saks (2006) used a multidimensional approach to examine EE. Saks was the first scholar to present $\mathrm{EE}$ as a dichotomous concept; job engagement and organizational engagement (Shuck, 2011). Engagement was defined as "a distinct and unique construct that consists of cognitive, emotional, and behavioral components that are associated with individual role performance" (Saks, 2006, p. 602). The definitions given in previous literature were included in Saks' (2006) definition of EE (Harter et al., 2002; Kahn, 1990; Maslach et al., 2001; Shuck \& Wollard, 2010). The sample comprised 102 employees from various jobs and organizations who also attended graduate courses at a large Canadian university. The findings showed a significant difference between job and organizational engagement. Results suggested positive associations between job characteristics, perceived organizational support, and procedural justice. There were also indications of positive relations between employee engagement and job satisfaction, organizational commitment, and intent to quit. 
Defining EE is complex (Shuck, 2011). Kahn (1990) introduced this concept as a positive psychological construct applicable to organizations and human resource development. The literature on engagement suggested myriad definitions (Harter et al., 2002; Kahn, 1990; Maslach et al., 2001; Saks, 2006; Shuck, 2011; Shuck \& Wollard, 2010). However, conceptualization of EE came from Shuck and Wollard (2010) where employee engagement was defined as "an individual's cognitive, emotional and behavioral state directed toward desired organizational outcomes" (p. 103). Shuck (2011) presented four emerging perspectives of employee engagement based on the work of Kahn, 1990; Maslach et al., 2001; Harter et al., 2002; and Saks, 2006. A commonality between the four perspectives was that "for absorption [total commitment to the job] to occur, an employee must readily have physical, emotional, and psychological resources to complete their work" (Shuck, 2011). The research showed positive correlations between employee engagement and job satisfaction and intent to remain in the job (Harter et al., 2002; Maslach et al., 2001; Saks, 2006; Shuck, Reio, \& Rocco, 2011). However, Shuck and Wollard (2010) suggested that in order to fully comprehend EE there needed to be an examination of the antecedents. The concept of antecedents to employee engagement is explicated in the following section.

\section{Antecedents to Employee Engagement}

Shuck et al. (2017) emphasized, how individuals perceived their work environment and how the culture of their work environment influenced the amount of time and effort they put in their work. Therefore, an examination of the antecedents to employee engagement might elucidate factors contributing to the development or depletion of the workforce (Saks, 2006). Antecedents were defined as "constructs, 
strategies, or conditions that precede the development of employee engagement that come before an organization or manager reaps the benefits of engagement-related outputs" (Wollard \& Shuck, 2011, p. 432). Wollard and Shuck (2011) agreed this would be helpful to practitioners who were interested in presenting sustainable strategies, identifying possible challenges, and articulating clearer direction in their organization. In a structured literature review, Wollard and Shuck (2011) selected a total of 265 articles that were examined for variables and concepts relating to antecedents of employee engagement. The results of the study identified two levels of antecedents: individual antecedents and organizational antecedents.

Individual antecedents were "constructs, strategies, and conditions that were applied directly to or by individual employees... believed to be foundational to the development of employee engagement" (Wollard \& Shuck, 2011, p. 433). Individual antecedents of EE were measured at the organizational level, this included analyzing the employees' lives inside and outside of the workplace. Examples of individual antecedents were: meaningfulness, safety, personal involvement, linkages between personal life and the workplace, vigor, dedication, absorption the antithesis of exhaustion, cynicism, and effectiveness, employees' attitudes, and personality characteristics (Harter et al., 2002; Macey \& Schneider, 2008; Rich et al., 2010; Saks, 2006; Schaufeli, Bakker \& Salanova, 2006). Wollard and Shuck (2011) concluded that no one factor influenced particular individual antecedents and that individual antecedents did not operate in isolation of organizational climate. Rather, the presence of myriad factors that facilitated organizational climate influenced individual antecedents, which influenced individual EE. 
Organizational antecedents were based on human needs and factors extraneous to the employee that influenced employees behaviorally, cognitively, and emotionally (Wollard \& Shuck, 2011). To examine organizational antecedents, literature explored the role of the leaders in organizations. For example, the influence of the leader on selfefficacy, perceptions of the leader's expectations and role, providing a supportive environment, clarifying the organization's vision and goals, providing a safe environment, and developing and sustaining a positive culture (Darling-Hammond, 2003; Hirsch, Emerick, Church, \& Fuller, 2007; Kraft et al., 2016; Loeb et al., 2005; Pogodzinski et al., 2012). The outcome of the study suggested that positive organizational environments enhanced EE (Shuck \& Wollard, 2010).

\section{Measurement of Teacher Engagement}

An instrument commonly used to measure employee engagement is the Utrecht Work Engagement Scale (UWES). This instrument was developed by Schaufeli, Salanova, González-Roma, and Bakker (Shuck, 2011). It measures three areas of work engagement, behavioral, emotional, and cognitive (Attridge, 2009). These areas align to the work engagement themes of vigor, dedication, and absorption. The following are recent studies that utilized the UWES. Gugliemi, Bruni, Simbula, Fraccaroli, and Depolo (2016) used the UWES to measure variance of teacher engagement across age groups. Hakanen et al. (2006) used the UWES to examine the relationship between burnout and work engagement amongst teachers. A critique of Schaufeli et al. (2002) was that the cognitive processes developed by Kahn (1990) is absent from this approach to measuring engagement (Rich et al., 2010). Another limitation to the Schaufeli approach is that it 
conceptualizes engagement as the opposite of burnout, instead of as a separate state (Shirom, 2003).

Another popular instrument used to measure employee engagement is the Gallup Work Audit (GWA). This instrument is a product developed by the Gallup Organization. It is based on studies of "work satisfaction, work motivation, supervisory practices, and work-group effectiveness" (Harter et al., 2002, p. 269). It is a survey instrument that comprises items measuring employee perceptions of work characteristics and employees' perceptions of quality. Harter et al. (2002) used the GWA to conduct a meta-analysis measuring the relationship between employee satisfaction, employee engagement and business outcomes. The sample comprised 7,939 business units in 36 companies. The results of the study indicated meaning associations between employee satisfaction, employee engagement and business outcomes.

In another study using the Gallup survey researchers examined teachers' perceptions of levels of on-the-job engagement. The sample comprised 7,000 teachers. Bidwell (2014) reported seven to 10 teachers were dissatisfied and disconnected emotionally from their jobs. Two dominant areas of dissatisfaction emerged. First, teachers felt their opinions were not valued by leaders. Second, teachers felt leadership was not transparent and therefore did not trust their supervisors. The data also showed highest levels of engagement of young teachers who were teaching for six months to less than one year. The lowest level of engagement occurred with teachers who were teaching for three to five years. Levels of engagement rose again at 10 or more years of service. This correlates with the trends of teacher attrition. Attrition is highest among beginning teachers and teachers approaching retirement age and retiring teachers (Bidwell, 2014; 
Grissmer \& Kirby, 1987; Murnane et al., 1988; Grissmer \& Kirby, 1997). An advantage of the Gallup survey is due to the fact that it is a longer survey it is able to capture the general factors as well as the variances is work satisfaction (Harter et al., 2002).

The Employee engagement scale (EES) was developed by Shuck et al. (2016) to measure cognitive, emotional, and behavioral employee engagement. The researchers pointed out that the EES was the first instrument developed to measure employee engagement compared to previous instruments which generally measured "nuanced areas of engagement" (Shuck et al., p. 1). For example, job engagement and organizational engagement. This instrument was utilized in four independent studies where the researchers explored the reliability of the EES in explaining and measuring employee engagement. In the first and second studies, the researchers refined and tested the reliability and validity of the instrument. In the third study the scale items were reduced, and validity and reliability of the instrument was tested using additional evidence. Finally, the researcher tested the EES for incremental validity. The findings indicated that the EES comprised cognitive, emotional, and behavioral engagement as factors that explained employee engagement.

\section{Employee Engagement Framework}

An effective illustration of the relationships between the variables that comprise employee engagement is found in Macey and Schneider's (2008) framework which draws on Kahn's (1990) engagement theory. Macey and Schneider (2008) emphasized that engagement is not to be confused with job satisfaction; engagement is denoted by activation and energy (Christian et al., 2011). Whereas, job satisfaction is denoted by contentment or satiation rather than energy. In concert with the definition of employee 
engagement, Macey and Schneider's (2008) engagement framework highlights engagement as a state that supersedes organizational loyalty or commitment. Engagement includes the individual's personality, mood, and actions in the workplace. Therefore, engagement is an active feeling being focused, energized, and enthusiastic, being proactive, and persistent in performing work tasks. The framework supports the position that job characteristics, leadership, and personality traits directly influenced engagement which indirectly influence on-the-job behavior and performance. Further, leadership is critical in creating work conditions that promote employee engagement.

Several researchers subsequently used Macey and Schneider's (2008) framework in the study of various aspects of employee engagement. Meyer and Gagné (2008) admitted "we now have a better understanding of some of the key components of engagement" (p. 60) due to Macey and Schneider's (2008) comprehensive research conceptualizing engagement. In their integrated literature review examining the historical passage of employee engagement, Shuck and Wollard (2010) explained that Macey and Schneider's (2009) framework "helped to clear the cluttered, scattered, and unfocused conceptual state of employee engagement by breaking the engagement construct into distinct parts and debunking 'folks' definitions of engagement” (p. 101). This seminal work comprised 159 articles.

Nienaber and Martins (2014) utilized Macey and Schneider's (2009) framework to develop an engagement instrument and framework to measure engagement at the individual, team, and organizational levels. Macey and Schneider's (2009) framework was appropriate for this study because of its conceptualization of different levels and dimensions of engagement. Nienaber and Martins' (2014) instrument provided "a clearly 
defined, theoretical employee engagement measurement framework and instrument for the South African context" (Nienaber \& Martins, 2014, Abstract). The researchers pointed out that further studies were needed to ensure reliability and for validation of the construct.

Christian et al. (2011) conducted a meta-analysis of over 200 published and 30 unpublished articles in an attempt to obtain a common definition for engagement, whilst examining the uniqueness of engagement, and clarifying nomological constructs associated with engagement. Data were analyzed using Raju, Burke, Normand, and Langlois, 1991 (RBNL) meta-analysis procedure and multiple regression. RBNL is an analytical procedure that corrects for sampling error and unreliability of measures (Christian et al., 2011, p. 103). Findings of this study suggested a strong relationship between engagement and mandatory job and discretionary work performance. This outcome was partially at variance with Macey and Schneider's (2008) framework which points to significant associations between engagement and employee discretionary work.

Christian et al. (2011) concluded, workers who had some measure of support, voice in decisions, and collegiality were more likely to be engaged, effective, and efficient workers in both mandatory and discretionary roles. This in turn, may lead to a more successful organization. These researchers suggested two ways to improve employee engagement: (1) through job selection; and (2) through job design. In other words, employers needed to hire employees who are predisposed to be engaged (Shuck, 2010) and create an engaging work environment to facilitate engaged employees. In this way leaders can "set the stage for engagement" by creating contextual conditions that facilitate employees' perceptions of meaningful work" (Christian et al., 2011, p. 124; 
Kahn, 1990). Final outcomes also pointed to differences between engagement and job satisfaction (Macey \& Schneider, 2008). The researchers submitted that one limitation of this study was the limited number of data points in several analyses, this hampered efforts to test for some moderators.

Wu (2012) used Macey and Schneider's (2008) framework to propose and validate the reliability of a behavioral engagement scale. Behavioral engagement was defined as employee extra-role behavior, citizenship, employee ingenuity, and employee flexibility. The scale comprised questions from the United States Department of Health and Human Services (HHS) surveys. Participants were hospital support staff from five states: Illinois, Texas, Maryland, Kentucky, and Pennsylvania. A total of 1,922 surveys were distributed; overall, 1,307 individuals or 68 percent of respondents participated in the study. Data were analyzed using multiple linear regressions. The outcomes signaled the behavioral engagement scale as reliable and valid.

Findings of the study indicated a negative relationship between behavioral engagement and intent to turnover. That is, the more engaged the employee, the less likely the employee was to leave the organization. A positive relationship was observed between behavioral engagement and employee safety and willingness to recommend a workplace as a caring and safe organization. That is, the more behaviorally engaged the employee was, the more likely the employee was to recommend the organization as a good place to work. $\mathrm{Wu}(2012)$ concluded that behavioral engagement was influenced by "how one's colleagues behave, and how employees and colleagues function as a team, and how the organization and supervisors treat workers" (p. 159). 


\section{Factors Related to Teacher Attrition}

In this section, I discussed factors related to teacher attrition. The factors are school-level characteristics, classroom-level characteristics, and teacher-level characteristics and their influence on teacher attrition. School level and classroom-level characteristics include school type that is, rural versus suburban schools; high-poverty, high minority schools, and elementary versus secondary schools. Additionally, I presented literature on teacher supports systems and their influence on teacher attrition. Teacher-level characteristics include an examination of literature exploring the influence of teachers' age and experience, teacher quality, teacher gender, and teachers' race and their relationship to teacher attrition.

\section{School Climate}

School climate molds the quality of interaction amongst all stakeholders in the school community (Wang \& Degol, 2016). Further, empirical literature indicates strong positive associations between school climate and teacher attrition (Ingersoll, 2001; Kraft et al., 2016; Loeb, Darling-Hammond, \& Luczak, 2005; Marinell \& Coca, 2013). The climate illuminates the values, norms, vision, mission, instructional practices, and learning process in any school (Wang \& Degol,). Some researchers explicate school climate as teacher autonomy, administrative support, collegial relations, student behavior, school facilities - physical plant, and school safety. (Darling-Hammond, 2003; Hirsch et al., 2007; Kraft et al., 2016; Loeb et al., 2005; Pogodzinski et al., 2012).

Wang and Degol (2016) proposed that school culture was a multidimensional concept that explained schools' experiences, but it was also a flexible construct that lacked a common definition. Wang and Degol (2016) identified four broad categories that 
encapsulated the quality of the school climate. The categories were academic climate, community, safety, and institutional environment. Academic climate was the instructional environment and the quality of instruction. Quality of instruction included curricula, teaching training, and professional development. Community emphasized interpersonal school relationships. Safety focused on the extent of provision of physical and emotional safety provided by the school. Instructional environment focused on the school as an organization.

This section of the current review of literature examined the school climate characteristics that influence teachers to remain or leave teaching. Information exploring school climate characteristics was explicated using the following headings: school-level characteristics, classroom-level characteristics, and teacher-level characteristics. School characteristics and teacher characteristics was used to explain school climate from an academic and instructional context. Classroom and student characteristics incorporated the school climate dimensions of safety and community. Some overlap may occur in this exposition.

\section{School-Level Characteristics}

Scholarly research highlighted school characteristics as primary factors that influenced teacher attrition (Borman \& Dowling, 2008; Ghavifekr \& Pillai, 2016; Ingersoll, 2001; Ingersoll \& Strong, 2011). School characteristics were identified as school location, school size, administration support, school induction and mentoring programs for beginning teachers, teacher collaboration and teacher networks, opportunities for professional development, and teacher autonomy (Borman \& Dowling, 2008; Ghavifekr \& Pillai, 2016; Ingersoll, 2001). 
The schools reporting the highest percentages of teacher attrition are lowperforming, urban schools that serve low-performing, poor, minority students who are taught by inexperienced, beginning teachers (Cowan, Goldhaber, Hayes, \& Theobald, 2016; Hanushek, Kain, \& Rivkin, 1999; Ingersoll \& Merrill, 2013). This trend is generally harmful to the students at these schools (Hanushek et al., 2004; Kraft et al., 2016). Having high quality teachers in the classroom create a positive school climate which leads to increased teacher satisfaction and the increased probability that teachers will remain in their jobs. As a result, they gain the skills and experience needed to be effective teachers (Ghavifekr \& Pillai, 2016).

In examining teacher attrition in the context of school location, Ingersoll (2001) concluded that teachers who taught in urban schools were more likely to leave than teachers who taught in rural settings (Boyd et al., 2008). Conversely, Cowan et al. (2016) pointed out that school staffing problems were experienced by rural schools as well as schools seeking science, technology, engineering, and math (STEM) teachers. Ingersoll (2001) used data from the School and Staffing Survey (SASS) and Teacher Follow-up Survey (TFS) retrieved from the National Center for Education Statistics (NCES) to examine the relationship between teacher turnover and school staffing problems. The researcher also examined the relationship between school level characteristics and teacher turnover. The sample for this study comprised 6,733 elementary and secondary teachers.

Findings from the Ingersoll (2001) study established that although retirement accounted for some teacher turnover, job dissatisfaction and teachers leaving to pursue other careers superseded retirement as reasons for turnover. Job dissatisfaction was explicated as low salaries, lack of administration support, student discipline problems, 
and minimal input in decision-making. Ingersoll and Smith (2003) found that 68 percent of beginning teachers left teaching for similar reasons. Some researchers concluded that working conditions in schools predicted whether teachers would stay in teaching (Boyd et al., 2011; Simon \& Johnson, 2015).

Expansive research supports assertions that teachers leave less advantaged schools to teach in better environments (Borman \& Dowling, 2006; Ingersoll \& Merrill, 2013; Lankford et al., 2002; Rivkin et al., 2005; Smith \& Ingersoll, 2004). However, research by Hughes (2012) suggested otherwise. Using block-entry logistic regression Hughes (2012) conducted an analysis of 782 novice and veteran teachers from elementary, middle, and high schools in a southern state to determine how teacher characteristics, school characteristics, organizational characteristics, and teacher efficacy influenced teacher retention. School characteristics were school size, socioeconomic status (SES), standardized test performance, and student ethnicity.

The results of Hughes' (2012) study suggested a strong negative relationship between SES, years of teaching experience, salary and workload, parent and student engagement, the fear of growing technology requirements and teacher retention. Ingersoll's (2001) study also indicated that salary had a negative influence on attrition. Grissom and Strunk (2012) concluded that the effect of monetary incentives was based on the levels of teacher experience. Salary was an incentive that mainly attracted novice teachers at the beginning of their careers. Whereas, the lure of salary was less appealing to veteran teachers who were more swayed by working in a positive school climate and culture (Clotfelter et al., 2007). 
Contrary to the literature, Hughes (2012) found that teachers who taught in schools with low SES were more likely to remain than teachers who taught in high SES schools. Two plausible explanations were given for this outcome. One reason was the high number of rural schools with low SES populations in the sample and availability of few career choices outside of teaching in those communities caused teachers to remain in teaching. A second explanation was that awareness of the positive difference they made in the lives of the children made the teachers in low performing schools more committed to the job. Additional findings indicated most of the participants planned to remain in teaching until retirement although newer teachers were less likely to stay than teachers with 10 or more years of experience (Ingersoll, 2001, 2003; Alliance for Excellent, 2014). Nevertheless, Hughes' (2012) agreed that organizational characteristics such as low salaries, teacher workload, and inadequate parent and student support contributed to higher teacher attrition.

School administration and school leaders play a vital role in teachers' decisions to leave or to remain in teaching (Boyd et al., 2011; Chetty et al., 2014; Clotfelter et al., 2007). In a study of all novice teachers $(\mathrm{n}=4,360)$ in New York City Public Schools, Boyd et al. (2011) examined the relationship between school contextual characteristics and teacher retention. School contextual factors were teacher influence, administrator's support, staff relations, student behavior, facilities, and safety. After analyzing all six school factors and the control factors, the administration factor was the only variable that significantly predicted whether teachers intended to remain or leave teaching (Boyd et al., 2011). The researchers concluded, teachers who had negative perceptions of administrators were more likely to either leave teaching in New York City or transferred 
to other schools (Ingersoll, 2001; Ingersoll et al., 2014; Ingersoll \& Strong, 2011; Kraft et al., 2016). Conversely, Eckert (2012) identified teachers' sense of self-efficacy, defined as the personal satisfaction that comes from feeling competent to do the job well, as the main determinant in the decision to stay or leave teaching for both novice and veteran teachers. A survey of 2,000 current and former teachers in California revealed that teachers felt greater personal satisfaction when they believed in their own efficacy, were involved in decision making, and established strong collegial relationships (Eckert, 2012; Futernick, 2007).

Kraft et al. (2016) in their study on the relationship between organizational context, teacher turnover, and student achievement in middle schools in New York City concluded that improvements in school leadership, collegiality, and school safety had a positive influence on teacher turnover and growth in student achievement. These findings were supported by Ronfeldt et al. (2013) in their research of 278 middle schools in New York City that served low-income, minority students. Moreover, scholarly literature stressed school leaders' responsibility for motivating faculty, staff, and students, developing and articulating the school's mission and vision, communicating and modeling high performance expectations, facilitating communication with stakeholders, procuring resources, and encouraging student learning through effective instructional practices (Boyd et al., 2011; Leithwood, Louis, Anderson, \& Wahlstrom, 2004; Spillane, 2005; Tye \& O'Brien, 2002).

Any recognition and support extended to teachers by leadership would enhance teachers' intent to remain teaching (Boyd et al., 2011; Cherng \& Halpin, 2016; Pogodzinski et al., 2012). Other recommendations to enhance a positive school climate 
and by extension reducing teacher attrition, included providing teachers with directions on how to use student assessment data in planning and implementing standards-based curricula (Darling-Hammond, 2003; Hirsch et al., 2007; Loeb et al., 2005). Ingersoll (2012) and Ingersoll and Smith (2003) also suggested a plausible solution to the challenge of retaining new teachers to the profession may be providing induction and mentoring services to beginning teachers.

The effects of induction and mentoring on teacher retention are well-researched (Ingersoll \& Kralik, 2004). After conducting a meta-analysis on 15 empirical studies on the effects of induction programs, Ingersoll and Strong (2011) concluded that induction positively influenced teachers in three ways: teacher commitment and retention, classroom instruction, and student achievement. Support programs of this nature are beneficial to both beginning and veteran teachers (Ingersoll, 2001, 2003; Ingersoll \& Strong 2011). They provide orientation, support and guidance to beginning teachers (Ingersoll \& Strong, 2011). Moreover, induction and mentoring help to reduce rates of attrition by enhancing skills and abilities of beginning teachers as well as provide career advancement opportunity for veteran teachers (Feiman-Nemser, 1996). Indeed, DarlingHammond (2003) pointed out that failure to cater to the affective and professional needs of teachers may result in the good teachers gravitating to the schools where they will feel most appreciated.

However, both Ingersoll (2012) and Fideler and Haselkorn (1999) cautioned that schools and organizations should be aware of the limitations and implications to implementing adequately functioning induction and mentoring programs. Supporting programs of this nature varied in length, intensity, structure, the number of schools, and 
veteran teachers involved. Therefore, intentional consideration should be given to selection and training of mentors. Additionally, mentors and mentees should share similar academic interests. They should also share similar planning times and be allotted time for instructional collaboration with other teachers. Costs of implementing such programs also needed to be considered since mentoring and induction programs can only be successful if resources are readily available. Ultimately, the value of induction and mentoring programs may be seen in the positive student outcomes associated with highaccountability (Ingersoll \& Strong, 2011).

In conclusion, organizational or school characteristics influenced teacher attrition. School characteristics were identified as school location, SES, school leadership and climate, induction and mentoring programs. The literature indicated that work conditions in schools may predict whether or not teachers remained in teaching. Particularly, teachers' perceptions of school leadership influenced their intent to leave or remain in teaching. Furthermore, support programs such as induction and mentoring programs provide veteran teachers leadership opportunities whilst motivating new teachers to remain in their jobs. Overall, literature supported that student success was possible if students were taught in a stable school environment by more experienced teachers. The research also indicated that academically challenged students who come under the tutelage of inexperienced teachers are more likely to be low performers in achievement tests. The next section of this review entailed an exploration of classroom characteristics and their influence on teachers' career decisions. 


\section{Classroom Characteristics}

Extant literature examined the relationship between classroom and student characteristics and teacher attrition (Boyd et al., 2005; Clotfelter, Ladd, \& Vigdor, 2011; Feng, 2009; Hanushek et al., 2004). Students characteristics were identified as student socio-economic status (SES) (students who qualified for free and or reduced lunch), ethnicity and race, and student ability and achievement in tested versus non-tested classrooms (Simon \& Johnson, 2015). Classroom characteristics were class size, student behavior, and teaching environment (Feng, 2009; Figlio, 2007; Mont \& Rees, 1996).

Overwhelmingly, the evidence suggested that teachers typically left less challenging schools to teach in environments that were more conducive to student learning (Alliance for Excellent, 2014; Ingersoll, 2011; Ingersoll \& May, 2012; Rivkin et al., 2005). Hanushek et al. (2004) conducted a quantitative study examining all publicschool teachers in Texas and factors that increased the probability of teachers switching schools. The findings indicated a direct correlation between student characteristics and teacher mobility, particularly relating to students' ethnicity and achievement scores rather than salary, although salary did have a modest influence on retaining teachers (Boyd et al., 2005; Clotfelter et al., 2011; Mont \& Rees, 1996; Simon \& Johnson, 2015).

Grissom and Strunk (2012) posited that beginning teachers rather than veteran teachers would be more attracted to financial incentives. Veteran teachers' decisions to remain or leave teaching were more influenced by school climate and culture (Grissom \& Strunk, 2012). The student characteristics that deterred teachers in Hanushek et al.'s (2004) study were students who were low-SES, and Black or Latino students (Feng, 2009). 
Feng (2009) in his longitudinal, discrete-time multinomial-logit-hazard model study concluded that classroom characteristics were more likely to influence teacher attrition than student characteristics. Feng's (2009) research examined the impact of classroom characteristics and opportunity wages on four labor-market choices of 17,935 new public-school teachers in Florida. The data for the study was taken from Florida Education Data Warehouse (FL-EDW). The study extended over a period of seven years, from 1997 to 2004 with over 31,000 teacher observations. The teachers were categorized as: teachers remaining at their current schools, inter-school switching in the same school district, and leaving teaching.

According to Feng (2009) "the more challenging students a teacher has in his or her classroom, the more likely this teacher is to leave the school" (p. 1169). This was a finding espoused by Mont and Rees (1996). Feng (2009) continued, the greater the number of high achievers and well-behaved students, the less the stress generally associated with teaching. The higher the percentage of minority and low-SES students the more likely teachers were to leave teaching. Ingersoll (2001) concurred that schools with fewer students with disciplinary problems had lower rates of teacher attrition. Students' disciplinary problems not only influenced teacher attrition, but students' negative behaviors also adversely affected the school environment and peer behavior (Figlio, 2007).

A limitation that was noted in Feng's (2009) study was that the research did not explore the relationship between teacher quality or effectiveness and teacher job choice. Also, value-added measures could have been used to measure teachers' impact on 
students' performance and the effectiveness of teachers in responding to classroom characteristics.

High-accountability state-mandated student assessments were also linked to teacher attrition (Chetty et al., 2014; Clotfelter et al., 2007; Hanushek \& Raymond, 2005; Rivkin et al., 2005). Moreover, the effectiveness of school districts and schools, teachers, and students is measured by test performance, and schools are sanctioned if they fail to make adequate yearly progress (AYP) (Boyd et al., 2008; Chetty et al., 2014; Hanushek \& Rivkin, 2007; Ronfeldt et al., 2013). Empirical research showed that teacher attrition may vary between tested and non-tested classrooms. This was due to teachers trying to avoid teaching certain grade-levels because of the pressure to perform well and deliver high student scores in state exams (Clotfelter et al., 2004; Ronfeldt et al., 2013). However, Boyd et al (2008) found that teachers who taught tested grades were being retained at higher levels and that schools in New York were attempting to replace teachers who left teaching with more experienced and if possible high-quality teachers.

More recent studies suggested a negative association between stress and teacher attrition (Ingersoll, 2012; McCarthy, Lambert, Lineback, Fitchell, \& Baddouh, 2016; McCarthy, Lambert, \& Reiser, 2014). McCarthy et al. (2014) conducted a study on 185 veteran elementary school teachers' perceptions of the degree of classroom demands and availability of resources. The sample came from a large urban school district in a southeastern state. The average number of years of experience of participants was 10.05 years and five and one-half years at their current schools. The average class size was 21.51 students. Of the total student population, 23.64 percent were English Language 
Learners (ELLs), 13.08 percent had learning disabilities, 16.9 percent were behaviorally challenged, and 28.56 percent performed below grade level.

McCarthy et al. (2014) reported that teachers who perceived classroom demands to be more stressful and the job to be less satisfying were more likely to leave teaching. Teacher stress was described as the negative effects such as depression, anger, and frustration that came as a result of the teacher's job (Kyriacou \& Sutcliffe, 1978). Maslach et al. (2001) proposed feelings of frustration, depression, and anger were symptoms of burnout and the antithesis to employee engagement. Engagement was characterized as "vigor, dedication, and absorption" (Schaufeli et al., 2002, p. 74-75).

Chang and Davis (2009) supported McCarthy et al.'s (2014) findings. The researchers posited that stress may also be as a result of teachers' perceptions of their students, and that teachers' feelings of frustration and anger at students' behaviors had a negative influence on the classroom environment. Additionally, because beginning teachers are typically assigned classes with larger numbers of students with learning disabilities they may be at greater risks of experiencing stress due to lack of experience and lack of adequate resources to teach their student (Feng, 2009). One recommendation to prevent burnout was being proactive and pairing veteran teachers with new teachers to mentor and coach the new teachers, by extension providing veteran teachers training for future leadership positions (Ingersoll, 2001, 2012; Ingersoll \& Strong, 2011).

Other findings in McCarthy et al.'s (2014) study showed that class size and teacher experience were not predictive of teachers' intent to leave teaching. Writings by Loeb, Darling-Hammond, and Luczak (2005) and Schanzenbach (2014) suggested associations between increased class size, stress, and teacher attrition. These findings 
were supported by an earlier report by Mont and Rees (1996) who proposed a correlation between large class sizes and teacher turnover due to poor working conditions. The exceptions were veteran teachers, whose intent to leave or to remain in teaching was not influenced by class size due to the influence of tenure and unionization (Mont \& Rees; 1996). Unionization reduced teacher turnover owing to inclusion of layoff and class size provisions in union negotiations.

Kahlenberg (2015) clarified that tenure originated from the progressive movement whose intent was to improve the quality of teaching and education for all children. He also emphasized that 'tenure does not prevent [teachers'] termination, but it does require that employers show 'just cause' (a reasonable ground for action) for termination” (para. 8). Typically, American teachers earn tenure after a provisional three-year period (Kahlenberg, 2015).

Marinell and Coca (2013) in their study on middle school teachers in New York City Public schools concluded that three important factors contributed to teacher attrition: student behavior, lack of administration support, and lack of autonomy in decisionmaking (Ingersoll et al., 2014; Ingersoll \& Smith, 2003). Moreover, teacher turnover rates in middle school exceeded those of teachers in elementary and high schools. Teachers in the sample typically remained teaching in middle schools for an average of five years. Furthermore, teachers either exited middle schools to teach other grade levels or left the teaching profession altogether. This study examined a synthesis of data from Research Alliance investigation of teacher turnover in public middle schools in New York City. The sample comprised over 4,000 full-time middle school teachers. 
To summarize, this section of the review of literature discussed classroom and student characteristics that influenced teacher attrition. Characteristics that were discussed included student SES, ethnicity and race, and student achievement. Existing literature supported a correlation between teacher attrition and low-SES, low-achieving students, and Black and Latino students. The current research also discussed the relationship between student behavior and teacher stress. Teachers who taught students with behavior problems were more likely to experience stress and leave teaching. Additionally, inappropriate behaviors exhibited by students had a negative influence on the classroom environment and the students' peers.

Teachers' perceptions of their students influenced the classroom environment. This research also examined the relationship between class size and grade level and teacher attrition. Although class size did not predict teachers' intent to remain teaching, reports supported associations between class size, teacher attrition, and teacher stress. Finally, extant studies indicated teachers in secondary schools were more likely to leave teaching than teachers at the elementary level. The next section of Chapter 2 explores teacher characteristics that influence teachers' intent to remain or leave teaching.

\section{Teacher Characteristics}

Teachers are more critical to student learning than any other school-based factor (Chetty et al., 2014; Clotfelter et al., 2007; Rivkin et al., 2005; Sanders \& Rivers, 1996). The quality teachers who are needed most in vulnerable schools are most likely to leave (Alliance for Excellent, 2014; Boyd et al., 2005; Clotfelter at al., 2004). Retention of effective veteran teachers who possess specialized skills and experience may be essential to increase student achievement and turn-around low-performing schools (Ingersoll et al., 
2014). However, experience is not the only measure of teacher effectiveness or teacher quality. This section of the current study will examine teacher characteristics and how they influence teacher attrition. Teacher characteristics include age, teaching experience, gender, and grade level (Darling-Hammond \& Baratz, 2007; Dreyfus, 2004; Grissmer \& Kirby, 1994; Ingersoll, 2001; Ingersoll et al., 2014; Henke et al., 2000; Hughes, 2012), and teacher ethnicity (Achinstein, Ogawa, \& Sexton, 2010; Broughman \& Rollefson, 2000; Cherng \& Halpin, 2016; Hanushek et al., 2004; Ingersoll, 2001; Ingersoll \& May, 2012; Ingersoll et al., 2014; Marinell \& Coca, 2013; Murnane, Singer, Willett, Kemple, \& Olsen, 1991). Finally, this research will examine teacher quality and effectiveness and their relationship with teacher attrition.

Empirical research indicated there is a relationship between the age of a teacher and teacher attrition (Grissmer \& Kirby, 1994; Hughes, 2012; Ingersoll, 2001; Ingersoll et al., 2014). The teaching labor force is dynamic and changing as young college graduates and new older hires become teachers (Ingersoll et al., 2014). From 2004 to 2005 , about 30 percent of beginning teachers were 29 years old or older. These were people who made mid-career switches from previous jobs to become teachers (Ingersoll et al., 2014). Overall, beginning teachers account for approximately 45 percent of the teaching population (Ingersoll et al., 2014). Undoubtedly, both younger and older teachers are leaving teaching. However, beginning teachers who have been teaching for up to five years are more likely to leave the profession (Ingersoll, 2001; Ingersoll \& Smith, 2003; Perda, 2013). A U-shaped curve consistently indicates that attrition was highest amongst young beginning teachers, lower for mid-aged teachers, and rising again for teachers approaching retirement age (Bidwell, 2014; Grissmer \& Kirby, 1987; 
Murnane et al., 1989). From 1987 to 1988 the average teacher had 15 years' experience, from 2007 to 2008 one-year experience, and from 2011 to 2012 five years' experience (Ingersoll et al., 2014).

Notably, 45 percent of teacher attrition occurs in one-fourth of the nation's public schools (Ingersoll et al., 2014). Ingersoll et al. (2014) described these schools as "highpoverty, high-minority, urban and rural schools" (p. 23). Grissmer and Kirby (1991) suggested that attrition may occur because young teachers were not vested in teaching due to limited accumulation of knowledge and lack of expertise in the subject area. Other reasons for attrition of beginning teachers were termination due to underperformance, budgetary considerations, family and personal reasons, health issues and caring for family members (Ingersoll et al., 2014). However, most beginning teachers left teaching due to job dissatisfaction over salaries, student behavior, leadership, lack of resources, opportunities for professional development, and input in decision-making (Ingersoll, 2003; Ingersoll \& May, 2012; Ingersoll et al., 2014).

Conversely, research by Guglielmi, Bruni, Simbula, Fraccaroli, and Depolo (2016) showed that attrition varied across age-groups and that attrition was lower rather than higher amongst beginning teachers in Italy. Guglielmi et al. (2016) examined levels of engagement amongst elementary and secondary teachers in Italy across age-groups and job resources. The outcomes of this study may have been due to young teachers in Italy being more engaged and therefore more likely to remain in teaching. Motivational factors for young Italian teachers were consistent professional development, responsibility, collegial support, and intrinsic values (Ingersoll, 2003; Ingersoll \& Strong, 2011). Italian teachers also spent more time undergoing preparation and training for 
teaching than teachers in other countries (Guglielmi et al., 2016). On the other hand, Perrachione et al. (2008) found that teacher demographics such as age did not predict a teacher's intent to leave or remain in teaching; rather, attrition was attributed to extrinsic motivators such as stress, low salary, and work overload. Perrachione et al. (2008) used a mixed methods study to examine intrinsic and extrinsic variables that influenced teacher satisfaction and retention.

Although Ingersoll (2003) confirmed that older teachers left teaching due to retirement, this variable accounted for less than one-third of teacher attrition (Ingersoll et al., 2014). In fact, a downward trend has been noted in the number of teachers leaving teaching due to retirement compared to other contributing factors such as job dissatisfaction due to poor leadership and personal reasons (Ingersoll, 2001; 2003; Ingersoll et al., 2014). The average age of teachers is also commensurate with the decline in the number of teachers retiring. The average age was 41 from 1987 to 1988, 55 from 2008 to 2009, and 30 from 2011 to 2012. (Ingersoll et al., 2014). Further, the number of teachers 50 years and older has also decreased (530,000 from 1988 to $1989 ; 1.3$ million from 2008 to 2009; 1.2 million from 2011 to 2012) (Ingersoll et al., 2014).

Even though veteran teachers make up about one-fourth of the teaching population, the increasing number of new teachers may have a negative influence on student achievement (Ingersoll et al., 2014). Several benefits may be derived from retaining veteran teachers. Benefits include improved student scores and mentoring and coaching for new teachers in an effort to improve the quality of instruction (Henry, Fortner, \& Bastian, 2012; Ingersoll et al., 2014; Ingersoll \& Strong, 2011). Effective 
experienced teachers are generally better at dealing with student behavior, and working with diverse student populations (Ingersoll et al., 2014).

\section{Teacher Experience and Teacher Effectiveness}

According to Darling-Hammond \& Baratz-Snowden (2007), experienced teachers were more effective teachers. Therefore, retaining teachers, particularly effective veteran teachers who possess the experience and skills, was one way to produce successful students (Darling-Hammond \& Baratz-Snowden, 2007; Ingersoll et al., 2014). However, Ingersoll (2003) pointed out that employee turnover was a normal and necessary progression for any organization. Minimal turnover may result in stagnation of the organization, whilst turnover may lead to elimination of ineffective employees, and hiring of more effective replacements. Further, fiscal expenditure toward recruiting, training, and retaining beginning teachers was lower than expenditure on pensions and higher salaries for veteran teachers (Ingersoll, 2003; Ingersoll et al., 2014; Grissom \& Strunk, 2012).

From 2011 to 2012 the national average salary for public school teachers who had college degrees, but no teaching experience was $\$ 38,000$, whereas the average salary for veteran teachers with 15 years' experience was $\$ 73,000.00$ (Ingersoll et al., 2014). On the other hand, a high level of turnover is problematic and is likely an indication of underlying organizational challenges (Ingersoll et al., 2014). In the school context, the overarching objective is to produce successful, well-rounded students, and high teacher

turnover is counter to this effort (e.g., Cherng \& Halpin, 2016; Eckert, 2012; Hanushek et al., 2004; Hughes, 2012; Ingersoll, 2003; Ingersoll et al., 2014). 
Effective teaching is the most important factor that influences student achievement, especially in low-performing schools (RAND Education, 2015). DarlingHammond and Baratz-Snowden (2007) identified characteristics of effective teachers as the following. Effective teachers know how to use students' personal experiences and cultural backgrounds to contextualize students' experiences with the subject matter. They are perceptive and know what to teach, why they teach, and how to transfer their knowledge to their students. These teachers are pedagogically sound, effective managers of the classroom, possess knowledge, and have a range of teaching strategies to reach diverse students. Effective experienced teachers also know how to create and implement meaningful assessments to measure student learning. The research supports high attrition rates amongst beginning teachers, especially teachers in the first few years of teaching. This trend is an indication that many beginning teachers do not remain in teaching long enough to gain the experience and skills they need to become effective teachers (DarlingHammond \& Baratz-Snowden, 2007).

Teacher performance is typically used as a measure of teacher effectiveness (Goe et al., 2008). Reform policies such as Race to the Top (RttT) led the United States Department of Education (USDOE) to issue directives for participatory states and school districts to create systems that would improve teacher and school leaders' effectiveness (Ballou \& Springer, 2015). Under these systems student growth is measured, evaluative systems created and implemented to measure student growth, and teachers and leaders evaluated annually and provided with feedback. Evaluations would be used to create professional development opportunities, rewards, advancement, tenure, and certification (Ballou \& Springer, 2015). As a result, the Department of Education collaborated with 
Harvard University, the Wallace Foundation, WPS and three other counties, to present a five-point definition of teacher effectiveness. This definition was based on the following components: learning climate, classroom assessment and reflection, instructional rigor and student engagement, instructional relevance, and knowledge of content.

In concert with Darling-Hammond and Baratz-Snowden (2007) and using the Danielson Framework, the Department of Education emphasized the hallmark of effective teachers: first, effective teachers create a safe learning environment where positive relationships are fostered, and students are held to high expectations. Second, effective teachers work collaboratively with students to gather information, reflect on learning, and use data to inform instruction. Third, effective teachers use differentiated instruction to teach complex concepts and engage students in meaningful learning. Fourth, effective teachers collaborate with other teachers to make connections between disciplines to plan relevant instruction and link student real-life experiences, interests, and situations to the content to help prepare students for their future. Fifth, effective teachers demonstrate in-depth knowledge and understanding of content and apply the knowledge to current theories and situations to promote learning (Darling-Hammond \& Baratz-Snowden, 2007; Goe et al., 2008).

Additionally, effective teachers cater to the needs of a diverse population, including students with special needs and students at high risk of failure. Moreover, they involve parents in the learning process to create strong and supportive learning communities (Darling-Hammond \& Baratz-Snowden, 2007; Goe et al., 2008). Conclusively, effective teachers do not only stand in front of a class of students and 
lecture; effective teachers use multiple tools to assess what their students learn and know (Darling-Hammond \& Baratz-Snowden, 2007).

Teacher certification varies from state to state. Since the 2001 reauthorization of the Elementary and Secondary Education Act (ESEA) all classrooms are required to be under the tutelage of highly qualified teachers (HQT) (Redding \& Smith, 2016). To achieve the status of HQT, teachers must have at least a bachelor's degree, full state certification, or have successfully completed PRAXIS II and demonstrated proficiency in teaching a specific subject (Redding \& Smith, 2016).

State alternative certification programs are driven by the ESEA, and schools are pursuing these options as they strive to have their students taught by the most qualified and best teachers. Alternative certification programs (ACPs) incorporate all teacher education programs outside of the traditional teacher education programs (Redding \& Smith, 2016). Most states offered alternative certification for individuals with graduate degrees, no previous experience in education, and who wanted a career change (Redding \& Smith, 2016). Emergency certification was an option in times of teacher shortages to allow college graduates to teach while working toward state certification (Broughman \& Rollefson, 2000).

Typically, accelerated certification programs provide an accelerated entrance into teaching (Redding \& Smith, 2016). However, credentials and teacher certification are not measures of a teacher's effectiveness or teacher quality (Henke et al., 2000). Indeed, Clotfelter et al. (2010) warned that "not all teachers with weak credentials were poor teachers...not all teachers with strong credentials are effective teachers" (p. 676). In an article entitled Easy In, Easy Out: Are alternately Certified Teachers Turning Over at 
Increased Rates?, Redding and Smith (2016) used the School and Staffing Survey

(SASS) and Teacher Follow-Up Survey (TFS) of 2007-2008 to examine turnover patterns of ACP teachers. The researchers concluded there was a negative relationship between ACPs and teacher turnover. In other words, there was more likelihood of ACP teachers leaving teaching than traditionally certified teachers.

In order to raise the standard of teacher effectiveness the National Board for Professional Teaching Standards (NBPTS) established National Board Certification (National Board, 2018). The program was created by teachers for teachers as a means to provide a standard for teacher effectiveness and quality. Teachers may become certified in 25 content areas across 16 disciplines in Pre-K through grade 12 . This voluntary certification program is performance-based and is aligned to the NBPTS standards. Teachers are required to demonstrate their knowledge and competency in the areas for which they are certified. The program comprises four components: three portfolio entries and a computer-based assessment. Ultimately, evidence of the teachers' effectiveness must be demonstrated in Five Core Propositions: (1) Commitment to students and student learning; (2) Knowledge of the subject area and possess the pedagogical skills to instruct students in the subject area; (3) Ability to monitor and manage student learning; (4) Ability to reflect on their teaching practice and show evidence of ongoing learning; and (5) Participation in professional learning communities (National Board, 2018).

A quantitative analysis by Cowan and Goldhaber (2015) suggested that nationalboard certified teachers were more effective than non-national board certified teachers. The researchers used Washington State S-275, a survey of district personnel distributed by the Office of the Superintendent Public Instruction (OSPI) and data distributed by 
Pearson to collect a sample comprising 12,189 elementary and middle school teachers in Washington State. Pearson manages the assessment of NBPTS teacher candidates. The student sample comprised students from fourth through eighth grades. Student longitudinal data was collected from the ODPI for the years 2006 through 2013. The study was on the effectiveness of certified teachers and non-certified teachers based on value-added models in math and reading.

Other research conducted by the National Strategic Planning Analysis Research Center (2017) used descriptive and multivariate analysis to examine the relationship between Kindergarten students and third grade students taught by NBCTs and their performance in Reading on standardized literacy assessment. Information comprised an amalgam of data collected from the Mississippi Department of Education and the NBPTS for the 2015 to 2016 academic year. The data comprised 29,170 kindergarteners of whom 1,702 were taught by NBCTs and 37,929 third graders of whom 2,842 were taught by NBCTS. The results indicated that the students instructed by the NBCTs scored significantly higher than their peers. This study was conducted in a NBPTS project in collaboration with the Mississippi Department of Education in the 2015 to 2016 academic year.

To conclude, Croninger, Rice, Rathbun, and Nishio (2007) posited teacher preparation were better predictors of student achievement, particularly coursework covered in teacher preparation programs. However, the influence of teacher qualifications on student achievement may depend on individual teacher and collective teacher characteristics (Croninger et al., 2007). Also, teachers who enter teaching through ACPs were more likely to leave teaching than traditionally certified teachers. Moreover, 
National Board Certified teachers were likely to be more effective teachers whose teaching may result in improved students' scores. However, Pogodzinski, Youngs, Frank, and Belman (2016) cautioned against using qualifications as a measure of teacher accountability and effectiveness. Teachers were seen as a political investment in human capital and policymakers were more concerned with the results of teaching compared to preparation for teaching (Pogodzinski et al., 2016).

In this section of the chapter I examined teacher quality in relation to teacher attrition. In a review of Strong's (2011) book, The Highly-Qualified Teacher: What is Teacher Quality and How Do We Measure It, Maloney (2013) observed Strong (2011) stated that good teaching, often used as a synonym of effective teaching, was typically measured by improvement shown in students' performance in standardized tests (Strong, 2011). Strong (2011) advocated that the best measure of teacher quality was an amalgam of several factors including in-class observation by administration, value-added scores based on student achievement, student evaluations, or portfolios to evaluate teacher effectiveness. However, both experience and value-added scores garnered by the use of value-added models (VAM) were also used to evaluate teacher quality.

\section{Teacher Quality and Attrition}

The goal of educational institutions is to employ teachers who are highly qualified. However, there is a scarcity of literature examining the combined issues of teacher recruitment and retention with teacher quality (Guarino, Santibañez, \& Daley, 2011). Two factors contributing to the paucity of information on teacher quality and attrition were (1) a lack of a common definition for teacher quality; and (2) the scarcity of data that would aid researchers in identifying effective teachers and the factors 
influencing the recruitment and retention of effective teachers (Guarino et al., 2011). The lack of literature on teacher quality related to teacher attrition was corroborated by Rivkin et al. (2005) and Krieg (2006). Rivkin et al. (2005) pointed out that it was difficult to assess teacher departures due to lack of data matching students to teachers. Moreover, little variance existed between the median quality of new teachers versus the quality of teachers remaining. The measure of teacher quality in this study was student achievement based on school levels.

In an examination of teacher quality using value-added scores, Murnane (1984) utilized maximum likelihood Tobit analysis to conduct a study examining whether attrition of elementary teachers in an urban school district was systematically related to their productivity. Tobit analysis is a method used to analyze regression problems. Teacher productivity was measured using the median achievement scores gains of 1,027 students in reading and math tests and supervisors' evaluations of teachers. Results of the study showed that the least effective teachers were more likely to leave after teaching for one to two years, whereas, the more productive teachers tended to remain teaching in the more challenging schools. Further, there were positive relations between highly productive teachers based on supervisors' evaluations and teachers who remained. Two limitations to Murnane's (1984) study were the small sample size of elementary teachers $(n=104)$ and inability to determine if departing teachers left teaching altogether or transferred to other school districts.

Krieg (2006) used a two-stage regression analysis to estimate teachers' impact on their students' performance based on prior academic scores. Subsequently, this quality of measure was used to explicate teacher attrition. The teachers' value-added scores were 
used as the measure for teacher quality. The student population corresponded to 2,293 fourth grade teachers from Washington State. Findings from this study indicated that quality female teachers were less likely to leave teaching, whereas, teacher quality did not influence male-teacher attrition. Hanushek, Kain, O'Brien, and Rivkin (2005) also used student achievement gains to estimate teacher value-added. Teacher value-added scores was the measure of teacher quality. The sample comprised participants from urban schools in Texas.

Findings from the Hanushek, Kain, O'Brien, and Rivkin (2005) study revealed great variance in the quality of instruction. For example, teacher experience rather than teacher certification, influenced teacher quality. Also, quality teachers were effective at instructing students of all abilities. However, matching students and teachers based on race seemed to yield better student success. Further, teachers who remained in teaching tended to be better teachers than those who determined that they needed to leave teaching. These findings corresponded to findings by Murnane (1984), that is, the more effective teachers remained in teaching.

Goldhaber, Gross, and Player (2007) examined teacher attrition and mobility of beginning teachers in public schools in North Carolina from 1996 to 2002. Value-added scores were used as the measure of teacher quality. Participants comprised 10,921 fourth to sixth grade teachers statewide. The results of this study indicated that although teachers tended to leave the more challenging schools, the more effective teachers were less likely leave teaching (Hanushek et al., 2005; Murnane, 1984). Moreover, similar to Krieg (2006), Goldhaber et al. (2007) suggested that more effective teachers taught for 
longer periods and quality female teachers were less likely to leave teaching in North Carolina.

Ingle (2009) also used value-added scores to conduct a binomial logical regression study to examine if teachers with high value-added scores influenced staying or leaving tested subjects (reading and math) or grades ( 3 to 10). The finding indicated a negative relationship between reading teachers' value-added scores and attrition. Also, teachers who were likely to leave tested grades and subjects were secondary and alternatively certified teachers rather than elementary teachers. Teachers were also more likely to leave if they taught higher percentages of students enrolled in the free/reduced meal program. Overall, teachers who had more opportunities available and who had lower value-added scores were more likely to leave tested areas and grades. Krieg (2006) corroborated Ingle's (2009) findings. Additional outcomes from Krieg's (2006) study indicated that although secondary teachers were more likely to leave than elementary teachers, departures varied based on the subject taught. For example, whilst secondary reading teachers were more likely to leave than elementary teachers, secondary math teachers were less likely to leave teaching than elementary math teachers. This could be due to availability of fewer secondary math positions compared to elementary math positions.

In a more recent study, Harris, Ingle, and Rutledge (2014) conducted a comparative analysis of 30 schools in Florida comparing teacher effectiveness rating by principals and teacher value-added measures. Outcomes of this study suggested a weak correlation between value-added measures and principal evaluation. Sometimes principals gave low evaluations to teachers who scored high in value-added measures due 
to teacher characteristics. For example, lack of teacher participation or contribution to school or community activities resulted in low principal evaluation scores for some teachers even though they received high value-added scores. Teacher rewards may be based on these evaluative methods. Outcome of evaluations may influence teacher quality and by extension student performance.

A report by the American Educational Research Association (AERA) Council (2015) indicated that considerable ambiguity still existed concerning knowledge of VAM and whether such models were sufficiently developed to include into teacher accountability systems (Goldhaber, 2015). Goldhaber (2015) suggested using VAM may be an effective way to get rid of the least effective teachers and retain the most effective teachers (Goldhaber, 2015). For example, Chetty et al. (2014) estimated that if 5 to 10 percent of ineffective teachers were dismissed annually and replaced by more effective teachers, American students' performance on standardized test would improve drastically. Goldhaber and Hansen (2010) conducted a simulation to test this theory the findings of which supported Hanushek's (2009) and Chetty et al. (2014) suppositions. That is, using only value-added scores, the students of effective teachers in Goldhaber's (2015) study performed at higher levels than students of ineffective teachers.

Goldhaber (2015) pointed out that there were some factors to consider when implementing policies of this nature. First, value-added can only be calculated after the class has been taught by the teacher. Imprecise calculations may occur since student sample sizes vary based on the classroom, although teacher performance may remain unchanged. Second, although policy-makers may be stringent about teacher selection, rigorous standards about teacher performance inevitably leads to teacher turnover. 
Therefore, any gains made by hiring effective teachers may be countered by the disruptive effect of teacher turnover. For example, a study by Ronfeldt et al. (2013) showed the negative effects of teacher turnover on student achievement in English and Math. This study suggested that for every zero to two teachers that left a school with five teachers per grade level, student achievement dropped by two to four percent of a standard deviation in math. A third factor to consider was teacher behavior, for the "effects of selective tenuring and dismissal policies are far larger than those of performance incentives [and] high-stakes policies" (AERA, 2015; Goldhaber, 2015, p. 90). It is important to implement VAM with integrity. Failure to do so may result in serious negative consequences, for example "loss of advancement, loss of compensation, and even termination" (AERA, 2015, p. 449). In the following section, I discussed gender and teacher attrition.

\section{Gender}

Teaching is traditionally a female dominated profession (Ingersoll et al., 2014). Between the 1960s to the 1980s the percentage of female college graduates dropped from 67 percent to 17 percent (National Education, 2010) as more women started to work and there were increasingly varied job opportunities (Broughman \& Rollefson, 2000; Ingersoll et al., 2014). In a longitudinal study of more than 11,000 college graduates, Henke et al. (2000) reported women were more likely to have taught in schools, received teaching credentials, applied for teaching jobs, or even have considered teaching as a career (Ingersoll et al., 2014). From 1987 to 1988, 78 percent of females were new teachers (Broughman \& Rollefson, 2000). Despite opening of new job opportunities in areas such as law, medicine, pharmacy, and architecture, jobs typically dominated by 
males, the proportion of females entering teaching continued to grow (Ingersoll et al., 2014). Between 1980 and 2012 the percentage of female teachers increased from 27 percent to 76 percent (Ingersoll et al., 2014). Although, the number of males entering teaching increased by 22 percent in 2012, an even faster growth rate than the student population, the number of females taking teaching jobs increased twice as fast (Ingersoll et al., 2014).

Historically, elementary level is dominated by females who were twice as likely to teach in elementary schools. The exception was beginning females who were older and single (Henke et al., 2000; Ingersoll et al., 2014; Karge, 1993). Karge (1993) posited that single, older, beginning female teachers may receive less help and support from leadership than young, beginning teachers, due to age and assumed experience of the older teachers. This could influence feelings of isolation and estrangement from leadership and colleagues (Karge, 1993). However, Perrachione et al. (2008) in their study on retention and job satisfaction of elementary teachers found no statistically significant relationship between gender and the intent to remain in teaching. Rather, intent to remain in teaching seemed more correlated to teachers' satisfaction with teaching as a job than demographic characteristics, such as low salary, and role overload (Billingsley \& Cross, 1992; Boyd et al., 2008; Ingersoll, 2003; Lortie, 1975; Marinell \& Coca, 2013).

Male teachers dominated teaching at the secondary level until the late 1970s, in subsequent years increasing numbers have entered secondary education at secondary and at faster rates than in elementary education (Ingersoll et al., 2014). In 2011 to 2012 a total 
of 52 percent of females were principals, 64 percent at elementary level, 43 percent at middle school level, and 32 percent at high school level (Ingersoll et al., 2014).

Additionally, literature indicated that female teachers appeared more satisfied and stayed in teaching longer than male teachers (Bogler, 2002; Henke et al., 2000; Ma \& MacMillan, 1999) and married women seemed more satisfied to remain in teaching than single males and females (Goodlad, 1984; Karge, 1993; Lortie, 1975). Conversely, some research indicated otherwise (Adams, 1996; Gritz \& Theobald, 1996). Kirby, Berends, and Naftel (1999) stated that although attrition rates were similar amongst males and females, the rate was five percent lower for White males than females, and 10 percent lower for African-American males than females. While other research posited females were more likely to leave teaching than males due to marriage or spouses changing their jobs (Adams, 1996; Gritz \& Theobald, 1996; Ingersoll, 2001). Theobald (1990) proposed that females in their $20 \mathrm{~s}$ and 30 s were less likely to return to teaching due to pregnancy or child-rearing (Henke et al., 2000). Stinebrickner (1999) suggested negative associations between children and both male and female teachers remaining in teaching however, males were more likely to remain in teaching than females.

To summarize, there were associations between gender and teacher attrition. The teaching workforce is predominantly female (Henke et al., 2000; U.S. Department of Ed, 1997). Married women were more likely to remain in teaching than single people of both sexes and females were more likely to teach in elementary school than secondary schools. Female teachers appeared to be more satisfied and were more likely to remain in teaching than male teachers. However, female teachers were more likely to leave teaching due to marriage, pregnancy, and family situations. However, Perrachione et al. (2008) found no 
statistically significant relationship between gender and teacher retention. Following is an examination of ethnic factors that influence teacher attrition.

\section{Ethnicity}

Although current data indicate increases in the numbers of minority students and teachers in public schools, the disparity in minority student population compared to minority teacher population persists (Ingersoll et al., 2014; Riley, 1998). For example, in 2011 to 2012, 44 percent of students in the United States were minority students compared to 17.3 percent of minority teachers (Broughman \& Rollefson, 2000; Ingersoll et al., 2014). The disproportionality in numbers persisted despite the increased number of minority teachers recruited. From 1987 to $1988,325,000$ or 12.4 percent of minority teachers were recruited. From 2011 to 2012, the number increased to 666,000 or 17.3 percent of minority teachers who were recruited (Broughman \& Rollefson, 2000; Ingersoll et al., 2014). This disparity was not due to lack of recruitment but to decreased numbers of White student enrollment and increased numbers of minority student enrollment in public schools (Ingersoll et al., 2014).

Minority teachers enter teaching at higher rated than White teachers. (Ingersoll et al., 2014). Henke et al.'s (2000) in a National Center for Education Statistics Report examined the post-graduate experiences of 11,200 participants. The research yielded the following results: White females more so than males or minorities were more likely to become teachers after graduating from college. Asian-Pacific Islanders were the least likely to teach at any level compared to White, Hispanic, and non-Hispanic graduates. There was a 50 percent chance that Black and non-Hispanics graduates would become teachers compared to their White colleagues. Minority graduates were more likely than 
Whites graduates to teach in urban, high-minority schools that served low-income students.

The persistent demographic pattern indicated that a majority of the nation's minority students are taught by White female teachers (Cherng \& Halpin, 2016; Henke et al., 2000). This is not surprising as the majority teachers in the United States are White compared to minority teachers (Cherng \& Halpin, 2016; Ingersoll et al., 2014). For example, in New York City public school district with a student population of over 85 percent minority students only 40 percent of the teaching population was minority teachers (Cherng \& Halpin, 2016). Further, from a total of 34 states there is 20 percent points difference between numbers of minority and White teachers (Boser, 2014). Minorities were two to three times more likely to work in high-poverty, high-minority urban schools (Borman \& Dowling, 2006). Some researchers attributed this to "humanistic commitments" to students, particularly student of color (Achinstein, Ogawa, \& Sexton, 2010).

Darling-Hammond, Dilworth, and Bullmaster (1996) suggested that certain teachers possessed characteristics that made them effective at working with AfricanAmerican students. However, minority teachers were also more likely to leave teaching at higher rates compared to White teachers (Borman \& Dowling, 2006; Ingersoll, 2001; Ingersoll et al., 2014). Minority turnover rate increased by 28 percent from the 1980 s to 2009 (Ingersoll et al., 2014).

The schools that were most affected by high turnover amongst minority teachers were low-performing schools (Ingersoll et al., 2014). In an examination of literature studying the relationship between ethnicity and teacher attrition, Billingsley and Cross 
(1992) and Hughes (2012) suggested minority flight from teaching was due to less job satisfaction amongst minority teachers compared to White teachers. Ingersoll et al. (2014) concurred and highlighted specific variables that influenced job satisfaction, for instance working conditions, specifically lack of autonomy and level of input in decisionmaking in schools (Macey \& Schneider, 2008). Minority teachers leaving hard-to-staff schools where they were needed most, undermined efforts to diversify the teaching work force (Ingersoll et al., 2014). Conversely, other research suggested there was no association between ethnicity/race and whether novice teachers left or returned to teaching (Henke et al., 2000).

\section{Summary}

Research posited a relationship between ethnicity and teacher retention (Borman \& Dowling, 2006; Ingersoll et al., 2014), although reports by Henke et al. (2000) opposed this view. Despite increases in numbers of minority teachers, White teachers still dominated the teaching profession. However, minority teachers left teaching at higher rates than White teachers mainly due to dissatisfaction with working conditions. Minority teachers were more likely to teach in high minority, high-poverty schools. This pattern of minority teacher attrition was disruptive to the education of students who needed to be taught by the best teachers. The final section of this review of literature examined factors influencing veteran teachers to remain teaching in low-performing schools.

\section{Why Do Veteran Teachers Remain Teaching in Low-Performing Schools?}

Recruiting and retaining highly effective veteran teachers to teach in lowperforming schools is a constant challenge. Between 40 to 50 percent of new teachers leave the profession annually (Alliance for Excellent, 2014; Ingersoll et al., 2014; 
Ingersoll \& Smith, 2003; NCTAF, 2003; Perda, 2013). Some research shows that teachers who are the least qualified work in the lowest performing schools serving impoverished, low-performing, minority students (Alliance for Excellent, 2014; Boyd et al., 2005; Clotfelter et al., 2004; Lee \& Orfield, 2006). Proponents of retention suggest rather than spending money recruiting new teachers, money would be better spent retaining quality teachers (Berry, 2008; Ingle, 2009). However, despite well-documented challenges associated with teaching in low performing schools there is a cohort of highly effective veteran teachers who continue to teach in low-performing schools (Clotfelter et al., 2004).

Perrachione et al. (2008) used multiple linear regression and qualitative analysis to conduct a study of 201 veteran elementary school teachers who taught in public elementary schools in Missouri. The research examined intrinsic and extrinsic motivators influencing job satisfaction and the extent to which job satisfaction influenced teachers' intent to remain in teaching. Findings of the study suggested both intrinsic and extrinsic factors motivated highly effective veteran teachers to remain teaching in Missouri public elementary schools. Intrinsic factors were related to the job role and extrinsic factors were related to the teachers' work environment.

Intrinsic motivators strongly influencing veteran teachers to remain teaching in low-performing schools were personal teaching efficacy (PTE), working with students, and job satisfaction. Perrachione et al. (2008) posited positive work experiences provided teachers the opportunity to work with and nurture students while reducing instances of absenteeism and teacher attrition. Extrinsic motivators were schedule, time-off, and retirement. Conversely, teachers who left teaching were influenced by extrinsic factors 
only, such as low salary, role overload and ambiguity, and stress leading to negative teaching experiences. Work overload was a strongly significant factor. Other factors contributing to teacher attrition due to dissatisfaction were stress influenced by excessive paperwork and extra non-teaching duties. As teaching job dissatisfaction increased so did teacher absenteeism and attrition. The strength of Perrachione et al.'s (2008) study was seen in the shift from focusing on teacher attrition to examining factors influencing teachers' decisions to remain in the classroom.

Ashiedu and Scott-Ladd (2012) also posited that veteran teachers stayed in teaching due mainly to intrinsic and extrinsic motivators. Qualitative research was carried out in Australia with 36 respondents. Five respondents were retired veteran teachers with over 21 years of teaching experience who taught in public schools. In the Australian context, public schools were the schools experiencing teacher shortages. The rest of the sample were novice and veteran teachers in active service. Ashiedu and Scott-Ladd (2012) classified the veteran teachers who were "successful" [as having] "completed their career and left the profession by natural attrition or had taken early retirement” (p. 22). The other 31 respondents were active teachers whose teaching experience ranged from less than five years to over 21 years. The results of this study corresponded to those of Perrachione et al. (2008). Teachers were attracted to teaching for intrinsic reasons such as, personal characteristics, school location and perception of teaching as a profession.

Conversely, extrinsic motivators were more influential in motivating the participants to remain in teaching. However, teachers who were attracted to teaching for intrinsic reasons seemed more positive in intent to remain in teaching. Examples of extrinsic factors influencing teachers' intent to remain in teaching were work 
environment, defined as school and working conditions, curriculum, and extra duties, workload, and salary equity concluded that teachers who remained in teaching for intrinsic reasons would have to feel supported and their needs met by school leaders.

Petty et al. (2011) conducted a qualitative study on teachers' perspectives on staffing needs in high-need middle schools in North Carolina. The sample comprised 149 middle school teachers from 35 school districts. Noteworthy was that 71 percent of the sample had been working in their schools for less than five years. Eight percent of the sample worked in a high-needs school for more than 15 years. Results from this study were similar to those of Perrachione et al. (2008). Teachers indicated that they remained teaching in high needs schools because of their satisfaction with their job role and the positive influence they felt they had on children's lives.

In discussing teacher retention in relation to teachers' salary schedule Grissom and Strunk (2012) pointed out that after the first few turbulent years, teachers were more likely to remain in teaching for several reasons. First, teachers stayed because of their commitment to teaching (Perrachione et al., 2008). Second, they felt teaching was a good fit for their special skills-set and personality. Third, they had accumulated teachingspecific capital and were not prepared to start over in a new job. Fourth, they were anticipating pension after retirement (Perrachione et al., 2008). Conversely, Murnane et al. (1991) pointed out that the impact of salary incentives on veteran teachers was negligible after six to eight years of teaching which was when teachers were less likely to leave teaching due to tenure and unionization (Grissom \& Strunk, 2012). Teachers were most likely to quit during their first few years of teaching, and during the years 
approaching retirement (Bidwell, 2014; Hanushek \& Rivkin, 2007; Ingersoll, 2001, 2003; Ingersoll et al., 2014).

In conclusion, most of the studies examining reasons why veteran teachers remained in teaching were qualitative studies except for one mixed methods study. Most teachers indicated they were intrinsically motivated to remain in teaching. Intrinsic factors that motivated teachers were: personal job satisfaction, personal teacher efficacy, and the positive influence teachers exerted on children's lives. Teachers who were extrinsically motivated were more likely to quit. Examples of extrinsic variables were school and working conditions, curriculum, extra duties, workload, and salary equity.

\section{Chapter Summary}

This chapter outlined significant challenges that the United States faces in retaining highly qualified teachers. Attrition is persistent amongst both veteran and beginning teachers, but particularly beginning teachers, who typically leave the profession within three to five years after starting. The literature illuminated the schools most likely to be affected by this problem. These schools were high-poverty, highminority, low-performing urban schools where students were most likely to be taught by beginning inexperienced, and often the least effective teachers. The United States has responded to the challenge by initiating programs such as Troops-To-America and Teach for America to attract, recruit, and retain the best and brightest in the field. However, these attempts have only resulted in on-going staffing problems in certain schools. Consistent loss of effective teachers is detrimental to the students and schools that are held accountable for their students' performance in achievement tests. However, 
literature highlights a group of highly effective veteran teachers who continue to teach in low-performing schools despite the challenges typically associated with such schools.

In this chapter, I focused on thematic factors related to teacher attrition and retention. The two main themes were teacher engagement and school climate characteristics. The final section of the chapter explicated factors that influenced veteran teachers to remain teaching in challenging schools. Employee engagement (EE) is a positive psychological concept defined as an active, work-related, positive behavioral energy. EE was used as a proxy for TE. There were positive associations between EE and job satisfaction, organizational commitment, and intent to quit. Engaged teachers for whom teaching was a meaningful experience, who felt safe, and who had resources available to teach, would more likely continue teaching. Conversely, a lack of engagement leading to burnout and making teaching tedious and meaningless, would more likely lead to teachers departing teaching.

School climate was explicated as school characteristics, classroom characteristics, and teacher characteristics. School-level characteristics that influenced teacher attrition were mainly school location, lack of administration support, and high accountability in state mandated tests. School staffing problems were typical to schools in urban and rural settings and in the areas of science, technology, engineering, and mathematics. However, schools most likely to be affected by school staffing problems were low-performing urban schools. Quite often, teachers left teaching in these challenging school environments to teach in the wealthier, higher-performing schools.

Overwhelmingly, literature indicated that classroom environments most likely to deter teachers were poor schools with high populations of under-privileged, minority 
students. Moreover, attrition was mainly problematic in secondary schools, particularly middle school compared to elementary school. The research also emphasized that teachers' perceptions of their students influenced the classroom environment. Overall, the main variables that contributed to teacher attrition in middle schools were: student behavior, lack of administration support, and lack of autonomy in decision-making.

Teacher-level characteristic that influenced teacher attrition were age, experience, and teacher effectiveness and quality. Whilst age was not a determinant of teacher effectiveness, the research indicated that young, beginning teachers were more likely to leave teaching than older, more experienced teachers. Further, beginning teachers who left teaching within three to five years were deprived of the opportunity to gain valuable skills and knowledge needed to become quality experienced teachers. Typically, teacher quality was evaluated based on value-added and principal observation.

Only one qualitative study by Ashiedu and Scott-Ladd (2012) has been found to examine why effective retired veteran teachers and active novice and veteran teachers remained in teaching. "Effective" veteran teachers were teachers who had reached the natural end (retirement) to their teaching career. Petty et al. (2011) used a qualitative study to examine veteran teachers' perspectives on staffing in low-performing schools in North Carolina. Perrachione et al.'s (2008) mixed methods study examined intrinsic and extrinsic factors that influenced job satisfaction and how job satisfaction influenced teachers to remain in teaching in public elementary schools. Outcomes from Ashiedu and Scott-Ladd's (2012) and Petty et al.'s (2011) studies confirmed that intrinsic factors were most influential in motivating veteran teachers to remain teaching in low-performing schools. 
The research examining school-level, teacher, and classroom characteristics associated with teacher attrition has been largely quantitative by nature. However, very little qualitative research explores factors that influence teachers to remain teaching, in particular why highly effective veteran teachers remain teaching in challenging situations. This study is a valuable addition to qualitative literature as it presents individual teachers' perceptions of teacher engagement and school climate characteristics as factors motivating highly effective veteran teachers to remain teaching in lowperforming schools in WPS. Chapter III proposed the methodology for this research. The chapter includes the research questions, research design, and data collection methods. It also includes ethical concerns, limitations, and delimitations for this research. 


\section{CHAPTER III}

\section{METHODOLOGY}

The purpose of this study is to examine individual teacher engagement and school climate characteristics that influence highly effective veteran teachers to remain teaching in low-performing schools. The sample is drawn from a large urban school district in Southeastern United States. While numerous studies explore recruitment and retention of beginning teachers in K-12 teaching (Alliance for Excellent, 2014; Hughes, 2012; Perrachione et al., 2008), only one Australian study was found that examined the factors motivating highly effective retired veteran teachers to remain in the teaching profession (Ashiedu \& Scott-Ladd, 2012).

This research study offers a unique perspective as it explored factors that confirm or disconfirm engagement factors and school climate characteristics that influence highly effective veteran teachers to remain teaching in low performing schools. This chapter presents the research questions, research design, and context of the study, data sources, data collection, data analysis, researcher's positionality, and chapter summary.

\section{Research Questions}

This research examined individual teacher engagement and school climate characteristics that influence highly effective veteran teachers to remain teaching in lowperforming schools. The research questions are as follow: 
1. What are the characteristics of highly effective veteran teachers who remain teaching in low-performing schools as reported by principals and teacher colleagues?

2. In what ways are highly effective veteran teachers engaged in low-performing schools?

3. How do highly effective veteran teachers perceive their engagement as contributing to their commitment to remain in low-performing schools?

\section{Research Design}

I employed qualitative methodology to answer the research questions in this study. A qualitative approach is appropriate to this study because the researcher is seeking an in-depth understanding of the factors that influence highly effective veteran teachers to remain teaching in low-performing schools (Creswell, 2013; Merriam, 1988; Yin, 2014). Qualitative researchers have identified five possible approaches to inquiry: narrative research, phenomenological research, grounded theory research, ethnographic research, and case study research (Creswell, 2013; Glesne, 2016; Merriam, 1988; Yin, 2014). Following are brief descriptions of each approach and details explaining why the case study is most appropriate for this study and why narrative, phenomenological, grounded theory, and ethnographic research approaches are less appropriate for this study.

Narrative research is a method of analyzing stories individuals tell of their life experiences (Chase, 2005). These stories reveal the individuals' self-perception. Narrative research may be either spoken or written text collected from one or several individuals. The researcher records the stories of the participants in chronological order, 
even though the participants themselves may not have articulated events in a particular order. Data are typically collected from multiple sources including interviews, documents, pictures, and observations.

Whereas, a narrative study is a report of the lived experiences of one or more individuals, phenomenological research describes the common meanings of the lived experiences of several individuals (Creswell, 2013). Moustakas (1994) explained, first the researcher identifies a phenomenon, for instance "AIDS." Next, the researcher collects the data and creates a combined description of what the individual experienced and how he or she experienced the phenomenon. Typically, the researcher then develops the data into clusters in order to create meaning from the commonalities emerging from the data. An example of a cluster for a phenomenon like "AIDS" is "Physical deterioration." In this cluster, the researcher might describe the physical experiences of an AIDS victim in vivid terms to generate an image of AIDS. Data could be drawn from an actual victim or even someone who had seen a family member or close friend experiencing the disease (Creswell, 2013). Data may be collected using interviews, observations, poetry, music or different art forms.

Whilst narrative research focuses on reporting and analyzing lived experiences of participants, and phenomenological research focuses on describing the essence or common experiences of participants, grounded theory research emphasizes generating a theory for a process, action, or interaction (Creswell, 2013). Strauss and Corbin (1998) elaborated, grounded theory research progresses beyond a description of the phenomenon and seeks to develop a process that is rooted in the data collected from participants who experienced the phenomenon (Strauss \& Corbin, 1998). Then the researcher develops a 
theory of this process (Creswell, 2013). For example, a grounded theory approach may be selected if the researcher is seeking to establish a process regarding the development of a program to educate middle-school children about AIDS. In the end, the researcher would develop a theory of this process (Creswell, 2013).

Unlike grounded theory where the researcher is seeking to develop a theory based on examining several participants who share similar processes or interactions, ethnographic research focuses on examining shared patterns of behaviors or cultural norms of large groups of people who live in the same location (Creswell, 2013). The ethnographer collects data through participant observation as he or she immerses himself or herself into the culture under study. Data are collected through participant observation and interviews, as the ethnographer immerses himself or herself into the daily lives of people in the culture group (Creswell, 2013). For example, the ethnographer may immerse himself or herself into a school to observe teachers' interaction with children whose parents are AIDS victims.

Yin (2014) defined case study as "an empirical inquiry that investigates a contemporary phenomenon, in-depth and within its real-life context especially when the boundaries between phenomenon and context are not clearly evident” (Yin, 2014, p. 16). There are three approaches to case study research: explanatory, exploratory, and descriptive approaches. According to Yin (2014) the purpose of an explanatory case study is to "explain how and why some sequence of events occurred or did not occur" (Yin, 2014, p. 237). On the other hand, an exploratory case study seeks to "identify research questions or procedures to be used in a subsequent research study, which might or might not be a case study" (Yin, 2014, p. 237). The purpose of descriptive case study 
is to describe a phenomenon in "a real-world context" (Yin, 2014, p.237). An explanatory case study approach was most appropriate for this study because the current study seeks to uncover the factors that encourage a certain group of teachers to continue teaching in low-performing schools despite challenges that influence other teachers to leave. The explanatory approach to case study methodology is grounded in "thick description" and provides realistic, simplified data that communicate meaning to readers (Creswell, 2013; Guba \& Lincoln, 1981, p. 375-376). Data for case study may be collected in multiple ways, these ways include interviews, direct observations, documents, audiovisual materials, and tangible artifacts (Creswell, 2013; Yin, 2014). Data for this study was collected using interviews. In the final stage of the research, I review the data, revealed the findings, and made recommendations.

\section{Context of the Study}

WPS is home to 18 low-performing or priority schools. The student body comprises a diverse population; 46 percent White, 36 percent Black, 10 percent Hispanic, and 4 percent Asian, 4 percent Other. In the 2015-2016 and 2016-2017 academic years, the WPS district participated in the Community Eligibility (CE) pilot program (sponsored by the National School Lunch Program). The school district qualifies for this program because over 60 percent of the students receive either free or reduced lunch. This number exceeds both the state average of 55 percent and the national average of 51 percent ( Suitts, 2015). According to the National School Lunch Act (NSLA) children who qualified for free live in households whose incomes are equal to or less than 130 percent of the federal poverty level. Reduced lunch is based on households whose income is 
between 130 and 185 percent of the Federal poverty level guidelines (Harwell \& LeBeau, 2010).

The school district has over 6,000 teachers with an average of 10 years of teaching experience. The composition of the teacher population is not representative of the composition of the student population. Eighty-four percent of teachers in WPS are White, 14 percent African American or Black teachers, 1 percent Hispanic, .9 percent Asian, and .3 percent Other. The composition of the student population is 46 percent White, 36 percent African American or Black, 9 percent Hispanic, 4 percent Asian, and 4 percent Other. Table 3.1 shows comparison of the percentage of teacher and student participation in the school district by race.

\section{Table 3.1}

Comparison of Percentage of Teachers and Students Participation by Race

White African American/ Hispanic Asian Other

Black

\begin{tabular}{llllll}
\hline Teachers & 84 & 14 & 1 & .9 & .3 \\
Students & 46 & 36 & 9 & 4 & 4 \\
\hline
\end{tabular}

District data revealed that 97 percent of teachers in both priority and non-priority schools who teach core subjects are classified highly qualified and 7 percent are national board certified. The ratio of teachers and students in the school district matches the national ratio with most White teachers teaching minority students (Ingersoll et al., 2014).

Although the district has consistently met its annual measurable objective (AMO) for the past three years, WPS is currently classified as a "Needs Improvement" school 
district. I utilized 2015 to 2016 data for this section. There were no AMO scores for WPS in 2016 to 2018. The school district is currently transitioning in preparation for the new Every Student Succeeds Act (ESSA) regulations. The Department of Education describes AMOs as unique annual targets in Mathematics and Reading for each subgroup, school and district. In the state where WPS is located, schools or districts are categorized as distinguished, proficient, progressing, or needs improvement. The cut score for distinguished is 70.5. The cut score for proficient is 66.2. Districts classified as "Needs Improvement" are those whose scores are lower than the Proficient cut score of 66.2. WPS failed in achieving the minimum proficient cut score of 66.2 and is therefore classified as a "Needs Improvement" school district. State Department of Education data showed that the score in 2013 to 2014 was 64; the score in 2014 to 2015 and 2015 to 2016 was 63.

In this study, I examine priority secondary schools in the WPS district. The literature on teacher retention illustrated that low-performing secondary schools in the United States, especially those with higher numbers of minority students, have more difficulty retaining teachers when compared to elementary schools (AACTE, 2013; Marinell \& Coca, 2013). District data revealed that the teacher retention rate in WPS has been steadily declining over the three-year period from 2013 to 2016 (2013 to 2014 was 90 percent; 2014 to 2015 was 88 percent; and 2015 to 2016 was 87 percent). The teacher retention rate was the lowest in middle schools over the same period (2013 to 2014 was 87 percent; 2014 to 2015 was 83 percent; 2015 to 2016, was 86 percent). Compared with high schools for the same period (2013 to 2014 was 92 percent; 2014 to 2015 and 2015 to 2016 was 90 percent). In addition, 16 of the 18 priority schools in the WPS district are 
secondary schools: 8 high schools and 8 middle schools. The other two priority schools are elementary schools.

\section{Data Collection}

To acquire the data for this study, I interviewed three groups of participants: the principals of the priority schools, highly effective veteran teachers identified by their principals or assistant principal as exemplary in their last evaluations and by the WPS open records department as National Board Certified teachers, and teachers-colleagues who teach with the highly effective veteran teachers to triangulate the research. Teachercolleagues were identified by the principals or assistant principal participants or by the highly effective veteran teachers themselves. Triangulation is employed to ensure validity of the data. The protocols for the semi-structured interviews comprised open-ended questions (Glesne, 2016).

Rubin and Rubin (2011) explained that the semi-structured method facilitates guide conversations where questioning is fluid and informal. This approach also facilitates follow-up with probing questions to acquire greater detail and explanations. Asking probing questions helps the researcher to gain a deeper understanding of the complexity of the issues in the research (Glesne, 2016). Becker (1998) suggested using "how" questions rather than "why" questions to avoid creating an environment that is threatening to the respondent. The researcher must also be mindful of the interview setting. The location should be physically comfortable, quiet, private, and appropriate for the occasion. The comfort of the interviewee is essential to the interview process (Glesne, 2016). 
I contacted principals from the seven priority secondary schools identified by WPS Institutional Review Board (IRB) by phone and email informing them about the study and requesting interviews. The study was restricted to seven secondary schools as specified by WPS Institutional Review Board (IRB). There were two middle schools and five high schools. I interviewed six principals and one assistant principal. I sought permission to interview teachers from their schools who they classified as "exemplary" based on the teachers' last Summative Evaluations - Teacher Form D (see Appendix A). The measures on the teacher evaluation form are (a) Ineffective, (b) Developing, (c) Accomplished, and (d) Exemplary. For the purpose of this study, teachers who are rated Exemplary are classified as "highly effective". Highly effective teachers are also teachers who were identified by WPS open records department as National Board Certified teachers. In WPS there are 103 National Board certified high school teachers, 17 of which teach in low-performing high schools. A total of 54 National Board Certified teachers teach in WPS middle schools, 16 of which teach in low-performing middle schools. Five of the seven teachers who were identified as highly effective for this study were also National Board Certified teachers.

I interviewed teachers who were identified by the principals as "highly effective" and NBCTs identified by WPS open records department to gather data related to "teacher engagement" and "school climate." Teacher-colleagues were also interviewed in an effort to triangulate the data collected from the principals and highly effective veteran teachers. Table 3.2 below illustrates the research questions and data sources that were used in the study. There are three research questions that inform the protocols for each group of participants. I asked highly effective veteran teachers questions from the protocol that 
appears in Appendix C. I asked the principals and teacher colleagues questions from the protocol that appears in Appendix D.

\section{Table 3.2}

$\underline{\text { Research Questions and Data Sources }}$

Research Questions Data Sources

1. What are the characteristics of Principals, Teacher Colleagues (Appendix

highly effective veteran teachers $\quad$ D) Selected Highly Effective Veteran

who remain in low-performing Teachers (Appendix C)

schools as reported by principals

and teacher colleagues?

2. In what ways are highly effective Principals, Teacher Colleagues (Appendix

D) Selected Highly Effective Veteran

veteran teachers engaged in low- Teachers (Appendix C)

performing schools?

3. How do highly effective veteran Selected Highly Effective Veteran teachers perceive their engagement Teachers (Appendix C)

as contributing to their

commitment to remain teaching in

low-performing schools?

The data from interviews with principals, highly effective veteran teachers and fellow teachers were triangulated to identify emerging themes. Interviews were conducted in person and by phone (Creswell, 2013; Merriam, 1988). The interview protocols utilized information from the employee engagement scale (EES) that captures cognitive, 
behavioral, and emotional energies that employees bring to their work experiences (Shuck et al., 2016). I conduced one interview per principal, highly effective veteran teacher, and teacher-colleague as a single set of three for triangulation purposes. In total, I interviewed 23 participants.

In concert with Creswell (2013), I designed an interview protocol that allowed adequate space between the questions to write field notes about the participants' responses. Field notes were taken and the interviews with the participants were digitally recorded and transcribed using Rev Audio - an online service from Rev.com. Field notes are critical to the interviewing process because they provide a way to record conversation, emerging patterns, reflections, and mental notes for later analysis (Glesne, 2016; Miles, Huberman, \& Saldaña, 2014). Field notes are also essential in the event something goes wrong with the recordings. Audio-taped interviews and notes will help to ensure accuracy (Glesne, 2016). Interviews were recorded verbatim (Glesne, 2016). Beyond providing accuracy and context of the discussions with participants, recording interviews also gave the interviewer freedom to listen and to focus on the interviewee (Glesne, 2016).

\section{Data Sources}

Unlike quantitative studies, smaller groups of people who are knowledgeable about the issue are needed for in-depth study (Miles et al., 2014). I used purposeful sampling and snowball sampling. Purposeful sampling is appropriate to collect rich data with limited resources, using individuals who were knowledgeable about the issue (Palinkas et al., 2013). The respondents must also be available and willing to communicate experiences in an expressive, fluent, and reflexive manner (Spradley, 
1979). I also used snowball sampling. In snowball sampling, participants in a study recruit other relevant people who can contribute to the study (Merriam, 1988). This approach was preferred to ensure that I interviewed teacher-colleagues who really knew of the work and dispositions of the highly effective veteran teachers. For the purpose of this study, I asked principal participants to identify highly effective veteran teachers, and I used NBC teachers and teacher colleagues who could speak about the performance level of engagement of the highly effective veteran teachers. I interviewed teacher-colleagues to ascertain their perceptions of highly effective veteran teachers.

Case study methodology was used to gain information about the seven priority schools specified by WPS IRB (Creswell, 2013; Yin, 2014). Subsequent to receiving Institutional Review Board (IRB) and WPS approval to gain access to sites and information, each principal was contacted via phone to build rapport and to gauge their interest in participating in this research (Creswell, 2013). I sought permission to interview each principal in person (Merriam, 1988). I was able to interview three of the principal participants and the assistant principal participant in person. I was unable to interview the rest of the principal participants in person due to time constraints identified by the participants. Therefore, I interviewed these participants by phone.

I asked principals to identify highly effective veteran teachers who had been teaching in their schools for over five years and teacher-colleagues of highly effective veteran teachers who could speak about them. I contacted highly effective veteran teachers recommended by the principal and NBCTs identified by WPS open records department seeking their permission to interview them in their natural settings (Glesne, 2016; Merriam, 1988). Two of the highly effective veteran teachers identified by their 
principals as exemplary and five NBCTs agreed to be interviewed. I disclosed the purpose of the study, the amount of time needed to conduct the interviews, how the results of the study would be reported, and how all participants would benefit from the research (Bogdan \& Biklen, 1992; Creswell, 2013; Glesne, 2016) (see Appendix B). The interviews with principals and assistant principal, and teacher-colleagues of highly effective veteran teachers were completed in 25 to 30 minutes. The interviews with highly effective veteran teachers were completed in 30 to 35 minutes.

\section{Institutional Review Board Approval and Ethical Considerations}

It is important to avoid unintentional consequences during research that negatively affect participants. Therefore, I included ethical considerations in planning and designing the research (Glesne, 2016). I sought approval from the University of Louisville Institutional Review Board (IRB) and WPS to ensure the rights of participants would be protected in accordance with IRB standards. Participants were guaranteed anonymity through the use of pseudonyms for participants and the school locations (Glesne, 2016).

\section{Data Analysis}

According to Glesne (2016) "data analysis involves organizing what you have seen, heard, and read" in order to make sense of the data collected and experiences encountered (p. 183). In this qualitative study, data were collected using interviews of principals, highly effective veteran teachers, principals, and teacher-colleagues of highly effective veteran teachers. I used the process of inductive and deductive coding to organize the raw material and analyze the data (Creswell, 2013; Merriam, 1988). Inductive coding occurred in the iterative process of developing themes from the data. 
This involved "working back and forth" (Creswell, 2013, p. 45) to review the data, making reflective notes and comments, creating headings and coding the data to build themes surrounding the data (Merriam, 1988). When needed, I collaborated with participants to shape emerging themes (Creswell, 2013). The deductive process occurred as themes were built that were constantly checked for alignment with the data (Creswell, 2013). Following is Table 3.3 which shows deductive codes emerging from interview protocols. 


\section{Table 3.3}

$\underline{\text { Deductive Codes: Principal, Teacher-Colleagues and Highly Effective Veteran Teacher }}$ $\underline{\text { Protocols }}$

\begin{tabular}{cll}
\hline Theme & \multicolumn{1}{c}{ Code } & Abbreviation \\
& Reflective & REF \\
& Extracurricular Activities & ECA \\
& Time & TIME \\
Behavior Engagement & Flexible & FLEX \\
& Record-keeping & RK \\
& Frequent Communication & FC \\
& Relationship Building & RB \\
& Leadership Support & LS \\
& Job Satisfaction & JS \\
& Meaningful & MEA \\
& Job Commitment & JC \\
& Empowerment & EMP \\
& Safety & SAFE \\
& Resources & RES \\
& Challenging & CHA \\
& Autonomy & AUT \\
\hline \multirow{2}{*}{ Trait Engagement (TE) } & Conscientiousness & CON \\
& &
\end{tabular}

This list is based on Macey and Schneider's (2008) conceptual framework and the interview protocol for all participants (Miles et al., 2014). After interviewing the participants, the interviews were transcribed using Rev Audio - an online service from Rev.com. I reviewed field notes and compared them to the transcripts. This helped me to become familiar with the data and to develop an understanding of the major issues emerging from the data (Glesne, 2016). 
Once the interviews were transcribed, I analyzed the data using methodology recommended by Saldaña (2013). Saldaña (2013) recommended that data analysis be divided into two cycles. In the first cycle, initial codes were assigned to chunks of data in the interview transcript and field notes to detect repeated patterns. Coding is the process of condensing and assigning labels that can be used to detect patterns, categorize, and build theories using the data collected in the field (Miles et al., 2014). In concert with Miles et al. (2014), I used In Vivo coding to identify participants' own words or short phrases as codes in addition to highlighting researcher-generated codes. This strategy helped to identify patterns or terms that participants used regularly. To more effectively manage the data, I used color-coded markers to highlight and number phrases or words. I manually highlighted the codes in the right margins of the research transcripts (Miles et al., 2014) and then transferred the data to NVivo Plus computer software program. The NVivo computer software assisted with further coding for analysis of the data (Yin, 2014).

The codes emerging from the first cycle were grouped into smaller themes or categories in the second cycle (Miles et al., 2014). This strategy of patterning codes helped to isolate differences and similarities between categories and themes by dividing the information into smaller units of analysis. Isolating similarities and differences helped me to better understand perceptions and values, provide explanations or reasons for specific actions, and promote a better understanding of interactions between individuals (Miles et al., 2014). I wrote reflective comments in the left margins of the research transcript to build a logical argument (Glesne, 2016; Miles et al., 2014). Reflective 
comments can highlight important issues that may have otherwise been overlooked. They may also lead to revision of coding themes (Glesne, 2016).

\section{Validity and Reliability}

Validity is the potential threat to the trustworthiness of the study (Glesne, 2016; Miles et al., 2014). Reliability ensures the procedure in the study is consistent and stable and that it may be duplicated at any time (Miles et al., 2014). Lincoln and Guba (1985)

proposed the use of alternate terms to support the naturalistic characteristics of qualitative research. For example, the use of credibility instead of internal validity; transferability instead of external validity; dependability instead of reliability; and confirmability instead of objectivity align with Lincoln and Guba's (1985) recommendations. This section describes the measures taken to ensure the trustworthiness and credibility of the study. Verification for credibility and dependability of the research were accomplished in several ways: checking for researcher effects, member check, participant review, mechanically recording data and participant verbatim accounts, peer review, and triangulation.

Checking for researcher effect is important to avoid researcher bias. Outsiders (researchers) often influence the behavior of insiders (participants) (Miles et al. 2014). The presence of the researcher may influence normative behavior of the participants, which in turn may lead to biased interpretations and observations (Miles et al., 2014). Milner (2007) also stated that researchers in the course of conducting research must of necessity examine themselves and reflect on their motives for initiating the research. To minimize the risk of unintended influences, I was honest and open about the objective of this study. I also engaged in frequent self-reflections and communicate with unbiased 
mentors and advisors about the status of this research (Milner, 2007). In concert with Glesne (2016), the researcher's role is to be a good learner and listener, whose presence is reassuring rather than threatening, exhibiting an air of competence. The participants' experiences are paramount. Participants in this research were assured that observations and interviews would not be judgmental or evaluative. I adopted a neutral but encouraging stance to build trust with the participants (Miles et al., 2014).

Member checking also known as respondent evaluation is another credibility measure (McMillan \& Schumacher, 2001). It is frequently used by qualitative methodologists to ensure credibility in qualitative research (Miles et al., 2014). Member checking occurs during and after the interviewing process. During the interview, the researcher paraphrases, summarizes, or reiterates the information, and ascertains from the participants whether the researcher's interpretations of the participants' comments are correct. Subsequent to the data collection the researcher reports initial findings to the participants for critical feedback. Some of the feedback may be incorporated into the study (Altheide \& Johnson, 1994). In this study, I conducted member checks by rephrasing questions and giving prompts for clarification and correct interpretation of interviewees' responses. If discrepancies were noted during the analysis of the data, I contacted participants for clarification. This procedure also enhanced transferability for replicating the study by providing rich, thick description using the participants' perspectives (Lincoln \& Guba, 1985; Merriam, 1988).

This study included participant review to facilitate dependability of the research. In participant review the researcher asks the participants to review the data for accuracy and make recommendations for changes that would improve accuracy (McMillan \& 
Schumacher, 2001). Following this procedure provided opportunity for me to describe changes that may occur in the setting and explain how these changes affected my approach to this study (Merriam, 1988). The findings were shared with the participants who asked to respond by agreeing or disagreeing with the findings. Participants were asked to provide feedback about the emerging themes (McMillan \& Schumacher, 2001).

Data were triangulated to ensure credibility of the study. Triangulation is the use of multiple data sources and methods to reduce bias and support a conclusion (Miles et al., 2014). First, principal interviews were conducted. Principals were asked to provide specific feedback about his/her assessment of the highly effective veteran teacher participants and how they navigate the schools' climate and demonstrate engagement. Principals were asked to provide examples that support the classification of the participants as "highly effective veteran teachers." Further, principals were asked to identify at least one teacher-colleague who worked in the same department or who works closely with the highly effective veteran teachers (see Appendix D).

Second, I conducted interviews with highly effective veteran teachers (see Appendix C). Third, I conducted interviews with teacher colleagues who could talk about the highly effective veteran participants identified by the principals (see Appendix D). Sometimes the order in which interviews were conducted was reversed; this was dependent on the availability of participants. Teacher-colleagues were interviewed to ascertain if they would identify the same highly effective veteran teachers selected by the principals. Colleagues were also asked to identify the qualities exemplified by the highly effective veteran teachers. A similar interview protocol was used for the principals and teacher colleagues (see Appendix D). 
Freebody (2003) noted there were limitations to interviewing. For example, respondents may frame their answers to avoid sharing the total picture. This study addressed this limitation by asking respondents to share descriptive examples of scenarios that may be corroborated by other respondents in other locations and who worked under different circumstances. I took careful field notes to record descriptive details of verbal and non-verbal cues observed during interviews (Merriam, 1988). Body language and gestures help to decipher the effects of questioning, probing, and comments (Glesne, 2016). This helped to alleviate any attempts to elude sharing the total picture and further substantiate the quality of research.

Phone interviews were also used in the study. Novick (2008) recorded a bias against using telephone interviews as a qualitative data collection instrument. He noted that telephone interviews were not typical to qualitative research. Despite this bias, significant benefit may be derived from using this collection instrument. For example, telephone interviewing leads to decreased costs and travel, the ability to reach respondents who are geographically dispersed, and enhanced safety for the researcher (Burke \& Miller, 2001).

Factors that impact telephone interviews include a lower response rate, the need to make interviews short and manageable, and the inability to observe body language or gestures (Aquilino, 1994; Novick, 2008). While varying opinions exist about using recorded interviews (Patton, 2002), recording the interviews allow an accurate record of the participants thoughts, thus removing researcher biases and protecting the integrity of the data (McMillan \& Schumacher, 2001). 
To ensure credibility, I used Rev.com audio recording and transcription service, a digital recorder, and field notes to record the interviews (McMillan \& Schumacher, 2001). Interviews were transcribed, and verbatim scripts of the interviews were used to substantiate findings. I sought the help of external qualitative researchers who could confirm credibility of details recorded in the research. The external qualitative researchers peer reviewed samples of data for accuracy of codes and accuracy of the findings of the research (Merriam, 1988).

\section{Researcher's Positionality}

Glesne (2016) noted a researcher's positionality depends on the situation, methodology, research context, participants, and the researcher's personality and values. This is made possible through collaborating with the participants in the study to present an unbiased report reflecting the multiple perceptions of participants, thus creating a holistic perspective of the issue (Creswell, 2013; Dillard, 2000). The aim is to empower the participants by giving them a chance to tell their stories whilst minimizing the voice of the researcher. Milner (2007) proposed examining the qualitative issue using four frames: "Researching the Self," "Researching the Self in Relation to Others," "Engaged Reflection and Representation," and "Shifting from Self to System" (p. 395-397).

In "Researching the Self" the researcher reflects on his or her perceptions of the research issue in order to present an unbiased report (Milner, 2007). In this study, I reflected on personal experiences and epistemologies that shaped my decision to undertake this inquiry. My interest was rooted in personal experiences and observations as a veteran teacher in a priority school. I observed that despite subtle and sometimes overt dissatisfaction, some veteran teachers continued teaching in priority schools. 
Taking into consideration the skills and experiences that the veteran teachers bring to the classroom and their influence in shaping the school's climate and culture, retaining highly effective veteran teachers may be key to the successful turnaround of lowperforming schools. I conducted member checks with participants to avoid researcher bias and ensure validity of the study (Creswell, 2013; McMillan \& Schumacher, 2001).

In examining "The Self in Relation to Others," I acknowledge that this study is a coalition of multiple perceptions about the same phenomenon. Therefore, the approach will be one of seeking knowledge rather than already knowing (Milner, 2007). I negotiated through seen or unseen tensions or conflict in order to present authentic data (Milner, 2007). This study demonstrated that as the researcher, I am "answerable and obligated" (Dillard, 2000, p. 665) to participants to present an impartial report of their perspectives. This was evidenced in the measures taken to ensure credibility and dependability of the study.

"Engaged Reflection and Representation" occurred when I reflected on emerging themes in the data analysis. No one voice or narrative was treated as more important than the other. Rather, each narrative and counter narrative was presented to report a fair interpretation of the issue (Milner, 2000). I began coding by inductively organizing the data to build an extensive set of themes. The themes were checked deductively against the data and further themes derived, excluded, or amalgamated as needed (Creswell, 2013). Following this procedure strengthened and added authenticity to the study through the emergence of the varying viewpoints of all participants.

The objective of this study was to examine individual teacher engagement and school characteristics that influence highly effective veteran teachers to remain teaching 
in low-performing schools. "Shifting from Self to System" occurred when as researcher, I removed personal interests and inferences, and contextualized the findings of this study to consider the social, cultural, and political ramifications to the community under study (Milner, 2007). In concert with Milner (2007), questions that aided in the shift from self to system in the completion of this study were: (a) How will retaining highly effective veteran teachers in low-performing schools positively influence the turnaround process?; (b) How do the findings of this study align with findings in the literature review?; (c) What are the organizational obstacles and constructs that shape the participants' experiences; and (d) How might the school use this information to advance the turnaround process?

\section{Chapter Summary}

This chapter outlined the methods that were utilized to study individual teacher engagement and school climate characteristics that influence highly effective veteran teachers to remain teaching in low-performing schools in a large urban school district in Southeastern United States. It included the research questions, research design and context of the study. The data sources identified were semi-structured interviews using open-ended questions with a sample of secondary school principals, selected highly effective veteran teachers, and teacher colleagues. IRB and ethical issues were discussed. The chapter also examined the data analysis process. Data was analyzed using first cycle and second cycle coding. NVivo Plus computer software was used to assist in coding and data analysis. Issues of credibility and dependability were also addressed. The findings of this research will be examined in Chapter 4 . 


\section{CHAPTER IV}

\section{FINDINGS}

The purpose of this study was to examine individual teacher engagement and school climate characteristics that influence highly effective veteran teachers to remain teaching in low-performing schools despite the challenges known to be associated with such schools. For the purpose of this study the term "highly effective veteran teachers" was defined as national board-certified teachers or teachers classified as exemplary in their last teacher evaluations. They were also teaching in low-performing schools for over five years. Defining the term "engagement", a teacher was said to be engaged if he or she willingly invested himself or herself emotionally, physically, and cognitively in teaching.

Christian et al. (2011) explicated engagement as the act of employees bringing "their personal selves during work role performances, investing personal energy, and experiencing emotional connection with their work (Christian et al., 2011, p. 91). "School climate characteristic" may broadly defined as school-level characteristics, classroom level characteristics, and teacher level characteristics. School level characteristic are leadership, peer collaboration, and school size. Classroom level characteristics are student behavior, ethnicity, and classroom size. Teacher level characteristics are age, gender, and ethnicity (Wang \& Degol, 2016).

In this study, I utilized Macey and Schneider's (2008) engagement framework. The term "employee engagement" was used as a proxy for teacher engagement. Macey and Schneider's (2008) framework proposed three tenets to teacher engagement: Trait 
Engagement, State Engagement, and Behavior Engagement. Trait Engagement was explicated as the teacher's mindset, worldview, or disposition. State Engagement was explicated as the teacher's feelings or emotions. Behavioral Engagement was explained as the teacher's attitude to the job or discretionary effort. Macey and Schneider (2008) proposed that teachers' personal dispositions and their feelings about teaching influenced teachers' observable discretionary effort that showed whether or not teachers were engaged in their jobs.

The Macey and Schneider (2008) framework also posits that work conditions both directly and indirectly influenced teachers' feelings and attitude to teaching and discretionary effort. Transformational leadership, another important component of the Macey and Schneider framework, directly influenced how teachers felt about teaching and the discretionary effort they exerted. This study proposed that highly effective veteran teachers were more likely to remain teaching in low-performing schools because they found teaching personally rewarding. Further, school climate characteristics such as leadership influenced the teachers' mindset, feelings, and discretionary effort.

The three research questions that guided the study are as follow:

1. What are the characteristics of highly effective veteran teachers who remain teaching in low-performing schools?

2. In what ways are highly effective veteran teachers engaged in low-performing schools?

3. How do highly effective veteran teachers perceive their engagement as contributing to their commitment to remain teaching in low-performing schools? 
The research method was a qualitative case study. I used semi-structured interviews with open-ended questions to gather rich data from participants from seven low-performing secondary schools. The seven schools were selected and approved by WPS IRB committee. The two middle schools and five high schools were from Wimsel Public School (WPS) (a pseudonym used for anonymity). Samples were drawn from three employee categories namely, principals, highly effective veteran teachers, and teacher colleagues of the highly effective veteran teachers.

I presented the findings of this study in four major sections. In the first section, I examined the findings from the three participant groups for the first research question. In the second section, I presented findings for the three participant groups from research question two. In the third section, I presented findings from the three participant groups in response to research question three. Presenting the findings from each participant group within each question separately while showing points of convergence and divergence, facilitates the presentation of the rich detailed comments from each group. This makes it easier for the reader to observe the clarity with which each group presented their perspectives on the research questions. Finally, I presented a chapter summary at the end of the chapter. Following are brief descriptions of the participants and their schools.

\section{Profiles of Participants and Their Schools}

I interviewed six principals and one assistant principal from seven secondary schools. Two participants were middle school principals. There were four principals and one assistant principal from five high schools. I also interviewed seven highly effective veteran teachers from five secondary schools: one participant was from one middle school; the other six participants came from high schools. Finally, I interviewed one 
teacher colleague from one middle school. The other seven teacher colleagues came from five high schools. Table 4.1 presented the schools' demographic information and identified participants from each school.

\section{Table 4.1}

Demographic Information for Secondary Schools Participating in the Study 2017-2018

\begin{tabular}{|c|c|c|c|c|c|c|c|}
\hline School & $\begin{array}{l}\text { School } \\
\text { Type } \\
\text { High/ } \\
\text { Middle }\end{array}$ & $\begin{array}{l}\text { Enrollment } \\
\text { (Rounded) }\end{array}$ & $\begin{array}{c}\text { Student } \\
\text { Ethnicity } \\
\%^{*}\end{array}$ & $\begin{array}{l}\text { FRL } \\
\% * *\end{array}$ & $\begin{array}{c}\# \text { of } \\
\text { Faculty }\end{array}$ & $\begin{array}{c}\text { Teacher } \\
\text { Retention } \\
\text { Rate \% }\end{array}$ & $\begin{array}{c}\text { Principal/Asst. } \\
\text { Principal } \\
\text { Participant } \\
\#\end{array}$ \\
\hline $\mathrm{A}$ & MS & 410 & $\begin{array}{l}\text { W: } 53 \\
\text { B: } 26 \\
\text { O: } 20\end{array}$ & 73 & 33 & 94 & 1 Principal \\
\hline B & HS & 1,200 & $\begin{array}{l}W: 34 \\
\text { B: } 39 \\
\text { O: } 20\end{array}$ & 72 & 96 & 89 & 4 Principal \\
\hline $\mathrm{C}$ & HS & 1,110 & $\begin{array}{l}\text { W: } 31 \\
\text { B: } 49 \\
\text { O: } 18\end{array}$ & 76 & 72 & 88 & 5 Asst. Principal \\
\hline $\mathrm{D}$ & HS & 1,300 & $\begin{array}{l}\text { W: } 22 \\
\text { B: } 55 \\
\text { O: } 22\end{array}$ & 79 & 104 & 88 & 7 Principal \\
\hline $\mathrm{E}$ & MS & 770 & $\begin{array}{l}\text { W: } 42 \\
\text { B: } 43 \\
\text { O: } 14\end{array}$ & 80 & 53 & 67 & 9 Principal \\
\hline $\mathrm{F}$ & HS & 1200 & $\begin{array}{l}\text { W: } 59 \\
\text { B: } 19 \\
\text { O: } 21\end{array}$ & 70 & 75 & 91 & 11 Principal \\
\hline G & HS & 1370 & $\begin{array}{l}\mathrm{W}: 43 \\
\mathrm{~B}: 31 \\
\mathrm{O}: 24\end{array}$ & 66 & 86 & 93 & 12 Principal \\
\hline
\end{tabular}

Note. ${ }^{*} \mathrm{~W}$ : White; B: Black; O: Other; **FRL: Free or Reduced Lunch 


\section{Findings from Interviews in Response to Research Question 1}

The following are the findings related to research question one: "What are the characteristics of highly effective veteran teachers who remain teaching in lowperforming schools? I present each of the three perspectives, and a summary in the final paragraph of this section.

\section{Findings from Principals' Interviews}

Seven participants: two middle school principals, four high school principals, and one high school assistant principal participated in the study. Three of the seven participants were between the ages of 46-55 years. All of the participants were white. There were five females and two male participants. Each participant had been an administrator for over five years. All six principals had been leaders at their schools for less than five years and the assistant principal had been in her current role for three years. Three of the participants had been at their current schools for over five years. I interviewed four of the participants by phone because it was the most convenient way for them to accommodate the interview. Each interview lasted between 25 to 30 minutes. Table 4.2 shows the participants' demographic information. 


\section{Table 4.2}

Demographic Information of Leaders of Secondary School

\begin{tabular}{|c|c|c|c|c|c|c|c|c|}
\hline $\begin{array}{c}\text { Participant } \\
\#\end{array}$ & $\begin{array}{c}\text { Age } \\
\text { Range }\end{array}$ & Race & Sex & $\begin{array}{l}\text { School } \\
\text { (High/ } \\
\text { Middle) }\end{array}$ & $\begin{array}{c}\text { Principal } \\
\text { or AP }\end{array}$ & $\begin{array}{l}\text { Years (as } \\
\text { Admin) }\end{array}$ & $\begin{array}{c}\text { Years } \\
\text { (Current } \\
\text { School) }\end{array}$ & $\begin{array}{c}\text { Years (as } \\
\text { Leader } \\
\text { Current } \\
\text { School) }\end{array}$ \\
\hline 1 & $46-55$ & $\mathrm{~W}$ & $F$ & $\mathrm{M}$ & $\mathrm{P}$ & 20 & 7 & 3.5 \\
\hline 4 & $36-45$ & W & $\mathrm{F}$ & HS & $\mathrm{P}$ & 7 & 7 & 7 \\
\hline 5 & $27-35$ & W & F & HS & AP & 9 & & 3 \\
\hline 7 & $46-55$ & W & $\mathrm{M}$ & HS & $\mathrm{P}$ & 23 & & 3 \\
\hline 9 & $46-55$ & W & $\mathrm{F}$ & M & $\mathrm{P}$ & 17 & & 2 \\
\hline 11 & $36-45$ & W & $\mathrm{F}$ & HS & $\mathrm{P}$ & 7 & 7 & 3.5 \\
\hline 12 & $27-35$ & W & M & HS & $\mathrm{P}$ & 6 & & 1 \\
\hline
\end{tabular}

Note. W: White; F: Female; M: Male; MS: Middle School; HS: High School; P:

Principal; AP: Assistant Principal

In response to research question number one: "What are the characteristics of highly effective veteran teachers who remain teaching in low-performing schools?" the principal participants reported that highly effective veteran teachers established meaningful relationships with the school's stakeholders (school administrators, teacher colleagues, students, and parents). They consistently communicated clear expectations, established norms, routines, and procedures for their students. They were effective managers of student behavior, and they engaged students both collectively and individually. Highly effective veteran teachers also planned and prepared effectively for classroom instruction. They also used differentiated instruction to enhance the learning of their diverse student population and effectively executed their professional responsibilities. 


\section{Building Relationships with Students}

Overwhelmingly, feedback from principal participants indicated that building relationships with students was critical to being a highly effective teacher. According to Participant 11:

Our most successful teachers are teachers who take the time to build relationships with kids whether it's through conversation ... or student advisory. Through advisory they get to know all the students in the school. Maybe they don't even have them in class... Student advisory at this school involved teachers providing remedial academic help for students at particular times during regular school hours. The relationships between highly effective veteran teachers and students allowed the teachers to exert a positive influence on the students' lives and push students beyond their limits.

Participant 7 highlighted:

You know you hear the old clichés about "students don't care how much you know until they know how much you care", and that truly goes here...our students are so used to having adults come in and out of their lives, that's what they expect their adults to do here. Once they see that the adults are here for them, and the adults are going to stay and they're [the students] not going to be able to run that adult off, it changes the whole perception and the relationship.

Participant 5 emphasized:

I think...highly effective teachers have not only positive relationships with kids but relationships where they push students beyond... what those students are capable of...those teachers just have a way of reaching students where they don't feel like they're being forced to do something... and they [the students] want to learn more.

Relationships were established through the creation and delivery of clear expectations,

norms, routines, and procedures in which students have an input.

They put relationships...high expectations...expectations of agreed-upon norms...routines in front of the students, and they do it collaboratively with the students. They do things with the students instead of to the students, and the students see the respect....so, my most effective teachers are relationship-builders [they] make students stakeholders and involve them in a lot of decisions of the classroom. (Participant 9) 
Highly effective veteran teachers consistently established expectations, norms, routines, and procedures from the beginning of the school year. Therefore, "one day in their classroom looks like day 175 in their classroom" (Participant 7). The primary goal of each teacher was to create a classroom environment where students felt comfortable and safe. According to Participant 4, there were "those symbols or objects that say: kids live here, and the kids in this classroom can see themselves represented in the room somewhere...[teachers used] a "community approach to language" that students are familiar. This language made students feel a sense of ownership for how their classrooms functioned. It conveyed the feeling to students that "it's our classroom, this is our class, and we don't do that." The sense of community was particularly important in managing behavior issues.

The positive relationships that existed between highly effective veteran teachers and their students facilitated management of student behavior in the classroom and generally in the school. Participants explained that managing student behavior did not mean that students sat quietly in their seats. According to Participant 12:

The one thing I would say is that highly effective teachers have the control of their classrooms. That doesn't mean students are seated and quiet. But it means that the classroom functions so that they can teach, instruct, and deliver lessons.

In response to the question regarding how highly effective teachers managed student behavior when the behavior contradicted the teachers' behavior expectations, participants agreed that issues were handled in a respectful manner. Participant 7 highlighted that tone was important in behavior management. He stated:

The effective teachers just have a great way, they don't yell. They focus on the behavior, not the kid... [they] have that relationship where they pull them [students] to the side.... and have hallway conversations. They're big on not 
embarrassing the student...[students] know that when behavior is unacceptable, it's always going to be unacceptable.

This observation was supported by comments made by Participant 11, she elaborated on the nature of communication between effective teachers and their students. She stated that communication was: "Always in a respectful way. We have several different opportunities for students to refocus... Our most successful teachers call parents when students are doing well, as well as maybe when they're falling behind or need special attention." The participants agreed that the success of highly effective veteran teachers was underpinned by "effective classroom management...along with relationships that they have with the students...that [helped students to] see purpose behind what they're doing and they want to learn more" (Participant 5). The students know "there's always the opportunity to start over tomorrow" (Participant 11).

\section{Planning and Instruction}

Although planning and instruction may vary depending on the schools and the school levels, a common finding was that highly effective veteran teachers spent a significant amount of time preparing and planning instruction for their students. Participant 4 stated: "My most effective teachers spend a lot of time planning." Another principal concurred: "I think that planning effectively is crucial to being a highly effective teacher" (Participant 5). Participant 7 emphasized that the teachers did not engage in planning student instruction because it was a part of their job. Rather, they engaged in intentional and intense planning because they loved their students. Participant 4 agreed that the love for their students influenced highly effective teachers' commitment to teaching: "the most important thing to them [highly effective teachers] is teaching and their kids." Participant 5 stressed that highly effective experienced teacher understood 
that "if people put in a lot of time up-front, they're going to seem seamless in the classroom."

The interview data also suggested that principals observed that highly effective veteran teachers tended to work for longer hours than less effective teachers. The consensus amongst participants was that the work day of these teachers typically began early in the school day and extended beyond the official end of the day. They were the first teachers to arrive at school and the last ones to leave school: "It's generally highly effective teachers [who] a lot of times go forward when others don't. They're often...the teachers you find working in the building before and after school when a lot of other teachers have left" (Participant 12). It was not unusual to find them using their personal time preparing and planning student instruction. Participant 12 stated: "I just don’t think you can do 7:25 to 2:35 day in and day out. I think it takes more time than that." In providing a description of how she saw her highly effective teacher planning for student instruction, Participant 4 stated:

My most effective teachers spend a lot of time planning...I can't even imagine really how much time they probably spend, but I would guarantee its five to ten hours a week planning for their classes...I'll walk by the room of some of my most effective teachers, and whether it's their embedded PD [professional development] or it's their planning period, they're planning, they're talking, and they're collaborating. I know some where Sunday is their planning day, and they talk electronically, or on the phone, or get together to shop somewhere and plan together for the week.

As a result of extensive planning, instruction provided by highly effective veteran teachers is "rigorous, authentic...student-driven... and relevant to students' abilities but still tied to the standards" (Participant 5).

The principals also pointed out that the quality of teaching provided by highly effective veteran teachers and their interaction with students improved with experience. 
This was because they "had the chance to build their toolkit, their teaching repertoire" and they were "willing to try, even though they may fail, they're willing to try new things" (Participant 7). They have a "growth-mindset... [and] they're always intentional about their instruction" (Participant 9). Highly effective veteran teachers also use their planning periods to collaborate in professional learning communities (PLCs) with their peers. Participant 11 elaborated: "Effective teachers tend to plan together...the most successful teachers I see are teachers who work at special learning community and planning common assessments that really ask kids to learn, not just recall.” Participant 4 agreed that highly effective veteran teacher used their second planning period "either working on applying what they learned in embedded PD, or they're just doing those things that teachers need to do, like plan." Participant 9 stated:

They have the experience upfront to plan ahead...they've gotten to the point where they tweak their lessons...they know what works and what doesn't work... what meets needs of students and what is applicable to students' lives, and what engages the students.

The participants concluded that highly effective teachers understood their students and knew that if "they're not well-planned, things are not going to go well...[the] kids are tough customers, so they expect us to be on our game" (Participant 4).

Further, interview participants indicated that highly effective veteran teachers used a variety of instructional strategies to reach their diverse student population. Participant 5 stated:

The highly effective ones [teachers] are always looking for ways to hook students, to engage them. They're looking for ways to take something going on in their [students] every-day lives, something that's relevant to students, and translate it into what they're doing in the classroom. 
Participant 7 also shared that their flexibility and willingness to learn new instructional strategies made quality veteran teachers stand out:

Our effective teachers are experienced teachers who are very flexible, [and] willing to change...They're not behind the desk, they're not just sitting somewhere at a work area. Data shows that... our most highly effective teachers are the ones ... in the power zone. They're either monitoring or assisting...they're doing something constantly in the classroom.

They understood that a prerequisite for successful student instruction and engagement was creating a classroom environment that was conducive to student learning.

The participants agreed that highly effective teachers used cooperative learning strategies to instruct their students. They pointed out that classes were more studentcentered than teacher-centered. Participant 11 stated: "I would say that...being a higheffective teacher would be the fact that your classroom is student-centered. That it provides opportunities for collaboration and cooperative learning...[using] strategies to try to work with the demographic of students with which they are working." To emphasize this point, Participant 7 compared the teaching strategies of highly effective veteran teachers to those of less effective teachers. He commented:

Cooperative learning is very big, but less effective teachers just don't have that concept of how to do cooperative learning...The teachers [less effective teachers] feel like the longer [they] talk, the better [the] students behave... so [they] do a lot of lecture. Our effective teachers... know how to do intentional grouping...They're always building relationships, planning every day, allowing students to do work... [and] to have purposeful talk. The teachers who struggle, their instructional strategies are geared [more] towards behavior management, than learning in the classroom.

Ultimately, the goal of each highly effective veteran teacher was to have "coherent, clear lesson plans that give teachers the knowledge on what students know, don't know, have learned or didn't learn" (Participant 12). The instruction of effective teachers caters to the diverse needs of a diverse student population. Participant 11 stressed: 
I would say that effective teachers use strategies that provide opportunities for kids to learn in different ways...So in every class period different strategies are used to reach learners who learn in different ways. The kids are involved in sharing and providing filters for one another in the classroom.

\section{Professional Responsibilities}

Another result that emerged from this study was that highly effective veteran teachers were aware of and adhered to their professional responsibilities. Their professional responsibilities included reflecting on their professional growth and teaching practice. They also had a system of documenting and keeping records. Another professional responsibility was facilitating communication and building relationships with students' families, school administrators, and other stake holders. Finally, highly effective veteran teachers participated in school activities and professional development. Each of these sub themes is presented below.

\section{Self-Reflecting and Record-Keeping}

Teachers are required to reflect on their instruction and professional practice as a part of their formal evaluation. The findings from interviews showed that six of the seven principal participants believed that highly effective veteran teachers reflected both formally and informally on their instruction and professional practice because they take their jobs seriously. Participant 4 opined:

I think that effective teachers have systems for lots of things...they value their profession and so they take everything very seriously. If a reflection is a part of what [they're] supposed to do as a professional, then as an effective teacher [they're] probably going to do a better job at that. [They] value reflection in general, so [they're] going to make sure they do it.

Self-reflection was continuous. Findings indicated that highly effective teachers reflected with their PLCs, other teachers, with principals, assistant principals, and instructional coaches. Participant 4 stated: 
They will oftentimes reflect in their PLCs, they will reflect just in the hallway talking to one another... They don't keep their reflection or their struggle to themselves...they don't just write the reflection when it's due for evaluation. They reflect all year long, and they involve other people in that... They will also come to me, an AP or an instructional coach and say: "Hey, I'm trying this thing, and I don't know if it's working. What do you think about this, or have you ever thought about that?

Participant 9 agreed that highly effective veteran teachers were always reflecting on how they can improve. This participant stated:

I think in the area of self-reflecting they are constantly tweaking things. They don't just continue to do the same thing if it's not working. They reflect every period... they reflect every day...they will constantly seek out feedback.

Participant 7 highlighted that effective teachers at his school were able to reflect on their teaching practices. He facilitates this reflection by providing opportunities for them to mentor teachers and to lead in internal professional development sessions. Participant 5 shared similar perspectives as the other principal participants. She explained:

They [highly effective veteran teachers] are highly reflective...they don't allow things to get them down. Whereas some people might say "that went terrible, I'm a terrible teacher," they [highly effective veteran teachers] say, "that went terrible, what am I going to do next?" So, it is a growth mindset, not a deficit mindset that keeps them there. They are resilient.

Findings indicated that principal participants believed that documenting interaction with students, student grades, and other events related to student progress also illustrated the teachers' professionalism. The participants were divided over whether highly effective veteran teachers regularly kept appropriate documentation of interaction with students and their parents. On the one hand, some participants pointed out that record-keeping was a growing skill for some effective teachers. Conversely, other participants commented that effective teachers documented student interactions, grades, and other events better than less effective teachers. According to Participant 9 effective 
teachers "aren't necessarily the best record keepers, [but] they make the documentation that they need to make.” This suggested that effective teachers at the very least understood what was critical for documentation purposes. Participant 12 concurred. However, Participant 4 emphasized that highly effective teachers had a system of keeping records. She compared a "brand-new" teacher's system of keeping track of students' interaction with that of a highly effective veteran teacher:

I was in a brand-new teacher's class the other day, and he was using a strike system... but I didn't see him writing strikes down anywhere...I asked him about it and he said: "Well, I'll just try to remember."...Whereas, an effective teacher is going to have a system for that. It may be a slip of paper in the kid's notebook that they keep in the classroom every single day...or they keep it on a clipboard...they have systems for managing these expectations.

Participant 12 agreed with Participant 4 with regard to the comparison of effective and less effective teachers. He stated: "Let's say in general, they [highly effective teachers] are better at record-keeping than less effective teachers" (Participant 12). It is noteworthy that Participant 11 pointed out that her teachers "never really had problems with that piece [record-keeping]." She explained: "Our teachers do a really good job with recordkeeping because they tend to do it as a team...The teams meet each week...talk about it, and record that [data]" Participant 11).

\section{Communicating with Parents and Other Stakeholders}

Communicating with parents and students' families is an important part of a teacher's professional responsibility. All of the participants highlighted communication with parents as an area of growth for their teachers. However, each principal pointed out that highly effective teachers were more likely to make contact with parents and families more frequently than less effective or new teachers. Participant 9 commented: "I think my effective teachers are always willing to do whatever it takes for the benefit of the 
kids." Participant 4 agreed with Participant 9 and compared the steps taken by highly effective veteran teachers to communicate with parents and families to the measures taken by less effective teachers or new teachers. Participant 4 stated:

I think my more effective teachers are more likely to call and involve parents than the least effective teachers. They will call parents and then document that they've called...including the parent is a part of their strategy. Whereas, a brand-new teacher or less effective teacher may not think of [contacting parents] until the assistant principal says: "Have you ever talked to a parent about these things?" It's not their go-to.

Participant 5 indicated that the highly effective teachers in her school were:

“organized...and communicative." Participant 11 highlighted that communication between teachers and parents was a regular occurrence at her school. However, she pointed out that highly effective veteran teachers did not only make negative calls to parents about students, they also contacted parents when students were doing well at school. Participant 11 pointed out: "My most successful teachers call parents when students are doing well, as well as when they're falling behind or need some special attention." She also explained that communication with parents and families was required at least once every three weeks. Participants indicated that Communication with parents and families was facilitated in multiple ways. These ways include social media, Remind 101 (a text messaging phone application where teachers, parents, and students can send and receive messages), and the schools' website. The participants felt communicating with parents and family was important to building and strengthening relationships with students.

When asked to describe the level of communication between highly effective teachers and other stakeholders, the principal participant group agreed that "contact that highly effective teachers have with various stakeholders varies greatly" (Participant 12). 
Participant 7 commented that communication varied 'from department to department. For example, the Math teacher in his school had a close relationship with the district Math specialist. Conversely, such strong lines of communication were not seen between other departments and the school district.

\section{Findings from Interviews with Highly Effective Veteran Teachers}

In this section I discussed findings from the interviews with highly effective veteran teachers in response to Question 1 . Teachers who were classified as highly effective were either National Board-Certified teachers or teachers who were evaluated as exemplary by their supervisors in their last evaluation. First, I presented brief description of the participants. Second, I presented the findings from the interviews with highly effective veteran teachers. The themes emerging from research question one: "What are the characteristics of highly effective veteran teachers who remain teaching in lowperforming schools?" were Building Relationship with Students, Planning and Instruction, and Professional Responsibilities with sub-themes: Self-Reflecting, Communicating with Parents and Record-Keeping. These themes were consistent with the themes that emerged from the interviews with the principal participants.

\section{Profiles of Participants}

I interviewed seven highly effective veteran teachers. All of the participants were female teachers. Of the seven participants, one participant was a middle school teacher, the other six participants taught in high school. Five of the teachers were National Board Certified. The other two teachers were classified as exemplary by their principals in their last evaluations. All of the participants were White with the exception of one female participant who was Black. To protect their identity in the data collection phase, I 
assigned a number to each participant. Numbers were based on the order of the interviews. Four of the seven interviews were conducted in person. Two participants indicated meeting after school hours was more convenient to them due to other commitments. I met these participants at locations that were convenient to them. I met one participant at a coffee shop and the other participant at a restaurant. The other two face-to-face interviews were conducted in the teachers' classrooms. Three of the interviews were conducted by phone. Two participants whom I interviewed by phone indicated phone interviews were more convenient for personal reasons. One of the two participants had agreed to an in-person interview but had to leave because one of her children became ill. The other participant was on maternity leave from school and was otherwise unavailable. Each interview took between 35 and 40 minutes to be completed. The demographic data for highly effective veteran teachers are presented in Table 4.3. 


\section{Table 4.3}

$\underline{\text { Demographic Information for Highly Effective Veteran Teachers }}$

\begin{tabular}{|c|c|c|c|c|c|c|c|c|c|}
\hline $\begin{array}{c}\text { Participant } \\
\#\end{array}$ & $\begin{array}{c}\text { Age } \\
\text { Range }\end{array}$ & Race & Sex & $\begin{array}{l}\text { School } \\
\text { (High/ } \\
\text { Middle) }\end{array}$ & $\begin{array}{c}\text { Years } \\
\text { (as } \\
\text { Admin) }\end{array}$ & $\begin{array}{c}\text { Years } \\
\text { (Current } \\
\text { School) }\end{array}$ & NBCT & $\begin{array}{l}\text { Exem- } \\
\text { plary }\end{array}$ & $\begin{array}{l}\text { Grade } \\
\text { Level/ } \\
\text { Subject }\end{array}$ \\
\hline 3 & $36-45$ & $\mathrm{~W}$ & $F$ & HS & 17 & 12 & Yes & & $\begin{array}{l}9-12 / \\
\text { Music }\end{array}$ \\
\hline 8 & $27-35$ & W & $\mathrm{F}$ & HS & 9 & 9 & Yes & & $\begin{array}{c}\text { 11/ } \\
\text { English }\end{array}$ \\
\hline 10 & $\begin{array}{c}\text { Over } \\
55\end{array}$ & B & $\mathrm{F}$ & HS & 14 & 14 & Yes & & $\begin{array}{c}10 / \\
\text { English }\end{array}$ \\
\hline 13 & $36-45$ & W & $\mathrm{F}$ & HS & 14 & 6 & Yes & & $\begin{array}{l}\text { 10-12/ } \\
\text { Math }\end{array}$ \\
\hline 15 & $36-45$ & W & $\mathrm{F}$ & HS & 13 & 7 & Yes & & $\begin{array}{l}9-12 / \\
\text { ESL }\end{array}$ \\
\hline 21 & $27-35$ & W & $\mathrm{F}$ & HS & 9 & 9 & & Yes & $\begin{array}{c}9 / \\
\text { Science }\end{array}$ \\
\hline 22 & $27-35$ & W & $\mathrm{F}$ & MS & 15 & 8 & & Yes & $\begin{array}{l}\text { 6-8/ } \\
\text { ECE }\end{array}$ \\
\hline
\end{tabular}

Note. W: White; B: Black; F: Female; HS: High School; MS: Middle School; NBCT: National Board-Certified Teacher; Itinerant Teacher; ESL: English as a Second Language Teacher; ECE: Special Education Teacher

\section{Building Relationships with Students}

The findings for research question one indicated that highly effective veteran teachers were effective because they spent time developing their teaching practice and pedagogical skills. They engaged in building lasting and positive relationships with their students which were integral to creating a positive classroom environment. These findings are very consistent with the perspectives that were shared by the principal participants. Participant 10 pointed out that students will respond positively when they 
know that you care about their well-being. This participant stated: "I think that it's really important that kids need to feel that they can trust you. Because when they trust you, they can open up to you and they will ... do whatever you ask.” Participant 13 agreed that "relationships are everything." She emphasized: "If you don't have relationship with your kids, I don't care if they know how to do fractions or not, they're not going to learn." Moreover, participants asserted that the reason why some teachers encountered problems managing students' behavior was because they did not model the right behaviors to their students. In concert with the principal participants, the highly effective veteran teachers impressed that an atmosphere of mutual respect should exist between teacher and student.

You know, it [respect] has to go both ways. I think a lot of colleagues...they feel like because they're adults they shouldn't respect the students. I've had students tell me that because I respect them, they respect me...respect is kind of a two-way street. (Participant 10)

Participant 3 concurred:

One thing I've noticed with the teachers that have trouble in the school that I'm in is that they expect students to respect them but they don't respect the students. I feel like modeling good behavior and creating a mutual respect... is really important. (Participant 3)

She felt that the golden rule should be applied to student-teacher interactions that is: "treat others the way you want to be treated" (Participant 3).

Highly effective veteran teachers identified common ways to establish strong, positive relationships with their students. The highly effective veteran teachers affirmed what the principal participants said about relationship management and classroom expectations. They indicated that from the beginning of each school year and consistently throughout the year, they developed rules, routines, and procedures for all of their classes. Some of the participants also allowed their students input in creating the class 
rules. All of the participants intentionally created a respectful and positive classroom environment. Participant 10 stated: "When school starts I go over my rituals and routines, and one of the biggest things I talk about is respect. What it looks like, what it sounds like, and what it's going to be like in my classroom." Participant 15 explained: "At the beginning of the school year, I communicate the cell phone policy and what I expect in class and course preparation. [I also inform them] on the materials they need, taking charge, or talking while others are speaking." Participant 22 emphasized the importance of creating a comfortable yet structured environment to enhance the success for all of her students. She said:

I think it's just important first of all to get to know your kids. And second of all to make them feel as comfortable as possible in your room so they feel like they want to learn because they're comfortable and they have that relationship with you.

This participant described her classroom as:

Kind of quaint because I have the same kiddos all day long. My room has bean bags, lights, and things like that, and little inspirational signs all over the place. Me and my kids together come up with our classroom rules, so they would have some type of ownership in it. (Participant 22)

She continued: "We go over the rules every single day. We are not allowed to be disrespectful...the kids end up calling each other on it if they've said something."

The participants also concurred that because their students were children, there would be times when they exhibited inappropriate behaviors. "I hate to say it, but teenagers are going to fight and they're going to get into alterations" (Participant 3). However, there were ways of dealing with such matters. One respondent recommended, rather than getting angry and responding negatively to a negative and potentially volatile 
situation, one needed to remain calm, deal with the situation, and walk away. This

participant stated:

I stay calm. That is the biggest problem young bucks [inexperienced teachers] have. They lose their temper. I did too. But you let it go. You do relaxation techniques in your brain while they're saying whatever they want to say to you. And you just give them the directive multiple times, and you walk away from them. You just don't engage them. A lot of young teachers have a hard time wanting to prove that they're right to a teenager. A lot of times they'll comply once they realize they've lost. If they continue, then I do a progressive behavior [procedure]. (Participant 13)

Another way of dealing with students' inappropriate behaviors is addressing the matter immediately and directing students to stand outside the door to await redirection from the teacher. Both participants 10 and 21 use this de-escalation tactic.

I immediately say something about it, I think sometimes that's what gets new teachers, they kind of let things slide, I do not. So, I immediately say something and then usually depending on what it is, if they do not redirect, send them outside my door and have them wait out there until I come. And I get the class doing something so I can get outside to talk to them. (Participant 10)

Participant 21 stated: "I go to a hall conference, so I tell them to go stand in the hall. I give them a couple of minutes to cool off, and then I'll go to talk to them about their behavior."

All of the participants asserted that typically they experienced minimal behavior problems from students because of the relationships they established with the students. One participant also made reference to times when her decision to redirect offending students was supported by other students who were present at the time. This respondent stated:

It is very rare...not impossible...that I have a student that flat out won't comply. And I've had another kid go. "Dude, she's (the teacher) not a jerk! Just do what she asks!" So, it does help that apparently, I have enough respect from other kids that they look at each other and go: Come on, don't do that to her type of thing. (Participant 13) 
Overall, the teachers indicated that they tried their best not to send students from their classes because it only results in the missing instruction. Participant 10 stated: "I try my best not to send them out because all that does is make them miss classroom time...so then they're behind even further."

\section{Planning and Instruction}

Principal participants indicated that effective planning enhanced classroom instruction and learning. They indicated that highly effective teachers exemplified consistent effective planning and they spent much time perfecting their craft. Highly effective veteran teachers corroborated the assertions made by the principal participants. They indicated that highly effective veteran teachers develop lesson plans and instruction that are relevant to student needs and try to communicate with the parents of their students regularly.

Findings from the research showed that although planning for highly effective veteran teachers became easier with time, still many of them spent hours planning. Time spent planning for instruction varied based on the subject and students each participant taught. Participant 22 taught four different subjects because she was a Special Education teacher. Therefore, her planning for instruction time was 15 to 20 hours weekly. Participant 3 was an itinerant Music teacher. This participant indicated that she mostly planned for "long-term performance-based projects" and she spent "a lot of time dealing with small groups and individual needs."

The other participants indicated that they spent a lot of time planning. Participant 10 stated "Because my level of kids need to be truly engaged, I spend a lot of time planning." Participant 8 indicated that she spent "hours a week" planning for instruction 
depending on whether her courses were honors courses or Advanced Placement (AP) courses. She spent more time planning for the honors courses. This participant described her planning time: "For AP, I do [planning] on my own. For English 111, we get together every weekend and plan for three or four hours and probably between six to eight hours of planning a week ... outside of school planning time” (Participant 8). Principal participants indicated that effective teachers were often observed in joint planning sessions. The comment made by Participant 8 is consistent with the assertion made by the principal participants in the previous section.

However, most of the participants indicated that it was easier planning for instruction because they had taught for so many years. As a result, they were able to adapt lessons to suit their students' needs. According to Participant 15, "I've done it for several years now, so planning is relatively easy because we have a lot of stuff put together." Participant 21 compared planning when she was a new teacher to planning as a veteran teacher. This participant said:

Early on, it took hours and hours. Now I can reuse a lot of what we've done, and we just tweak things and make them work for our new group of students. [Now] I would say [I plan] probably at least seven hours a week still, between my PLC, staying after school, finishing up lessons, setting up activities, things like that.

The findings show that participants planned lessons both individually and collectively with their professional learning communities (PLCs). Participants 3 and 22 stated that they collaborated with the regular teachers, although Participant 3 stated that she mostly planned on her own. Participant 22 also planned with her teaching assistant. Each participant opined that working collaboratively with their peers facilitated their planning for instruction. Participant 3 stated: "Along the way I collaborate with others to 
get ideas or help or situational advice based on things that happen." Participant 13

admitted:

My first couple of years teaching, I really wanted to be a lone wolf. I didn't want anybody to help me because I was smarter than everybody because I'd just gotten out of school. As I've gone on, I've wanted to collaborate a lot more because newer teachers sometimes have better ideas. I rely a lot on my PLC to do Algebra 2.

The consensus amongst participants was that teaching in small group settings was more conducive to student success. Small group settings helped to create a family community setting and helped students to create positive relationships with each other. Participant 10 stated: "We build the classroom community so we get to know each other." Participant 3 opined that working in groups gave them "time to get to know each other... and helps build rapport and trust within the group." According to Participant 13: It is "kind of like forming a little family in the classroom." Working in small groups also helped students "to communicate well with one another, work well with partners, even whom they may not like" (Participant 21).

Highly effective veteran teachers must plan instruction that caters to students of all abilities. They must possess the aptitude to use different teaching methods based on student needs (Goe et al., 2008; Popp et al., 2011; Stronge, 2007). Similar to assertions by the principal participants that effective teachers practice differentiated instruction in their classrooms, feedback from the effective veteran teachers indicated that they were intentional in using multiple strategies to accommodate their students' needs. Participant 3, a music teacher, stated that she used direct, peer instruction, individual instruction, and small group instruction. This participant described the modifications she made that facilitated students of all skill-levels to participate in concerts and projects: 
I try to make accommodations with the music. I try to find more advanced things for my more advanced players to challenge them, while at the same time cutting back and simplifying things. I do a lot of arranging, rewriting of things to make sure that students can be successful at whatever level they're at the time. This leads to an all-inclusive environment. (Participant 3)

Participant 15 explained that she used a variety of strategies to teach her nonEnglish speaking students. These strategies include: independent reading, grammar in the students "native languages", practice of oral skills when students shared aloud about the books they read. This participant also stated: "For the kids that are a little bit struggling, on an individual basis, I reach out to them or go over with them aloud. I do a lot of reading out loud for the whole class." She chuckled as she commented that the strategies that she used in her ESL classes were often borrowed by regular teachers to use in their regular classes with their regular students. Participant 22 said that "every day, every period is something different... engaging things like, hands-on activities [and] labs where they can kind of facilitate their learning." Participant 8 stated that she was trying to be more flexible and therefore she was trying to incorporate student input in making decisions about teaching strategies that would work in her classes. This respondent stated:

I start with my assessments and my standards and do backward design...I'm trying to include more student voice this year in [giving students] choice. So, it'll be like, "What would you guys say would be the best way to approach this?" And they'll say: "Well why don't, we just..." [and we'll do] whatever it is they say.

\section{Professional Responsibilities}

Effective teachers are deliberate in engaging in their professional responsibilities

(Goe et al., 2008; Popp et al., 2011; Stronge, 2007). The principal participants spoke extensively about how effective teachers were very deliberate in executing their professional responsibilities. While there were some mixed responses about the degree to 
which effective teachers consistently kept good records, the principal participants asserted that the effective teachers were exemplary in meeting all of their other professional responsibilities. In similar manner, this study revealed that highly effective veteran teachers thought that they were intentional in carrying out their professional responsibilities. These responsibilities included purposeful reflecting on student learning. The teachers were also purposeful about communicating with the parents of their students. Finally, highly effective veteran teachers kept records of their interactions with students and other stakeholders.

\section{Self-Reflection}

The findings in this research indicated that highly effective veteran teachers spent time reflecting on their students' learning. "This is reflecting on how student learning is going on and how you are doing with the kids" (Participant 21). Participant 10 was thoughtful as she commented on the ways in which she reflected on student learning. She said that she kept a journal in which wrote her reflections of her students' progress and her professional practice. This respondent also commented that each year she attended various professional development workshops to help her to learn new teaching strategies to accommodate the diverse needs of her students. Her comments are as follow:

I usually think from year to year I can honestly say that I've never taught a lesson the same way. I'm always trying to reinvent the wheel and take it to another level because my students are different. I'm always trying to find different ways to do that, so I go to all kinds of professional developments. (Participant 10)

Participant 15 indicated that grading her students work was time-consuming. She pointed out that as she graded her students' work she spent time reflecting on her students learning and how to address any misconceptions. This participant stated: 
My most time-consuming planning is based on the work that is due from the kids. When I grade their work, when I read their writing, I'm thinking of how to address the misconceptions of that later on. That always takes extra time.

Participants 8 and 21 indicated that they reflected with their PLCS.

\section{Communicating with Parents and Record-Keeping}

Another aspect of professional responsibilities is communicating with parents. Highly effective veteran teachers acknowledged that parent support was another way of strengthening relationships with their students. Highly effective veteran teachers in this study stated that they tried to communicate with parents in some way to provide both positive and negative feedback about their students' progress. Participant 3 stated:

I make phone calls pretty regularly; I don't save them for parent-teacher conference days...I have a few parents who communicate back and forth with me constantly because they're the ones who are really keeping tabs on their kids and their kids' education.

This participant continued: "I wish they had more time to be able to come in and meet with all of us... [but] they have jobs and lack transportation." Both participants 10 and 21 communicated with parents frequently via emails, phone calls, Remind Text, and sending mass emails using the district's software. Participant 22 stated that she kept in close contact with all of her students' parents. This participant stated: "I actually get along with my parents. They do have a trust in me. I talk to them on a regular basis either through text or phone...I keep on trying to build that relationship so I have their support."

All of the participants felt it was important to keep track of any interaction with students and their parents. Documenting is a good way of keeping track of trends in students' academic performance, attendance, methods of interacting with the students and parents, or recording anything that the teacher thinks is important. Participant 21 noted: 
I keep students' grades week to week on a clipboard with attendance...My parent log; I keep on a clipboard in my desk drawer. It's a Word document. It has the date, the student name, a form of communication...post card, email, a phone call, and a little bit about what we talked about.

Participant 10 stated: “

I have a notebook where I keep it all. Also, in that notebook I keep a folder, I write down as far as grades and things... like if I notice something or somethings going on. I always keep notes on these and keep those just in case.

Methods used to document correspondence were: the district website, spreadsheets, word documents, and writing the information in notebooks. Participants 15 kept their records in her teacher plan book. Participant 22 said she kept a student points sheet to record her students' behavior. This was very important because some of her students has disabilities. She also used the district's website to record all interactions with students and parents.

\section{Findings from Interviews with Teacher-Colleagues of the Highly Effective Veteran}

\section{Teachers}

This section of the study examines the research questions from the perspectives of the colleagues of highly effective veteran teachers. The participants were identified by principal participants or the highly effective veteran teachers themselves. The participants were worked closely with highly effective veteran teachers or were members of their PLCs. This group responded to question one: "What are the characteristics of highly effective veteran teachers who remain teaching in low-performing schools as reported by principals and teacher colleagues?"

Similar to the principal participants and the highly effective teacher participant groups, the themes emerging from research question one with the teacher colleagues of the highly effective veteran teachers were: Building Relationships with Students; Planning and Instruction, and Professional Responsibilities. The sub-themes emerging 
from Professional Responsibilities were: Self-Reflection, Record-Keeping, and Communication with parents.

\section{Profile of the Teacher-Colleague Participants}

I interviewed a total of eight participants, seven of whom taught at high school level and one participant taught at a middle school level. There were six female participants and two male participants. All of the participants were White. Phone interviews were most convenient to the majority of the participants ( 7 of 8 participants) due to the inclemency of the weather, school closures, and unsafe road conditions during the data collection period. Each interview took an average of 30 minutes to be completed.

The following table shows the participants' demographic information. It is important to note that there were no restrictions in the selection process for this study regarding the length of time that the teacher colleagues worked at the schools. This is because they are primarily observers of the highly effective veteran teachers who will affirm their attitudes, behaviors and activities. The number of years they were in the schools ranged from six months to seven years. Four of the eight participants were between 27-35 years old. The other four participants were 36 years or older. See Table 4.4 for demographic information of Teacher-colleagues of Highly Effective Veteran Teachers. 


\section{Table 4.4}

$\underline{\text { Demographic Information for Teacher-Colleagues of Highly Effective Veteran Teachers }}$

\begin{tabular}{|c|c|c|c|c|c|c|c|c|}
\hline $\begin{array}{c}\text { Participant } \\
\#\end{array}$ & $\begin{array}{c}\text { Age } \\
\text { Range }\end{array}$ & $\begin{array}{l}\text { School } \\
\text { (High/ } \\
\text { Middle) }\end{array}$ & Sex & Race & $\begin{array}{c}\text { Years } \\
\text { (Teaching } \\
\text { Experience) }\end{array}$ & $\begin{array}{c}\text { Years } \\
\text { (Current } \\
\text { School) }\end{array}$ & $\begin{array}{c}\text { Student } \\
\text { Grade } \\
\text { Level }\end{array}$ & $\begin{array}{l}\text { Subject } \\
\text { Taught }\end{array}$ \\
\hline 2 & $36-45$ & MS & $\mathrm{F}$ & $\mathrm{W}$ & 20 & $6 \mathrm{mos}$ & 7 & Science \\
\hline 6 & $36-45$ & HS & $\mathrm{F}$ & W & 13 & 3 & $9-12$ & Business \\
\hline 14 & $27-35$ & HS & $\mathrm{F}$ & W & 12 & 2 & 9,10 & English \\
\hline 16 & $36-45$ & HS & $\mathrm{F}$ & W & 14 & 4 & 11,12 & English \\
\hline 17 & $27-35$ & HS & M & W & 6 & 6 & 10 & English \\
\hline 18 & $27-35$ & HS & $\mathrm{F}$ & W & 4 & 4 & 11 & Math \\
\hline 19 & $46-55$ & HS & $\mathrm{F}$ & W & 10 & 7 & $9-12$ & $\begin{array}{l}\text { Marketing/ } \\
\text { Hospitality }\end{array}$ \\
\hline 23 & $27-35$ & HS & M & W & 4 & 4 & $9-12$ & Music \\
\hline
\end{tabular}

Note. MS: Middle School; HS: High School; F: Female; W: White

\section{Building Relationships with Students}

In response to research question one, relationship building emerged as one of the characteristics of highly effective veteran teachers. All of the participants stated that building relationships with students was a priority amongst highly effective veteran teachers. Establishing strong relationships was a way of assuring students that the teachers cared about them as individuals. This finding asserts that all three groups of participants believed that teachers demonstrating care and concern for their students helped to build bridges that enhanced the classroom environment and positively affected student learning. Participant 16 explained:

I think that relationship building is probably the most important part...especially in priority schools where kids are going through a lot of tough situations. I think highly effective teachers build relationships first, and I have observed that this has been one of the attributes of my colleague [Participant 8]. 
Participant 14 concurred that building relationships was paramount. This participant added: "I think that that is a big part of being an effective teacher. Getting to know the students, what's important to them, what their situation is like at home, what's effective for them in terms of motivation."

Other findings show that teacher colleagues thought that most effective teachers recognize and treat students as people with individual needs. Building relationships with students was a way of motivating students to trust that the teachers were concerned about their development. Participant 16 observed that highly effective teachers empathized with students “...talking to them [students] like they're people. You would often see Participant 8 pulling a kid one side to get him or her in line with expectations." This participant continued: "I think so many kids get talked down to. Once they're in your room...they're yours. It's kind of your responsibility to look out for them" (Participant 16). Participant 17 reiterated that highly effective veteran teachers understand that "they're [students] going to get distracted and that's okay. [They] find out a little bit about the kids rather than just trying to teach to a test."

Teacher-colleague participants also indicated that classrooms of highly effective veteran teachers were highly structured. "They're very well organized... so students know where they stand and know the standards and what they need to do to accomplish what goals they have in a classroom" (Participant 19). This statement is in concert with both the principal participant group and the highly effective veteran teacher group. Effective teachers have clearly defined student behavior expectations, routines, and procedures. Expectations and behavior management systems were consistently implemented from the first day and throughout the school year, in every classroom. Participant 18 explained "I 
feel like it's setting very clear expectations and following through with them." Participant 16 stated that effective teachers were:

Consistent and fair...they follow through with progressive discipline. In my observation, my colleague (Participant 8 ) is very consistent with implementing disciplinary measures. The kids would talk about her and the fact that she is very consistent but fair. Therefore, students understand disciplinary protocol.

Participant 16 continued: "It's about setting the clear expectation that if I see you with your cell phone out three times, then I'll call your parent. Then, the fourth time, I'm writing you up... Just following through with that.” Although the classes were structured, participants also indicated that highly effective veteran teachers maintained a positive classroom environment. Students felt safe and comfortable being in the classrooms and being with the teachers. It was a mutually respectful environment. Participant 23 opined:

I think that effective teachers [like my colleague] (Participant 3) always try and relate to the students on a level that is respectful for both student and teacher...[There is] that sense of respect that the students understand that the teacher is the one that is in charge of the classroom. Also, the teacher is going to guide the students and teach them what the students need to know to be successful...Theirs is a mutual level of understanding that the students need to trust the teacher and trust that the teacher's going to provide them with all the correct information.

Despite the challenging conditions typically found in low-performing schools, participants emphasized that highly effective veteran teachers were rarely challenged by disruptive students. Participant 2 compared her student behavior and classroom management skills to those of highly effective veteran teachers in her current school. She commented that managing unruly students in her classroom was a daily struggle for her. This respondent stated: "This has actually been my biggest struggle this year...dealing with the amount and extreme nature of the behavior." She continued: "I'm not sure what could have prepared me for this. It's very different." Conversely, Participant 2 opined 
that she thought that highly effective veteran teachers "are amazing...because I know how challenging the position is at that school...I know sometimes it's a struggle to get kids to focus." She continued: "I think they [highly effective veteran teachers] manage things very well. I think what's a real key, is that their behavior management and their classroom management are excellent. I think that's a real strength."

An interesting finding was that Participant 2 identified highly effective veteran teachers as "teachers who had been [teaching] at [her middle school] for more than a year... and stayed at that school." She mused that "a lot of teachers that did choose to stay are really very strong." This is an interesting finding because of the high degree of turn over to which teachers have grown accustomed. The idea that surviving one year was an achievement highlights the degree to which teachers who have been there five or more years are indeed committed to the work that they are doing.

The findings suggested that one characteristic that helped highly effective veteran teachers to manage student behaviors and their classrooms was remaining "very calm and not responding" despite the occasional disruption (Participant 18). Participant 14 reiterated that being calm and concise in communication were tools she had seen utilized by effective teachers. This participant explained:

It's especially important to stay calm because attitude is kind of a buzz word. A lot of kids are very sensitive to the teacher's attitude toward them, or their perception of that. Calm, concise, matter of fact statements or non-verbal cues... are the most effective tools.

Highly effective veteran teachers cultivated an unobtrusive way of dealing with potentially disruptive students. Participant 14 reflected on the effective teachers in her school and explained how they managed the disruptive students. She said, first, the teachers were non-confrontational, and second, they removed the students from the 
negative situation. In some cases, these teachers ask the students to sit in with another effective teacher who would "hold" that student for the duration of the class period. Participant 17 observed that effective teachers like Participant 10 "have conversations [with students] out in the hallway... [they] just don't send kids the office." Participant 6 noted that for highly effective teachers "out of 100 kids a day...only one or two may not respond [positively to redirection], but for the most part they respond well."

The teacher-colleagues also agreed that relationship building was important to student learning and managing student behavior. One participant said, "The kids want to be around teachers that like kids... There's a good enough relationship established that ...most of the time, get them to want to cooperate" (Participant 6). Their positive, encouraging demeanors reassured students that highly effective veteran teachers were "the ones they can talk to. The ones who care about them, the ones who are doing their job. [Students will not] necessarily just tell about their personal lives, but also trust that their time will not be wasted" (Participant 16).

\section{Planning and Instruction}

The teacher-colleague participants indicated that highly effective veteran teachers were often observed spending significant time planning for instruction. The teachercolleague participants also attested that effective teachers planned both individually and collaboratively during and after school hours. Participant 23 emphasized "there is a combination of using planning time during the school day to be effective, but also you've got to take some of your classwork home with you and study that." Participant 2 stated that she observed that due to schedule changes that eliminated an extra PLC planning period at her school, she saw highly effective veteran teachers engaging in informal 
planning at every opportunity. This included "chatting in the hallways, or chatting in the copy room, or just kind of getting together with... other teachers.” However, Participant 14 commented: "I think that they [highly effective veteran teachers] do spend a lot of time planning."

Participant 14 also confirmed that highly effective teacher often planned their lessons collaboratively with other teachers. This participant stated: "they absolutely collaborate with other teachers. It's something that you can do if you take the whole summer and plan out the whole year. That is as effective as having a map of where you want to go." The teacher-colleague participant said, "This is a common thing in my school...the effective teachers try to get together during the breaks to prepare for the year. That way they can start the year running rather than playing catch up" (Participant 14). According to Participant 16, "I collaborate with (Participant 8)...collaboration when you have a good team is priceless.”

Some participants also agreed that more time is needed to carefully plan effective lessons. Participant 19 emphasized, "You have to plan minute-to-minute to be really effective." Teacher experience was also highlighted as an essential characteristic by the teacher-colleague participants. Both the principal participants and the highly effective veteran teachers referred to how having years of experience allowed them to draw from years of accumulated materials and knowledge of the subject matter. One teachercolleague similarly stressed that having teaching experience made planning for instruction easier. Highly effective veteran teachers had a repertoire of resources and knowledge that allowed them to be effective teachers. She commented:

They seem to have a toolbox of other things they can pull from to help them [students] understand... I think the only way you can do this is if you've been 
teaching for a long time. You have accumulated knowledge and resources over the years. For beginning teachers, it is harder: beginning your teaching career...it's so time-consuming to find these resources. (Participant 2)

Differentiated Instruction in classrooms also emerged as a major finding with this group of teacher-colleagues. This is similar to the findings from the principal participants and the highly effective veteran teachers. The teacher-colleague participants indicated that it is important to meet the needs of diverse groups of students. The findings of this study indicated that highly effective veteran teachers responded to student needs by using multiple teaching tactics in their classrooms. According to Participant 16, the ultimate goal was to promote a "growth mindset" amongst the students. Some of the tactics that participants observed highly effective veteran teachers like Participant 8 using in their classroom were: working in small groups, having "peer-to-peer time" and "discussion time" (Participant 16). Participant 2 observed students participation in "flexible groups" based on their performances in tests.

The highly effective teachers were also observed helping students who had difficulty mastering key concepts in their classes. Teachers would often have them come in to school early before class and would take the time helping them understand the concepts. Students who succeeded in mastering the concepts would move on to "something new or something related so it takes them to a greater depth." Participant 14 also stated that she observed highly effective teachers using "modeling... [providing] exemplars and thinking aloud [as] all effective tools that they [highly effective veteran teachers] use a lot." This participant continued that highly effective veteran teachers gave "students multiple ways to respond or their choice of ways to respond." Participant 17 stated that highly effective veteran teachers "try to get the kids to work together a lot, 
move around the room, and have conversation with each other... as discussions are extremely important in all classrooms that work well.”

\section{Professional Responsibilities}

Teacher-colleague participants indicated that highly effective teachers were effective because they carried out their professional responsibilities. Professional Responsibilities included: reflecting on professional practice and on their students' learning, communicated with students' parents, and documented interaction with stakeholders. These themes are consistent with the findings from the two other participant groups. The themes also serve to provide the preponderance of evidence needed to confirm that these exemplary characteristics are critical to teacher effectiveness.

\section{Self-Reflection}

The findings showed that highly effective veteran teachers reflected on their students' learning. The participants in this study observed their colleagues reflecting during their PLC times. The teachers who were highly effective were more intentional in reflecting on their students' learning and their personal performances. In response to the interview question: "Describe the ways in which highly effective veteran teachers selfreflect," one respondent explained that teachers at her school were required to write reflections based on monthly in-house professional development. This respondent stated that some teachers found writing the reflections challenging, but highly effective veteran teachers were intentional in writing their reflections. She reported: "the teachers who are really committed to instruction and to bettering their instruction do take the opportunity to really reflect on what's changed and how things could go better in the instruction" (Participant 16). The requirement to write reflections is a nuanced difference since most 
effective teachers tend to undertake these activities on their own. However, it is significant that the school to which the respondent referred emphasized the importance of reflection. Participant 17 echoed that he observed highly effective teachers including Participant 10 in his PLC purposefully reflecting on their students' performances. According to this respondent, their PLC met weekly to discuss and formally reflect on their students' performances in test and to review other data:

I know that my PLC and I meet specifically to discuss what we've done in class that we can test and look at data. [We] discuss what was successful and what wasn't. We type it all. We have a long, long document about all of it. So, we know what works well for us, and what doesn't. What we need to change and ways to move forward. I think that's pretty nice. (Participant 17)

In her response, Participant 14 confirmed that highly effective veteran teachers at her school spent significant time planning and reflecting. She also described tools the effective teachers utilized to complete their reflections. Participant 14 stated:

The real key [to student success] is being responsive to reflecting on how the previous lesson has gone... how it could be retaught more effectively, how it could be built on reaching the next learning target. What are the next logical steps for students to take, and how they'll build on what they learn...I think they [highly effective veteran teachers] all have their own tools to do that [reflecting]...They all have different strategies. Whether that is collecting data, statistical data, or keeping a class chart with all the names and taking notes based on student conferences or keeping a log as you grade something of errors that keep popping up, or different observations you make.

Both Participants 18 and 16 stated that they thought reflective teachers were usually better teachers.

\section{Communication with Parents}

The findings indicated that the teacher-colleagues agreed that highly effective teachers communicated with parents of their students. The methods of communication they typically used were: Remind Text, emails, social media like Twitter, and the school 
district website (Participant 19). Participant 14 noted that she observed highly effective veteran teachers at her school attempting to contact parents on a consistent basis. Participant 23 stated that highly effective teachers like [Participant 3] "do interact with them [parents, and] it's always something positive." This respondent continued:

I know when we have parent/teacher conference or an Open House, or SBDM meetings, these highly effective teachers are the ones that make the effort to come and speak to parents or make phone calls home when they are needed. [They] definitely establish that connection. (Participant 23)

\section{Record Keeping}

Seven of the participants indicated that they knew of highly effective veteran teachers who documented important information about their students. Information included students' grades, communication with parents, attendance, behavior, and other data. Participant 16 stated that one highly effective teacher from her PLC documented data both electronically and on paper. Participant 23 stated that he had also observed his highly effective colleagues who kept both a "written log" as well as the "online system" that was utilized by the school district. Participant 19 stated that she observed highly effective teachers using Google Docs to document important information. All seven participants agreed that highly effective veteran teachers kept both online and paper records of important data pertaining to their students.

In summary, there was significant convergence in the perceptions of the three groups (principals, highly effective veteran teachers, and teacher colleagues) about the characteristics of highly effective veteran teachers. These are based on the observations of the principals and the teacher colleagues of the highly effective veteran teachers and the experiences of the highly effective veteran teachers. The consensus was that effective teachers worked consistently to build strong, positive relationships with students which 
created an atmosphere of mutual respect and trust that facilitated free communication in the classroom, effective behavior management, and a culture that was conducive to learning (Darling-Hammond \& Baratz-Snowden, 2007).

Additionally, despite having a "treasure trove" of resources from teaching the classes from year to year, effective teachers spent considerable time planning in order to deliver relevant, rigorous instruction to their students (Goe et al., 2008; Kreig, 2006; Popp et al., 2011; Stronge, 2007).

References were made about summertime pre-planning, planning in informal groups and through the formal professional learning communities. The participants indicated that effective teachers were consistently spending 7 to 10 hours per week building on their previously successes while keeping the curriculum fresh and relevant. Effective teachers were also deemed to be collaborative and worked with their colleagues to gather new ideas and tactics for teaching. At the core of this process is personal and group reflection on how to become better at carrying out their instructional and professional responsibilities (Goe et al., 2008; Popp et al., 2011; Stronge, 2007).

Effective veteran teachers were also hailed as problem solvers and tended to have a positive outlook despite limited time and resources. Principals identified them as their partners in creating a positive school climate. They were amongst the first to help in problem-solving student behavior issues and are often observed interacting with students in the hallways providing coaching of different types. Although documenting student and parent interaction was an area for overall teacher development, effective teachers were more likely to be the ones who recorded their interaction with stakeholders. 
One divergent observation emerging from the data is that teacher-colleagues could not speak about the effectiveness of the instruction of the effective veteran teachers because they have had little opportunity to observe them teaching. This is mainly due to the fact that they are teaching at the same times. This presents an opportunity for ongoing professional development where less effective teachers may benefit from opportunities to observe the more effective veteran teachers during instructional time in their classrooms.

\section{Findings from Interviews in Response to Research Question 2}

Question two of this study is "In what ways are highly effective veteran teachers engaged in low-performing schools?" In this section, I present the findings from the three participant groups, namely principals, highly effective veteran teachers and teachercolleagues of the highly effective veteran teachers who participated in the study. Engagement is a psychological concept that incorporates enthusiasm, commitment, involvement, purpose, and passion that influence teachers' attitudes and behaviors (Macey \& Schneider, 2008). Erikson (2005) describes engagement as "the willingness to invest oneself and expend one's discretionary effort to help the employer succeed" (p.14). Christian et al. (2011) submit that engagement is employees "bringing their personal selves during work role performances, investing personal energy and experiencing emotional connection to their work" (p. 91). For the purpose of this study, teacher engagement is defined as an active, work-related positive psychological state operationalized by the intensity and direction of cognitive, emotional, and behavioral energy (Shuck et al., 2017; Shuck et al., 2016).

The findings that emerged from the interviews will be aligned with the engagement framework proffered by Macey and Schneider (2008). The researchers 
described engagement as a "disposition... an inclination or orientation to experience the world from a particular vantage point" (p. 5). They highlight the three facets of employee engagement in the framework namely, (a) Trait Engagement (mindset), (b) State Engagement (feelings/emotions), and (c) Behavioral Engagement (work attitude). Trait engagement and state engagement (energy, enthusiasm, perseverance, and effort) mediate behavior engagement (attitude, extra-role behavior).

Trait engagement is an employee's worldview or disposition. It is defined as a positive perspective on life and work. Employees with proactive personalities are resourceful and conscientious workers. Employees with autotelic personalities work for self-gratification rather than for incentives or rewards. The researchers propose that employees whose work experiences are positive and stimulating are more likely to put forth optimum effort to get the job done. They are also more likely to engage in the job and "go beyond what is necessary to initiate change to facilitate organizationally relevant outcomes" (Macey \& Schneider, 2008, p. 21).

State engagement may be described as one's job and work directly influencing one's pride in the occupation, the amount of energy, enthusiasm, perseverance, and the effort one exerts in doing the job. That is, work influences the level of job satisfaction, involvement, commitment, and feeling of empowerment for the employee. State engagement is an antecedent to behavioral engagement. This indicates that how a person feels about his or her job influences what he or she actually does in the job. Teachers who are behaviorally engaged identify with the job by being "focused, connected, and integrated" in the jobs (Macey \& Schneider, 2008, p.12). They use their skills, abilities, and available resources to get the job done (Kahn, 1992). Work conditions both directly 
and indirectly influence employees' feelings and attitudes towards their work. They have an "I feel, therefore I do" mindset (Macey \& Schneider, 2008, p. 5). Work conditions are identified as: nature of the tasks, how stimulating the tasks are, and the amount of autonomy afforded to get the tasks completed. Additionally, work indirectly influences or moderates the relationship between trait engagement (one's disposition) and state engagement —one's sense of pride and energy dedicated to the job.

\section{Trait Engagement}

\section{Findings from Interviews with Principal Participants}

The findings from this study suggested that highly effective veteran teachers were committed to continuing to teach in their current schools despite daily challenges. The participants believed that two main factors influenced the teacher's commitment to remain teaching in low-performing schools: (a) their commitment to their students; and (b) finding purpose and meaning in their jobs. According to Participant 4, "You know, [from] the classrooms you go into, [where the] kids are smiling, they're [the teachers] are smiling, there's laughter, there's a sense of joy." Participant 5 attributed the positive feelings to the fact that "there is a greater purpose...they [highly effective veteran teachers] have an end goal in mind." Participant 12 agreed: "I would say [they] find purpose in their work...It has meaning" Participant 7 pointed out that: "They see themselves as the school or part of the school...it is never about I do this to get paid...it is about the students."

Another participant submitted that highly effective teachers maintained their positivity because they are single-minded and focused on their students. Participant 9 concluded: "I don't think highly effective teachers...get distracted by the limited 
resources or things that are out of their control inside the schools or constraining events.

Another participant said, "They just focus on the task at hand...that task is student

learning [they] keep diligently working there...they rarely bring a negative air, a negative

mindset" (Participant 12). Participant 7 iterated "they are willing and they are

flexible...they're always positive." It is their "positive and can-do attitude...that

separates the really good teachers from the ones that are just not going to make it with the

kids" (Participant 9). Participant 11 also spoke about the positive nature of highly

effective veteran teachers: "All of these teachers are positive and they contribute...new

ideas, innovative ways of doing things." This participant continued: "Our highly

successful teachers...they create opportunities. They're highly successful because they

don't let those limitations get in the way..." Participant 4 explicated:

I think they are the ones that are the role-models, they are the leaders, they're the ones that are exemplars in a lot of ways. They're the ones willing to get dirty. They're the ones willing to stay after. They're the ones willing, if there's a new initiative, to implement it in their classroom, to test subjects. They're also willing to provide feedback. They're willing to stand up in faculty meetings and present, they're active on social media. I think they are, in a lot of ways, the face of the school.

Participant 9 concluded: "They truly love their kids. They truly love, care about, respect, see their job as a calling. They're passionate about their role as a teacher of at-risk... kids."

Participants agreed that the highly effective veteran teachers were committed to teaching in low-performing schools. Participant 5 referred to the teachers as:

Goal-setters...they understand that there is a path along the way to achieve that goal, so even if they haven't achieved it because of some setbacks, they still know what the end goal is and they work toward it... They have a plan. 
Participant 9 described the teachers as dedicated "they have a vested interest in what's going on in the school, more than teachers that are less effective." Participant 7 highlighted that it was love for their students and passion for their work that influenced highly effective teachers to remain teaching in low-performing schools such as his school:

The biggest thing is they [highly effective veteran teachers] have a passion and a love for their work... a lot of times people go into teaching because they love the subject matter, but [in] a school like ours [low-performing school] you have to love the kids. The "passion" and "love for the kids" influence the teachers' commitment to their jobs.

\section{Findings from Interviews with Highly Effective Veteran Teachers}

The findings from this study revealed that highly effective veteran teachers were dedicated teachers who are committed to their students' success. The participants are passionate about their jobs. Some of the participants opined that this was their purpose in life and they found deep meaning in teaching. Following are a some of the responses highly effective veteran teachers gave to the interview question: "Given your experiences, what is it about your job that allows you to persist in the teaching profession?"

Participant 3 spoke reflectively as she stated: "I feel like I could teach any subject if I knew it [the content] because I like connecting with kids and watching them...helping. [I like] helping them understand things at a new level.” The resolve was strong as Participant 8 stated: "I think everyone deserves the opportunity...you deserve to have access to whatever it is you want to have access to, and that's my job...to help give you that. It's hard, but that's it...they depend on you." Participant 10 explicated that teaching was a second career for her. After working in another job for number of years 
and having the opportunity to interact with interning teenagers she knew that teaching

was the job for her. She explained:

Teaching is a second career. I was supervising teenagers and I would supervise them in a way that it was like a classroom setting. I would teach them...I would nurture them and give them advice. So then, as they got older, grew up and came back they started to tell me what type of impact I had on their lives. So then, I realized that I was missing my calling. I truly believe that teaching is a calling. You've got to really want to do it in order to be effective at it. (Participant 10)

Participant 21 gave an emotional response:

I love it here. I know people think I'm crazy, but I do...The thing I kept telling people over and over again was, my babies, my kids at home, know that they're loved, and they get loved by everyone who talk to them all day long. But I come to work, and these poor kids don't know that. Sometimes you're the only person in the whole day that love them...It is a challenging group, but I love building relationships with [students].

Participant 15 pointed out:

I think with experience, you get better at it...It's a part of my life, that's what I would rather be doing...I miss my students, even the ones that I taught first year of teaching 2004. They have kids and stuff, they are married and they're all grown up, and they still remember something from the school and from my class. We laugh about it. Yes, the impact that I make is left somehow.

Participant 22 stated:

Teaching is a hard profession, no matter where you teach...But I've always been at low-performing schools...our kids are the same as others. They just need extra care. If you asked me if I would go to a high-performing school, my answer would be "no" because I love helping the kids with their challenges. I love celebrating the small successes. I love being here for the kids that need just someone to care about them and teach them. I've always wanted to work with atrisk children. It's something I've always wanted to do. Sometimes the days are hard [and they] kind of drains you, but in the end, I love going to my job...It kind of pushes me to be a better person for my kids and for my school.

The feedback from participants indicated that highly effective veteran teachers worked long hours and they felt obligated to complete their jobs to the best of their abilities. One participant commented: "I guess I really enjoy my work because I put a lot 
of work and effort into it" (Participant 10). In response to the question: "To what extent do you feel obligated to effectively complete your work assignment?" Participant 10 stated:

I feel totally obligated to do that [complete my work assignments] if I want to be effective in the classroom. Students know when you're genuine and when you're not, or when you're doing what you're supposed to do and when you're not [doing what you're supposed to do].

Further, the participants stated that their students were the most important part of their job and they did their best to ensure their students' success. Participant 13 described a situation when she went beyond her job responsibilities to assist one of her students whom she perceived was in danger of dropping out of school. This participant reported:

I had a kid a couple of years back. I knew something was up. Something was wrong, she just quit coming to school. She hadn't looked well. Something was wrong. So, I kind of dug deep, tried to figure out where she was. [I] emailed home...so I finally got to the bottom of it, the kid was addicted to meth. The mom had gotten her out of school for two weeks to help her detox...mom didn't want to say anything...I managed to get her back here. She is going to graduate this year. But that took a lot of me going, something's wrong... something is wrong.

Participant 10 stated that she thought her optimism contributed to the positive climate at her school. She said:

I think one of the things is my optimism, I'm always optimistic and upbeat and smiling and dancing. So, I think it's infectious. [People ask] "how do you stay that way?" and "How do you do this?" I think it's all in the attitude. That helps to contribute to the overall environment as well.

Participant 13 said that she did not allow circumstances that she could not control dictate her actions and feelings. This participant explained that she made every effort to help her students, however, she also recognized the constraints of her span of control.

You know, I see stuff, but if it's happening within these four walls [classroom] it's my problem. If it's happening in the hallway and common areas, I can't control that...I have to realize that there are problems in every school. The problems I can control, I'm going to worry about. The problems I can't control, I 
can't do anything about them...I'm going to take care of my hundred kids... That's how I'm getting through and not stressing over stuff I can't deal with, I can't control.

This mindset was corroborated in a statement made by principal Participant 9. As previously stated, each week (Participant 22) spends as much as 20 hours preparing instruction for her students. She admitted that teaching is hard and challenging. However, this participant was also involved in several extra-curricular activities. Participant 22 stated: "I'm a resource teacher. I am in charge of intervention studies for failing students, Saturday school, and I do the yearbook. I also do the comprehensive school survey." She continued: "It's why I always wanted to be a teacher because I feel I was put on this earth to help children."

\section{Findings from Interviews with Teacher-Colleagues of Highly Effective Veteran}

\section{Teachers}

Teacher-colleagues of highly effective veteran teachers submitted that highly effective veteran teachers were committed to teaching and committed to their students' success. Participant 23 stated:

I mean, those are the teachers that get there early to make sure that their lesson plans are ready to go... Despite all the obstacles that may come up, whether that's students getting pulled out of class to go to do testing, or students that are absent for a couple of days at a time because they get sick, it's always making and taking that extra step to reach those students and continue to push them to success.

Participant 17 highlighted that despite limited resources at his school, highly effective veteran teachers always did their best: "Regardless of time or instructional materials, they [the highly effective teachers] make the best of what they've got...despite being frustrated...all that of is insignificant in the light of a kid that has learned something..." Participant 14 concluded that highly effective veteran teacher at her school, were 
"realistically positive...they make a choice at the end of the day to kind of focus on the positive."

In conclusion the three participant groups converged in their agreement that highly effective veteran teachers showed evidence of trait engagement. The teachers seemingly found purpose and meaning in their jobs. All of the participants observed highly effective veteran teachers to be optimistic, and realistically positive. Highly effective veteran teachers were described as "single-minded" and "innovative." They view daily work issues as possibilities rather than limitations.

All of the participant groups also agreed that highly effective veteran teachers are "goal-setters." They have a vested interest in the schools where they teach, therefore they feel accountable for their students' success. Highly effective veteran teachers saw teaching as "a calling" and they are committed to teaching at-risk kids. Teaching is a job they feel they were born to do. Regardless of frustrations, all of the participants agreed that highly effective veteran teachers felt obligated to do a good job for the students.

\section{State Engagement}

The following section examined research question two: "In what ways are highly effective veteran teachers engaged in low-performing schools?" The following findings emerging from the responses from Principal participants were related to the theme "State Engagement." State Engagement focuses on the teacher's feelings and emotions pertaining to his or her job. Macey and Schneider's (2008) framework shows that one's job and work directly influence one's pride in the occupation, the amount of energy, enthusiasm, perseverance, and the effort one exerts in doing the job. That is, work 
influences the level of job satisfaction, involvement, commitment, and feeling of empowerment for the employee.

\section{Findings from Interviews with Principal Participants}

Based on the feedback from Principal participants the highly effective veteran teachers tended to exemplify the tenets of state engagement. One participant stated that highly effective teachers "found purpose" in teaching and were committed to their jobs (Participant 12). Participant 5 stated: "they're happy because they know there is greater purpose in what they do." Participant 11 agreed:

I would say that our teachers enjoy their jobs. They definitely recognize the challenges, and they feel the stress and urgency of working in a low performing school, but they enjoy working with their teammates. They enjoy working with children.

The participants also concurred that some degree of job satisfaction emerged from the positive relationships that existed between administration and highly effective veteran teachers. The teachers were appreciative of leadership support. Participant 12 commented: "school administration like the highly effective teachers." According to Participant 4:

They [highly effective veteran teachers] are usually very positive. If anything, they [highly effective veteran teachers] get frustrated with us because we can't give them more feedback fast enough...They want us in their rooms more...But the good thing is that they will tell me.

Participant 5 concluded:

I think that sometimes they're [highly effective veteran teachers] kind of the gauge to how the rest of the faculty might take something. I think you have to have positive relationships with your best teachers in the building to retain them...Y You are more apt to listen and work with them when that have concerns as well because you know they are genuine in what they're doing and working hard to implement what you've asked. 
Another participant described the relationship between administration and highly effective veteran teachers as: "collegial, cooperative, positive, trusting, and I think I give them ... a lot of autonomy, a lot of freedom to do what they need to do, because they produce results" (Participant 9). Participant 4 appreciated the fact that highly effective veteran teachers were transparent about their feelings towards administrators. This participant stated: “as far as I know, they're not secretly gathered up in the parking lot bashing school admin, but they're in my office saying...we've got to do something about this."

Findings also revealed collegiality amongst highly effective veteran teachers and their peers brought a degree of job satisfaction. Participant 9 observed that relationships between highly effective veteran teachers and their peers were "mutually respectful." However, the participant also noted that highly effective veteran teachers in her school generally associated with a core group of teachers with similar mindsets. Participant 9 stated: "I have a core group of teachers that are good teachers. It seems that the core group feed off each other, and spends time together, and collaborates within and out of school." She continued:

I just believe that birds of a feather hang together...So, if you're effective and you're doing what you need to do, those people hang together... and those people that aren't as effective....may not be a part of that.

Participant 9 emphasized: "I think that the involvement, the caring, and the relationshipbuilding within the adults carry over to the building of relationships with the kids."

Conversely, some participants admitted that although mutual respect and collegiality existed between most teachers, some teachers who were not classified as highly effective may harbor bad feelings against teachers classified as highly effective. 
Participant 5 proposed: "they have positive relationships with their peers. I think that sometimes their peers can be jealous of them." Participant 12 echoed a similar view, he stated: "I'd say the majority [of relationships] are positive, but highly effective teachers that work hard can sometimes rub their peers in the wrong way too. Those other people can feel like they're being shown up." Participant 11 was the only participant whose perception differed. This participant described her school as "a very strong community." This participant explained:

We operate as a family, we have joint ownership of our school and of our students, and they're our students. So, I think something that's unique about this school and our most highly effective teachers [is that] we see ourselves as public servants. We're here to serve kids and that's what we do.

\section{School Safety}

Kahn (1990) determined that varying degrees of a worker's physical, cognitive, and emotional selves were present at particular times when they performed work roles. Further, levels of engagement varied based on workers' perceptions of meaningfulness, safety, and availability of resources. Participant 11 asserted that there were no safety concerns amongst her highly effective veteran teachers. This was because of the level of trust that existed between the school administrators and the teachers. Participant 11 remarked: "I would say that none of those teachers have safety concerns...they trust in our administration and our security measures to get things handled safely." Participant 4 stated that the highly effective veteran teachers in her school feel that:

Safety is very important. They don't make a huge deal out of normal, average things. They'll report safety concerns...they feel ownership in the school, and they expect that administrators are going to do their job, and trust that they will. 


\section{Concerns about Limited Time and Resources}

All of the participants agreed that limited resources and time, were barriers to total job satisfaction for highly effective veteran teachers. With regard to limited resources, some principals clarified that because the schools were low-performing schools they had access to resources from the school district. However, despite availability of resources, highly effective veteran teachers simply spend personal funds buying what they needed for their students. Participant 4 commented they "just get what they need... whatever it is." She explained: "The most important things to really effective teachers...is teaching and the kids, so the teacher's chair may be falling apart, but they hardly sit in it, so what do they care?"

Time on the other hand, was always limited. The effective veteran teachers did not like to engage in activities that distracted them from teaching activities. To resolve the concerns about limited time, some principals changed their schools' schedules to accommodate a seven-period day instead of a standard six-period day. A seven-period day schedule allowed teachers to teach for five periods, the other two periods were for planning student instruction. One planning period was contractual based on teachers' contracts, and the second planning was used for working with PLCs and attending inhouse professional development or embedded professional development (PD).

\section{Findings from Interviews with Highly Effective Veteran Teachers}

According to Bass and Riggio (2006) and Rao (2014) transformational leaders are visionaries who inspire their supports to extraordinary levels of performance. Thus, teachers are more likely to go above and beyond what is needed to complete the job. In this section, I discussed highly effective veteran teachers' perceptions of their 
engagement (State Engagement) relative to the schools' climate and leadership in their schools. This section also examined highly effective veteran the teachers' perceptions of challenges associated with teaching in low-performing schools.

\section{School Safety}

Highly effective veteran teachers explained that they worked in challenging conditions where fights and conflict were common occurrences. Yet, in concert with principals' perceptions, most of the teachers stated that they felt relatively safe working in their schools. They opined that their schools had specific protocols in place to deal with unsafe situations. Also, they trusted the administrators at their schools to handle any conflicts effectively. Participant 3 explained:

I don't have a lot of safety concerns because I know the administrators and security team are always where they're supposed to be at all times. Students moving through the hallway and the lunchroom...the door is closely monitored. We have teachers in place and it's a very simple process...Morning and afternoon assignments and the expectations are that everyone is in the hallway looking and watching and paying attention... When class starts, the expectation is that doors are closed and locked, so we don't have to really ever worry...All the safety lockdown procedures are clearly stated. We know exactly what to listen for and what to do and how to act.

Participant 3 continued: "I feel like anytime I have seen or hear a fight in the hallway...there was an adult nearby with a plan in place...I feel like the process for meeting with the disciplinary team is effective." Participant 15 also agreed that the leadership at her school encouraged a feeling of security. This participant commented:

I think a good aspect of our school, if we see a problem and we address it, we try to address and fix it. That's a good thing that and usually brings positive change. The leadership changed, and I feel better with that positive change that the leadership brought...I think it's a pretty safe place.

Most of the participants opined that they worked in a positive school climate and that they looked forward to coming to work every day. Participant 3 described the climate 
at her school as “...good, it's safe, everybody communicates well. Lots of people come to work with a smile on their face." Participant 21 echoed similar sentiments. Participant 10 reflected on her previous full-time job at a local agency:

I have given up my position as a customer service manager. I would pull into the parking lot and cry before I had to go in there, that's how much I didn't want to go there. [Now], I look forward to seeing the students...I'm there for them and they know that. (Participant 10)

\section{Trust in Administrators Lead to Sense of Security}

Most of the participants shared that they liked and trusted their administrators. The majority of the participants felt that their principals did their best to support them. Participants also reported that they felt their leaders gave them opportunities to voice their opinions. Participant 21 reminisced about her previous principal. This principal had been promoted to a different job in the previous year. This participant stated: "I loved my administration. I worked for a [previous principal] up until last year. He was phenomenal, a great leader, an innovator. I feel like [my school] is always trying something new." She commented about her current principal: "I love the leadership. I've always been happy with the support given us, the feedback given" (Participant 21). At the same time, this participant expressed the hope that the school would continue to grow under the new principal. She explained that "part of what makes it appealing to stay here [at her current school] is people have always been supportive of one another and excited about new programs" (Participant 21). Participant 13 highlighted the leadership at her school as being supportive, and genuinely caring of staff and faculty. This participant identified leadership as one of the factors that influenced her to remain at her current school. She reported as follows: 
The big thing is the administration...they listen. They are not a "give us your opinion and we don't care," I mean, at faculty meetings she [the principal] has the plus Delta chart up. We're encouraged to put sticky notes on a parking lot. She will email us with all the parking lot questions and answer all of them in an email. I mean, she's very open with communication. I know people say, "I have an opendoor communication." No, she's legit...she's not in her office anyway. But if you talk to her, email her, I mean, she really creates that climate in the staff.

The participants seemed appreciative that the administrators at their respective schools scheduled time for them to work with their PLC teams. This level of support for this item is essential because it provides the opportunity for collaboration. The participants opined that working in PLC teams facilitated their effectiveness as teachers as they planned and worked together. As a team, the teachers were able to analyze their students' performance data, discussion of successful teaching strategies, and create new ways of presenting content material.

Some participants shared that they appreciated critical feedback from their peers after peer observations. Participant 21 identified someone in her PLC who also taught Science. She explained: "It's a great partnership. We complement each other well. It worked really well for us to be able to talk about what he does in class and what I do in class, and what we can incorporate to help us become better teachers. I think PLC has definitely been one of the best things." Participant 13 also stated that working with her PLC help her to be a more effective teacher of Mathematics.

\section{Concerns about Limited Time and Resources}

Despite schedule changes at some schools to accommodate more time for teacher preparation, some of the participants identified lack of time to complete tasks was in large part due to excessive state and district regulations that result in preparation in paper work as a common challenge. This finding is consistent with what principals observed 
about the teacher's concerns about activities that infringed on their instructional time.

Participant 10 opined:

I think what's challenging about it is the fact that there's so many constraints coming from district and central office that they don't allow us to teach... They put so many rules and regulations on what you do... So that's often a challenge to me because it's very time-consuming. It always seems to be too much paperwork. I understand for accountability's sake you have to do evaluations, but it seems like every time you turn around there's something they want you to turn in. I wish I had less administrative type forms to do.

Participant 8 agreed with Participant 10:

I push back against what I view to be needless paperwork. I get that I'm not an administrator, and I'm sure there are reasons that we do things we do, but sometimes I'm happy to question these reasons... The amount of work I have to do to be good at what I do...it's too much, it's overwhelming. (Participant 8)

\section{Findings from Interviews with Teacher-Colleagues of Highly Effective Veteran}

\section{Teachers}

In this section I examined the participants' perceptions of their highly effective veteran teacher's job engagement. I also discussed findings related to school safety and school leadership. The majority of the participants in their responses indicated that they observed that highly effective colleagues appeared to be satisfied with teaching in lowperforming schools despite the challenging work conditions. Participant 2 stated: "I think they [highly effective veteran teachers] enjoy their jobs. They look like they're happy. They're smiling...I don't see them complaining or I don't hear them grumping or fussing about anything. Also, I see their class climate that it seems very positive. The kids work for them." Participant 17 commented: "They enjoy it or they wouldn't be here anymore." However, this participant added that he believed that the highly effective veteran teachers were frustrated at times. He referred to Participant 10 and he noted: 
Even the positive teacher that I mentioned earlier, she has some kids who are really tough that make her despise her job sometimes. Then again, it's the kids that come back to her and thank her for these things. You can tell, no matter what's happened that day that one little comment has brought her cheer back up to "disgusting" levels. She's ready to go on to the next kid and see how she can help them. (Participant 17)

Participant 23 noted that Participant 3 and other highly effective veteran teachers at his school were "approachable." He believed they "really have a passion for teaching, in that they are there because they want to make the students better and they want to help them succeed." This participant further clarified:

I mean, going to work, it's not necessarily work because it's something they enjoy doing...I always believe it's ingrained in your system...that's what you want to do and that's what you're going to do...You're going there to do what you love to do. And that's definitely is existing in these high-quality teachers. (Participant 23)

All of the participants agreed that highly effective veteran teachers contributed positively to the school climate, particularly in the area of school safety. Participant 16 opined that the problem was that "a lot of teachers are reactionary like, will escalate any kind of behavioral thing. Whereas most effective teachers can kind of cut those problems off before they're problems." In contrast, the positive attitudes exhibited by highly effective veteran teachers brought a sense of calm and peace in the midst of chaotic situations (Participant 23). Another participant compared the attitude of a highly effective teacher and how she dealt with "two boys brawling" when compared to the attitude of "the less effective teacher" (Participant 16). This participant stated:

It's making sure that other students do not become involved and maintaining that level of safety...it's just making sure that the teachers know the proper procedure what to do in case that [a fight] happens. I guess the less effective teacher would just ignore it, stand around, and shut their door.

Participant 6 observed that the effective teachers were prepared by doing the drills and becoming acquainted with relevant safety measures. Some participants also pointed 
out that highly effective teachers were not only calm, they were also "commanding, and that they direct students not involved away from conflict...they know how to tell them to, or they know where to tell them to go... They would [also] contact security and administrators" (Participant 14). This participant also highlighted that highly effective teachers were “in the hallways or constantly monitoring. They're not sitting back but they're interacting with students pretty much constantly."

In summary, there was consensus between the principal participants, highly effective veteran teacher and the teacher colleagues regarding the themes that align with Macey and Schneider's State Engagement. Principal participants and teacher-colleagues shared their observations and perceptions of the highly effective veteran teachers in relation to State Engagement. They indicated that highly effective veteran teachers always seemed positive and satisfied with their jobs. The teachers tended to remained calm, having a commanding presence in the midst of chaotic school situations.

The teacher-colleague participants observed highly veteran teachers to be knowledgeable about safety procedures and this brought a sense of reassurance that there was no situation that arose that they could not adequately address. They were observed redirecting students away from conflict. Highly effective veteran teachers were energetic and constantly monitoring student activities in their current schools. The participants also agree that the infringement on their time was one of the major pet-peeves amongst the effective veteran teachers who preferred to be engaged in instruction related activities. Nevertheless, they were openly supportive of the administration on which they depended to help create a safe and positive work climate. 


\section{Behavioral Engagement}

\section{Findings from Interviews with Principal Participants}

This section examines behavioral engagement. According to Macey and Schneider (2008) behavioral engagement is one's work attitude. The work attitude is influenced by one's mindset (Trait Engagement) and feelings (State Engagement) towards the job. The framework also supports the position that effective leadership is critical in creating work conditions that promote teacher engagement. In this section, I will examine evidence of behavioral engagement based on the perceptions of the principals group, highly effective veteran teachers group, and teacher-colleagues of highly effective veteran group as they relate to research question two: "How are highly effective veteran teachers engaged in low-performing schools?" The themes emerging from the findings are: Involvement in School Activities and Creating a Positive Classroom Environment.

\section{Involvement in School Activities}

Shuck et al. (2017) emphasized how individuals perceived their work environment and the culture of their work environment influenced the amount of time and effort they put in their work. Rich et al. (2010) pointed out that engaged employees were willing to invest energy and time doing completing assigned work roles and making discretionary effort in their jobs. The finding in this study suggested that highly effective veteran teachers made discretionary efforts that improved student learning. The teachers were also more likely to be committed to helping the school in any capacity when compared to teachers who were not as effective. One participant stated:

I think that their dedication and their involvement within the school community is usually a lot more than the teachers that are not effective... with the students. They 
may be involved in coaching, or some type of after-school activity, or something that benefit the student... They're a jack of all trades and will do anything you asks them to do for the benefit of the kids. (Participant 9)

Another participant agreed that highly effective teachers were involved in multiple activities that strengthen their relationships with their students.

All of our teachers are involved in different student activities. They don't all coach teams or anything like that. But they do get involved with different clubs and organizations with kids... Our most successful teachers have relationships with kids that bring them to kid events, like band concerts...they stay involved even if they're not coaches, or directors, or leaders. (Participant 11)

Participant 5 commented that "they have a leadership role in some capacity." Participant

4 agreed with this comment. This participant added:

They may not be a coach or a sponsor, they may not be an ongoing member of a committee... but they will say I see a need for this or so here's what I'd like to do, what do you think about this?...It may be a short-term thing or it may be a longterm thing...there's this sense of like they don't mind and they look for ways to be involved. They don't see that as extra. It's getting to know the kids, it's helping the school, it's part of being professional in their minds.

Participant 9 concluded "they're always those teachers that [say] whatever it takes to get the job done, whatever you need me to do, if it's going to benefit the students then I want to be part of it."

\section{Creating a Positive Classroom Environment}

It is interesting to note that participants' unanimous response to the question: "What is your perception of how highly effective veteran teachers exemplify creating a positive classroom environment and communication expectations to students?" The findings indicated that building effective relationships with students was key to a high level of behavior engagement amongst highly effective veteran teachers. In communicating her perception of how highly effective veteran teachers managed student behavior, Participant 4 stated: 
A lot of times they [highly effective veteran teachers] can get them [students] back on track with a redirect or a prompt or, "Hey, we talked about this yesterday, and "I know you can do this"... Or it's a hallway conference. I'll walk in the hallway and some of my most effective teachers are having those hallway conferences like a mama would. They can connect to the kid and you can tell there's relationship there. A lot of times the kid will apologize and go back to the classroom...I think that I see them build community, clear, positive expectations and lots of opportunities to keep the kid in class. (Participant 4)

Participant 5 commented: “They're [highly effective veteran teachers] also effective classroom managers, which I think comes along with those relationships that they have with students... in the end I really think that that's what makes a highly effective teacher." According to Participant 9: "My effective teachers...their goal is to build relationships, and to build respect with the student... work to build relationships before they start having the high expectations...talking to with the kids, talking with the parents."

\section{Findings from Interviews with Highly Effective Veteran Teachers}

In this section I examined evidence of behavioral engagement based on the perceptions of highly effective veteran teacher participants. The participants showed evidence of behavioral engagement. Macey and Schneider (2008) explicated behavioral engagement explicated as the teachers' attitude to teaching and on-the-job discretionary efforts. This section is divided into two themes: Involvement in School Activities and Creating a Positive Classroom Environment.

\section{Involvement in School Activities}

Highly effective veteran teachers concurred that they tended to be involved in discretionary school activities. The teachers felt that involvement at this level facilitated them becoming more effective teachers. Macey and Schneider (2008) also highlighted discretionary effort as a characteristic of behavior engagement. Most of the participants 
in this study indicated they are or had been involved in some after-school activity.

However, despite their desire to be involved, some participants indicated that they each had small children which negatively impacted the time they might dedicate to participating in extra-curricular activities at schools.

Of the seven participants, one participant was a member of the school's council. She also regularly attended and presented at various professional development workshops, both locally and nationally. She felt that workshops of this type helped her to become a more effective teacher. This participant also described her participation in intervention for students in her school who were struggling academically. Participant 10 enthusiastically explained:

We have an academic enrichment session on certain days of the week. We have an hour for lunch... and kids have the ability to go to a teacher and make up any work...we call it an office hour...we have our door open for students. And then my door is closed and I should only have those ten students for the first half hour. The other half of the hour is our lunch. But I have my door open the whole time so that I have students, my room's like a revolving door...I have students constantly coming in there. Students I've had before bring their friends with them and so a lot of times I'm in conversations with them.

Participant 15 highlighted that as an ESL teacher, her focus was to bring a global awareness to her school. This participant stated: “I'm trying to focus on the global education and share what I know with other teachers." Participant 3 stated that she was involved in the Music Honors Society at her school, the school district music planning committee, and "a number of musical planning committees" because of her experience in this area. Participant 22 was also involved in a number of committees at her school.

\section{Creating a Positive Classroom Environment}

Evidence of behavioral engagement was apparent in highly effective veteran teacher participants' efforts to build relationships with their students. The participants 
made considerable effort to develop positive relationships with their students. The teachers explained that spending so much time on demonstrating their genuine concern for their students' well-being helped to alleviate some behavior problems that students are likely to exhibit. Participant 10 emphasized that she outlined and reiterated her "rituals and routines" from the beginning of the school year. She stated:

We have to practice it and it takes a while for them to get what I mean. I'm like a mother, a grandmother to them. I do not tolerate the talk-back, the way they talk...those types of things...I think a big thing is building a rapport with the students because once you build that relationship with them and they feel like you're disappointed with what they're doing then usually, just like a mother, I give them that look and "I'm sorry." They'll straighten up.

Participant 3 stated that she always spent time providing students with justifications that show the importance of having and following guidelines, routines, and procedures. She believes that if students understand the reasoning underpinning certain rules and regulations they would be more likely to follow the rules. They would also be more receptive to consequences for failure to comply. Participant 3 stated:

I think reminding students of those expectations regularly and again explaining if something goes wrong, what happened, and why it would be best if we could stick to the rules and expectations of the class. I don't like it when rules don't make sense...It's things that I believe in and I can back up not just having rules for no reasons.

Participant 21 explain how she builds relationships with her students by giving them "good news postcards."

If they do something exceptional or they've shown great improvement, I write them a postcard that they can take home and show their parents... [I try]to use as much positive reinforcement as I can, so that they know that when I'm hard on them it's because I care about them and I want them to do well. 


\section{Findings from Interviews with Teacher-Colleagues of Highly Effective Veteran}

\section{Teachers}

The following are the major themes emerging from the data collected from the teacher-colleagues of the highly effective veteran teachers. Verbatim statements are also included as examples of comments that participants made in response to the interview questions.

\section{Involvement in School}

Fifty percent of the teacher-colleague participants shared information about their highly effective veteran teacher colleagues' involvement in school activities. Participant 23 expressed that the highly effective veteran teachers from his school such as Participant 3 were "very proactive":

They attend a lot of events that the school hosts. They get involved...they are either showing up at meetings or they're giving their ideas or their responses to somebody who is going to those meetings. They definitely are thinking about it. Thinking about those important things that make up a school besides just going there for the school day. (Participant 23)

Participant 14 also identified highly effective veteran teachers who were involved in extra school events. This participant highlighted her colleagues who were either "sponsoring, chaperoning, or are showing up to events that their scholars are participating in. Or they are providing extra help after school as tutors." Participant 17 also highlighted some of his highly effective colleagues who were involved in school activities. He identified one teacher in particular who was "in every kind of organization [involving] teachers, students, and parents that you could name." This participant emphasized that school involvement was "another good way that we get to know them [the students] and build those relationships." 


\section{Creating a Positive Classroom Environment}

Teacher-colleagues of highly effective veteran teachers responded that highly effective veteran teachers worked on developing positive relationships with their students in response to the question: "What is your perception of how highly effective veteran teachers exemplify creating a positive classroom environment and communicating expectations to students?" This finding is consistent with the feedback from the principal participants and the teacher-colleagues who were interviewed in the triangulation data collection process. Participant 14 explained that highly effective veteran teachers spent time "making expectations clear and consistent...keeping them [students] interested throughout the school year...being visibly there." Participant 23 opined that highly effective veteran teachers:

Always try and relate to the students on a level that is respectful for both student and teacher... building that positive relationship to where the students feel safe to ask questions when they don't understand something and they're not going to be worried that the teacher may be upset or angry with them because they've asked a question... [creating] a very positive, open environment to learn and teach.

Participant 16 stated that highly effective veteran teachers have "established routines...legitimate routines...[they are] proactive about their behaviors, like noticing if something's wrong than being reactive."

In conclusion, the findings indicated that most the participants observed evidence of behavioral engagement in highly effective veteran teachers. The teachers exerted discretionary effort in activities related to student learning. Highly effective veteran teachers sponsored after-school activities or participated as chaperones for after-school activities. They also collaborated with students outside of normal school hours. Highly 
effective veteran teachers deemed their involvement to be critical to them becoming more effective teachers.

The highly effective veteran teachers also spent time carefully developing and reinforcing classroom behavior protocols. They also thought that it was necessary to explain the importance of having classroom and school regulations. Highly effective veteran teachers also spent time creating rewards for their students. These incentives were intended to motivate students and to help them to perform at higher levels.

Moreover, the teachers were consistent in conveying the same expectations and routines throughout the school year. Highly effective veteran teachers worked to ensure safe comfortable classrooms where students performed to their optimum levels. The veteran teachers were also proactive rather than reactive. Highly effective veteran teachers were noticeably always present at school and their classrooms were comfortable where students felt free to express their true selves.

Macey and Schneider (2008) explicated engagement as a psychological concept that incorporates enthusiasm, commitment, involvement, purpose, and passion that influence teachers' attitudes and behaviors (Macey \& Schneider, 2008). Shuck et al. (2017) and Shuck et al. (2016) defined engagement as an active work-related positive psychological state operationalized by the intensity and direction of cognitive, emotional, and behavioral energy. Macey and Schneider's (2008) engagement framework shows three tenets of engagement; Trait (mindset), State (emotions/feelings), and Behavioral Engagement (attitude and discretionary effort). The framework shows that Trait Engagement influenced State Engagement. Trait and State Engagement mediate Behavioral Engagement. 
Highly effective veteran teachers in this study show evidence of high levels of Trait Engagement, State Engagement, and Behavioral Engagement. Due to Trait Engagement, highly effective veteran teachers who remain teaching in low-performing schools have positive dispositions despite the challenging nature of their jobs. Though frustration is commonplace, the highly effective veteran teachers are typically energized, enthusiastic, and committed to their jobs and their students (State Engagement). Leadership support is important in creating a positive and safe work environment in which the teachers can operate. Trait and State engagement mediate behavioral engagement where teachers are willing to exercise discretionary effort. Highly effective veteran teachers are welcoming of opportunities to engage in activities outside of their normal routines that enhance their students' learning.

\section{Findings from Interviews in Response to Research Question 3}

This is the third of three research questions framing the study that is focused on explicating the factors that influence highly effective veteran teachers to remain teaching in low-performing schools. Question one focused on the characteristics of highly effective veteran teachers. The second question focused on the ways in which teachers are engaged in low performing schools. This third question builds on the previous two questions by seeking to understand how the highly effective veteran teachers' engagement influences their decisions to remain in low-performing schools. This final question is targeted at the highly effective veteran teachers only and does not explicate any other view. The research question reads as follows: "How do highly effective veteran teachers see their engagement as contributing to their commitment to remain teaching in low-performing schools?" 


\section{Findings from Interviews with Highly Effective Veteran Teachers}

This section examined highly effective veteran teachers' perceptions of the engagement factors that influence them to remain teaching in low-performing schools. It focuses on perceptions of highly effective veteran teachers only. The themes emerging from the interviews were: School Climate and Relationships with Administration. This section is followed by a summary of the findings in Chapter 4.

\section{School Climate}

In recent literature, teacher engagement was defined as an active, work-related positive psychological state operationalized by the intensity and direction of cognitive, emotional, and behavioral energy (Shuck et al., 2017; Shuck et al., 2016). Kahn (1990) proposed that teachers are willing to invest their physical, cognitive, and emotional selves in their jobs when the work is meaningful, in a safe environment, with resources readily available to do the job. First, I asked highly effective veteran teachers to describe their school climate in order to create a context for the school environment in which the teachers taught. School climate are school-level characteristics such as leadership, peer collaboration, and school size; classroom level characteristics such as student behavior, ethnicity, and classroom size; teacher -level characteristics such as age, gender, and ethnicity (Wang \& Degol, 2016).

In providing a description of their schools' climates, the majority of the participants agreed that there were positive and negative factors that may be used to describe the schools' climates. Participants 21 and 15 described their schools' climates as being positive. Participant 21 compared the school's climate nine years ago when she began working at her current school to the current school climate. She stated: 
When I started working here, I think that staff morale was pretty low...I think that in the nine years of being here, the administration and the staff worked hard to make it a positive place and make the students understand that their education matter. I think that you can feel that even just in the hallways...[now] we're always on the cutting edge of [our school district] in terms of what programs we try, what initiatives we implement. It's been neat to be a part of something where we're willing to try new things and willing to challenge ideas, to move outside the box, to move our students.

Both participants 10 and 15 agreed with the above submission from Participant 21.

Participant 15 added: "For the most part, it's a positive climate. It's focused on academics, it's focused on sports. It's focused on getting kids involved and engaged in the school life. It's supportive." Participant 3 described the climate at her schools as "good, it's safe, everybody communicates well. Lots of people come to work with smiles on their faces." This participant also boasted that her school had been commended by the school district at the start of the school year for having a high teacher attendance rate. Participant 13 referred to her school's climate as: “very warm, inviting, [people] can feel it when they walk in the building." Conversely, Participant 22 explained that the climate at her school "really needs work... We have some teachers that don't necessarily get along. They're very frustrated. We've had a lot of changes this year, and the teachers feel like there's a lot in their plate."

When highly effective veteran teachers were asked about the aspects of the school climate that influenced their willingness to remain or leave at their current schools, the majority of the participants pointed to collegiality with their peers as a significant factor in influencing them to remain at their schools. Participant 21 replied: "I love the staff I work with!” Participant 15 stated: "I think the care of most people...I think that it's a good aspect of our school." Response from Participant 3 was in alignment with the 
response from Participant 15. Participant 3 also indicated that working with people who share similar ideals also encouraged her to remain teaching at her current school:

I think that the support amongst teachers... and everybody doing the same thing I do...I don't hear anything this year like I've heard in the past about "well, so-andso lets me use my phone," or she lets me get away with it. People are not getting away with sleeping and head phones and the phones. They're just not, and all of the teachers are onboard. It's good.

Participant 10 commented: "Well, I think the fact that there is comradery, there is that family-like atmosphere, because we've seen how they pulled together when people had been in crisis... and how colleagues have helped one another." The majority of the participants stated that there was nothing in their current school climate that would cause them to consider leaving their current schools.

The influence of peers continued to be a major factor in highly effective veteran teachers remaining in schools. Participant 21 stated that her peers "respect her as a teacher...they're my best friends." Participant 3 said:

I think I enjoy working with my department. They share similar philosophies with me. I appreciate that they recognize these kids need more than just a traditional academic environment... They go beyond and when I need help they're there to help me... So I like that relationship inside and outside of school.

Conversely, while the majority of the participants were complimentary of their peers, Participant 22 explained that the major factor influencing her to stay was wanting to see the kids in the school become successful. She stated:

There are certain relationships with my peers that are not exactly the positive kind. I try not to let it bother me, but sometimes it does. Would I ever leave because of it? No, because in the end, I'm not here to be friends with my peers. I'm there because I need to make sure those kids are successful.

Participant 8 shared a similar sentiment as Participant 22. Following is what she said about her relationship with her peers: 
I'm pretty sure some of the staff think I'm awful and hate me. I'm pretty passionate, and these are my kids, and so you better be doing right by my kids, or I will have something to say about it...the capacity for teaching here is not super high... and that bothers me for our kids... all kids deserve amazing teachers.

Participant 3 pointed to lack of consistency in implementing school protocols and Participant 21 pointed to changes in leadership or the schools' structure as school climate conditions that may influence them leaving their current schools, and to school location (distance from the participant's residence).

\section{Relationships with the Schools' Administration}

When asked to describe their relationship with school administration and the extent to which these relationships influenced their decisions to remain at the current schools, the majority of the highly effective veteran teacher participants indicated that they had good relationships with the administrators at their schools. However, not all participants were satisfied with the relationships between teachers and administrators.

The following comments highlight the positive relations with administrators. Participant 10 stated: "I think the fact that administration is, number one, willing to listen to us, number two, that they are consistent, and number three that they are available. So, I can go to any of them with a problem whenever... and I can't say it's just me.” Participant 3 stated regarding the school's administration: “They're ...personable people...they're open-minded. They're willing to try new things." Participant 21 said: "I love the leadership. I've been always happy with the support given us, the feedback given." This participant said there is no aspect of the school climate that cause her to consider leaving at this time.

The following feedback highlighted some of the challenges between the schools' administration and the highly effective veteran teachers. The feedback points to factors 
other than leadership that influence them to remain at their low-performing schools. It is their desire to see students succeed that is the main reason. In response to the interview question about leadership relations, Participant 22 opined:

The relationship with my administration, and not just me but for some of my peers...they're very frustrated with some of the administration. They feel like our voices aren't heard. They feel like the way...they're spoken to is not necessarily positive. It makes them very anxious to come to work and kind of walking on eggshells...it's just certain administrators. There have been a couple instances where I'm like. "Hmm," the way I was talked to..."Maybe I do need to transfer or something." But in the end...I'm here for my kids. I made a promise to myself, this is what I'm going to do so therefore I do what I can to try to make sure I try to stay positive and remember what I'm here for.

All of the participants indicated that they continued teaching at their current schools for their students. Participant 15 said: "I think they respect me and they respect the knowledge that I have. They view me, maybe like a role model in some aspects. I wouldn't want to change my school because I have good relationships with the kids." Participant 8 conceded: "That's it, that's the only reason I'm here. That's literally the reason I came back this year, is for my kids. Because I thought about leaving, but I love these kids." Participant 3 said:

I feel like my students really do [influence my decision to remain] they're motivated by what goes on in our classroom. I feel like they want to be successful, they want to sound good. They want to learn new things to the extent that they can...I feel like I inspire them to do more and do better. Not just in my class but in school and in life.

Participant 22 reiterated:

I enjoy being with my kids...the kids are what bring me to my job. Would they make me transfer? Absolutely not! Because I know the kids at that school, they need me, and they need other adults. They need stability. That's one thing that is not very present at our school.

Each highly effective veteran teacher participant highlighted one thing that they would like to change about their jobs if they could. The list is as follows: (a) less paper 
work and less truancy (Participant 13); (b) more parental support (Participant 13); (c) stable faculty and consistency in the school from year to year (Participants $22 \& 3$ ); (d) more of a focus on language development amongst ELL speakers and less on the age and grade levels of the students; (Participant 15); (e) smaller classes and more time to teach and do teachers duties. The majority of the participants indicated that they were not considering leaving their schools over the next two or three years.

In summary, this section examined the third research question: "How do highly effective veteran teachers perceive their engagement as contributing to their commitment to remain teaching in low-performing schools." The participants agreed that the school climate at their respective school was influenced by both positive and negative factors. The participants identified innovative leadership, strong peer relationships, and a high degree of communication amongst faculty staff and administration as positive influencers of the school climate. Conversely, frustration with school conditions and lack of unity were highlighted as negative influencers in some schools. Although the majority of the highly effective veteran teacher participants agreed that they had positive relationships with the administrators at their schools, the participants highlighted collegiality as an important factor that influenced their commitment to remain teaching in their current schools. Overwhelmingly, the participants focused on the relationships with students and wanting to see them succeed.

All of the participants indicated that wanting to see their students succeed and this appeared to be the strongest influence on their commitment to remain teaching. This is evidence of intrinsic motivation. Findings from previous studies indicate that teachers remain teaching in low-performing schools due to their satisfaction with their job role 
and the positive influence they felt they had on children's lives (Ashiedu \& Scott-Ladd, 2012; Perrachione et al., 2008; Petty et al., 2011). However, the overarching engagement factor is "Trait Engagement" where the teachers are influenced by the sense of accomplishment and meaning that comes from their work. The teacher perspectives align with the definition of Trait engagement as posited by Macey and Schneider (2008). They stated that Trait engagement is an employee's worldview or disposition. It is defined as a positive perspective on life and work. The researchers propose that employees whose work experiences are positive and stimulating are more likely to put forth optimum effort to get the job done. They are also more likely to engage in the job and "go beyond what is necessary to initiate change to facilitate organizationally relevant outcomes" (Macey \& Schneider, 2008, p. 21).

Most of the highly effective veteran teachers were not considering leaving over the next two or three years. However, the teachers highlighted some things they would change about their jobs if they had the power. These factors were: paperwork, truancy, more parental support, a more stable staff and consistency in the school structure and protocol, focus on language development amongst ELL students rather than focusing on the grade level, smaller classes, and more time for instruction and other teacher duties.

\section{Chapter Summary}

In conclusion, this chapter examined the three research questions. The findings from research question one: "What are the characteristics of highly effective veteran teachers who remain teaching in low-performing schools?" revealed that the factor underpinning the effectiveness of these teachers in building relationships with their students. Building strong, positive relationships with students facilitate the creation of a 
positive learning environment. Highly effective veteran teachers establish and consistently reinforce high expectations, clear norms, routines, and procedures. They spend significant time planning for authentic, rigorous classroom structuration that is differentiated to cater to a diverse student population. The findings of this research suggest that teacher quality increases with years of experience.

The findings also indicated that highly effective veteran teachers take their professional responsibilities seriously. They take time to reflect on student learning and their professional practice. The teachers also collaborate with their colleagues reflecting on their teaching and creating new strategies for teaching. They spend time contacting parents as a means of continued relationship-building with their students. Highly effective veteran teachers are also more likely to keep records of any interaction with stakeholders. One emerging divergent observation was that teacher-colleagues of highly effective veteran teachers could not speak to instructional effectiveness of highly effective veteran teachers because they had little opportunity to observe them teaching. This was mainly due to conflicting teaching schedules. This presents opportunity for ongoing-professional development.

I utilized Macey and Schneider's (2008) engagement framework to examine the second research question: "In what ways are highly effective veteran teachers engaged in low-performing school?" This engagement theory proffers three tenets of engagement:

(a) Trait Engagement (mindset), (b) State Engagement (feelings/emotions), and (c) Behavioral Engagement (work attitude). Trait engagement (mindset) and state engagement (energy, enthusiasm, perseverance, and effort) mediate behavior engagement (attitude, extra-role behavior). The findings indicated that highly effective veteran 
teachers showed evidence of the three tenets of engagement. The results also showed evidence of intrinsic motivation.

Evidence of Trait Engagement was seen in the fact that highly effective veteran teachers were observed to have an optimistic and positive mindset despite the challenges associated with teaching in low-performing schools. One participant stated that highly effective veteran teachers were "beacons of life" in his school (Participant 17). The teachers viewed their daily work as possibilities rather than limitations. Highly effective veteran teachers saw teaching as "a calling" (Participant 10) and a job they were born to do (Participant 22). The teachers also conscientious teachers, they put forth optimum effort and went above and beyond to get the job done. Highly effective veteran teachers showed evidence of state engagement. The data showed that highly effective veteran teachers seemed confident and satisfied with their jobs. The teachers remained calm and assured despite chaotic school situations. The teachers' mindset and feelings about teaching influenced the discretionary exerted by highly effective veteran teachers. 


\section{CHAPTER V \\ SUMMARY AND CONCLUSION}

Introduction

This chapter discusses the data and outcomes that were obtained through a qualitative case study. Data were collected from a sample of principals and teachers (highly effective veteran teachers and teacher colleagues) from Wimsel Public Schools (WPS) (a pseudonym for the school district). The topic of this study is "Individual teacher engagement and school climate characteristics that influenced highly effective veteran teachers to continue teaching in low-performing schools." This chapter is structured to interpret the findings presented in Chapter IV by analyzing and drawing conclusions based on the research questions that guided the study. It also presents a discussion of implications for action and recommendations for future research.

The research questions that guided the study are as follow:

1. What are the characteristics of highly effective veteran teachers who remain teaching in low-performing schools?

2. In what ways are highly effective veteran teachers engaged in low-performing schools?

3. How do highly effective veteran teachers perceive their engagement as contributing to their commitment to remain teaching in low-performing schools? Data from each of these questions were presented in Chapter 4 and will be discussed in this chapter towards reaching meaningful conclusions that may be used as 
parts of strategy to retain highly effective veteran teachers in low-performing schools throughout the school district. Given that this is a case study of a single school district, the findings are not generalizable beyond the district itself. However, there are learnings from this study that may inform approaches to the study of similar challenges in other districts.

The following sections are outlined below as reminders of how the study is structured and to provide context for the findings: statement of the problem, review of methods, summary of the results and discussion, connection to theory, limitations, significance of the study, and suggestions for future research.

\section{Statement of the Problem}

Retaining teachers in public schools is a national challenge. The schools mostly affected by high teacher attrition are low-performing, urban schools that serve poor, minority students (Alliance for Excellent, 2014; Boyd et al., 2005; Clotfelter et al., 2004; Lee \& Orfield, 2006). Over 41 percent of teachers hired to teach in low-performing schools are beginning teachers who leave within three to five years of beginning their careers (Ingersoll, 2001, 2003). Veteran teachers often leave low-performing schools to teach in more affluent schools that serve higher-performing students (Alliance for Excellent, 2014; Rivkin et al., 2005). Not only does this constant movement of teachers from low-performing schools have a negative influence on students' social, emotional, and academic growth (Stecher et al., 2016), but the continued underperformance of schools affects school districts which are penalized for students' failure to meet academic goals in state mandated tests. 
Ingersoll and Merrill (2013) established that "having an increasingly larger number of beginning teachers, along with an increasingly smaller number of veteran teachers in schools could only have a negative impact [on student achievement]" (p. 10). Conversely, in addition to influencing increases in student achievement, effective veteran teachers also bring a wealth of experience to the classroom and can serve as mentoring resources for beginning teachers to help them succeed in low-performing schools (Ingersoll \& Strong, 2011). Moreover, highly effective veteran teachers are well versed in working through student behavior issues and often know how to work with culturally diverse student populations (Ingersoll et al., 2014). Additionally, veteran teachers have experience with interacting and communicating with parents, encouraging self-efficacy, and inspiring a good work ethic in students, which are all essential to leading the turnaround in low- performing schools (Ingersoll et al. 2014).

Despite the large number of teachers exiting the low-performing schools to work in richer, higher-performing schools, there is a cadre of highly effective veteran teachers who remain teaching in low-performing schools (Clotfelter et al., 2004). Understanding the factors that help in retaining the highly effective veteran teachers in these schools will help in presenting strategic options to school leaders who are grappling with the challenge of teacher attrition in low-performing schools.

In this study, I focused on Wimsel Public Schools (WPS), a large urban school district located in a southeastern city in the United States. Recent district data sources indicated that the teacher retention rate in all schools in WPS was 89 percent. The retention rate in low-performing schools that are the focus of this study range from 68 percent to 93 based on 2017-2018 data from WPS. The turnover population includes 
veteran teachers who possess the knowledge, skills, dispositions, and experience that are required to assist principals lead the turnaround process in low-performing schools. As a result of the movement of veteran teachers, schools continue to lose traction that contribute to students' academic development, student socialization, effective behavior management, and ongoing dialogue that influences effective change (Ingersoll \& Merrill, 2013) It is therefore incumbent on the schools and school district to find ways to retain highly effective veteran teachers who are essential to leading the turnaround process in low-performing schools.

\section{Review of Methodology}

The study used semi-structured interviews with open-ended questions to collect data in a qualitative case study. Wimsel Public Schools (WPS) is the focus of this study. Samples were drawn from three groups of participants: principals, highly effective veteran teachers, and colleagues of highly effective veteran teachers from seven lowperforming secondary schools in WPS. The study was restricted to seven secondary schools as specified by WPS Institutional Review Board (IRB).

The highly effective veteran teachers were teachers identified as National Board Certified or teachers classified as exemplary by their supervisors in their last evaluations. Colleagues of highly effective teachers were either identified by the principals, assistant principals, or by the highly effective veteran teachers themselves in the context of a snowball sampling process. In snowball sampling, participants in a study recruit other relevant people who can contribute to the study (Merriam, 1988). This approach was preferred to ensure that I interviewed teacher colleagues who really knew of the work and dispositions of the highly effective veteran teachers. 
The data from interviews with principals, highly effective veteran teachers, and teacher-colleagues were triangulated to identify emerging themes. Triangulation also provided additional rich data by asking different groups of people to respond to the same questions. It also served to corroborate findings about the effectiveness and engagement of the highly effective veteran teachers who were selected for the study. The interviews with the participants were digitally recorded and transcribed using Rev Audio - an online service from Rev.com.

After transcribing the data, I used inductive and deductive coding to organize the raw material and analyze the data (Creswell, 2013; Merriam, 1988). Inductive coding occurred in the iterative process of developing themes from the data. The deductive process occurred as themes were built and constantly checked for alignment with the data (Creswell, 2013). I also used color-coded markers to highlight important words and phrases that were salient to the findings. This helped me to identify emerging themes and patterns. I then transferred the data to NVivo Plus computer software. This assisted with additional coding for further analysis of the data. Additional themes emerged from this process.

Several themes emerged from the data that were then used to answer the three research questions. The major themes emerging from research question number one regarding the characteristics of highly effective veteran teaches include: Building Relationships with Students, Planning and Instruction, and Professional Responsibilities. The sub-themes emerging from Professional Responsibilities were: Self-Reflection, Communication with Parents, and Record-Keeping. 
The themes that emerged from research question two were aligned to the three facets of Engagement (Trait, State, and Behavior) proposed by Macey and Schneider (2008). The first theme was Trait Engagement. The themes emerging from State Engagement were School Safety, School Leadership, and Concerns about Limited Time and Resources. The themes emerging from Behavioral Engagement were: Involvement in School Activities and Creating a Positive Classroom Environment. Research question three focused on highly effective veteran teachers only and the factors that influenced them to remain teaching in low-performing schools. The main themes that emerged in response to question three were: School Climate and Relationships with the School's Administration.

Milner (2007) proposed that researchers be honest and open with participants about the purpose of a research study that is being conducted before commencing the interview process. This is to minimize possible errors and unintentional influences during the research process. I therefore followed the Milner (2007) guidelines. Throughout the data collection process, I also engaged in frequent self-reflections and communicated with my mentors and advisors about the status of this research (Milner, 2007). During the interview conversations, I adopted a neutral but encouraging disposition to build trust with the participants (Miles et al., 2014).

To answer the research questions, I conducted interviews with principals, highly effective veteran teachers, and colleagues of highly effective veteran teachers at seven low-performing secondary schools in WPS. I used the same interview protocol for principals and colleagues of highly effective veteran teachers. This protocol focused on the observations of the principals and teacher-colleagues of the highly effective veteran 
teachers. I created a modified protocol for highly effective veteran teachers that sought to collect similar data but with questions that were phrased to ask about the personal experiences of the highly effective veteran teachers rather than observations as in the case of the principals and the teacher-colleagues. The interview protocols were designed based on information from the employee engagement scale (EES) that captured cognitive, behavioral, and emotional energies that employees bring to their work experiences (Shuck et al., 2016). I analyzed the findings from each group of participants separately and presented the findings separately under each question. I then identified points of convergence and divergence between the findings from each of the three groups and provided a summary at the end of each question.

\section{Summary of Results and Discussion}

In this section I integrated the findings of the three groups, principals, highly effective veteran teachers, and teacher-colleagues to present a holistic view of the answers to the research questions. I presented points of convergence between the three participant groups to substantiate the findings. I also presented points of divergence that have a noteworthy effect on the outcomes of this study.

The findings for the first research question: "What are the characteristic of highly effective veteran teachers who remain teaching in low-performing schools are as follow: All of the participants from the three interview groups provided feedback that supports the notion that highly effective veteran teachers tended to exceed job expectations and regularly engaged in discretionary activities without added incentives or rewards. The evidence suggested that highly effective veteran teachers had an autotelic outlook; that is, the teachers taught because they found purpose and meaning in teaching. Previous 
research by Macey and Schneider (2008) and Kahn (1990) supported this position. These researchers proposed that engaged teachers were integrated in their jobs because they found meaning and purpose in teaching (Kahn, 1990).

The principal and teacher-colleague participant groups submitted that highly effective veteran teachers were effective teachers and provided supporting reasons. First, highly effective veteran teachers were deliberate in building strong, positive relationships with their students and showed genuine concern for their students' well-being (DarlingHammond \& Baratz-Snowden, 2007). The positive teacher/student relationships facilitated growth of a mutually respectful classroom environment where student performance improved because of their teachers' high expectations (Darling-Hammond \& Baratz-Snowden, 2007; Goe et al., 2008). Students and teachers partnered to create class rules, routines, procedures that were consistently maintained throughout the school year.

There was evidence that the students of the highly effective veteran teachers tended to thrive because of the positive and safe classroom community where students felt a sense of belonging were held accountable for their actions. Students also tended to hold each other accountable for their roles in creating a safe and positive environment. The students seemed to trust their teachers and most students were willing to conform to the teachers' expectations. These positive partnerships proved that removing some of the stereotypical barriers of the teachers being the "bosses" in the classroom can lead to a comfortable classroom environment where students are learning and teachers are getting to teach without the major distractions. 
The findings also underscored the importance of teacher preparation. Observers indicated that highly effective veteran teachers spent significant time planning for instruction and student learning (Goe et al., 2008; Popp et al., 2011; Stronge, 2007). Through this preparation they demonstrated that they were knowledgeable of the course content and used multiple teaching strategies to facilitate their students' diverse learning styles (Darling-Hammond \& Baratz-Snowden, 2007; Goe et al., 2008). The findings also revealed that the highly effective veteran teachers took their professional responsibilities seriously because they were consistent in reflecting and constantly improving their teaching practice and pursuing their profession growth.

Research supports the notion that communication with students and parents are essential to student success (Goe et al., 2008; Popp et al., 2011; Stronge, 2007). The veteran teachers were found to consistently and deliberately make efforts to communicate with students and their parents via different media and were often found leading other school activities that supported student learning. This helped to reinforce the positive relationships and the respect that the teachers enjoyed in the classroom. Another good practice to which the participants referred is the deliberateness in keeping records of their students' growth. These findings are consistent with the literature review which identified effective teachers as professionals who exhibited high degrees of professionalism. They were also knowledgeable of content and pedagogy, and provided a safe, positive learning environment (Goe et al., 2008; Popp et al., 2011; Stronge, 2007).

The most noteworthy outcome from research question one was that all participant groups confirmed that positive and strong teacher/student relationships were foundational to the success of highly effective veteran teachers (Christian et al., 2011; Darling- 
Hammond \& Baratz-Snowden, 2007). The teachers seemed to present that this was essential to all other phases of success. The teachers viewed and treated their students like individuals with individual needs. The classroom environment was structured but flexible, student instruction varied but was rigorous, and teachers were firm but genuinely caring. The teachers were engaged because they willingly invested their physical, cognitive, and emotional selves teaching the students in their current schools (Shuck et al., 2017; Shuck et al., 2016).

In response to the second research question: "In what ways were highly effective veteran teachers engaged in low-performing schools?" the findings indicated that highly effective veteran teachers were highly engaged in their work and schools. They showed evidence of Trait, State, and Behavioral Engagement. Macey and Schneider (2008) explicates Trait engagement an employee's worldview or disposition. The teachers were said to always have positive outlooks on life and work. They were definitely not working for external rewards, but rather, there was a sense of fulfillment from accomplishing their tasks (Macey \& Schneider, 2008).

The highly effective veteran teachers were said to exhibit a high degree of Trait engagement. The participants used words such as: "positive" and "optimistic" to describe the veteran teachers' dispositions. Highly effective veteran teachers were also said to be "happy" and "smiling," "willing" and "flexible." The teachers were said to "see themselves as the school, or part of the school...it is never about I do this to get paid...it is about the students." A highly effective veteran teacher said: "sometimes the days are hard [and they] kind of drains you, but in the end, I love going to my job...It kind of pushes me to be a better person for my kids and for my school." Trait engagement 
emerges as an important attribute to help teachers rebound from situations that they can find discouraging. The ability to draw from within themselves and look beyond the circumstances serves the teachers well in such challenging environments.

Words and phrases such as: "energetic," "approachable," "not complaining," "not fussing or grumping," and "passion for teaching" were used to highlight ways in which highly effective veteran teachers express their satisfaction about teaching in their current schools. Consistent with the description of State Engagement, the low-performing schools need teachers who not only do the work but do the work with the energy that endears confidence in their colleagues and the students who are observing them. The attributes of State engagement are essential to creating a positive culture in which people feel that they can thrive. It creases a sense that we can overcome any challenge we encounter.

Given the anecdotal evidence that low-performing schools have high incidences of fights and unruly behavior that can derail the best planned lessons, it is interesting to observe that issues of safety were not major concerns for the highly effective veteran teachers. In fact, they were often found mitigating some of the potential challenges before they arose. Principals and colleagues of highly effective veteran teachers indicated that highly effective veteran teachers were knowledgeable of the safety procedures. Therefore, they remained calm and efficient in crisis situations, unlike teachers who were not as effective (Ingersoll \& Merrill, 2014). Some of the feeling of safety was attributed to the effectiveness of the leaders of the schools who developed the protocols and structures needed to navigate emergency or crisis situations (Kraft et al., 2016; Macey \& Schneider, 2008; Ronfeldt et al., 2013). 
Teacher experience was hailed as an important facet of teacher effectiveness and the resilience needed to thrive in low-performing schools. Previous literature supports the highest percentages of teacher attrition are in low-performing, urban schools that serve low-performing, poor, minority students who are taught by inexperienced, beginning teachers (Cowan et al., 2016; Hanushek et al., 1999; Ingersoll \& Merrill, 2013). This trend is generally harmful to the students at these schools (Hanushek et al., 2004; Kraft et al., 2016). Having high quality teachers in the classroom create a positive school climate which leads to increased teacher satisfaction and the increased probability that teachers will remain in their jobs.

Ingersoll and Merrill (2013) reported that having higher numbers of highly effective veteran teachers in schools had a more positive influence on students compared to higher numbers of beginning teachers. Therefore, the more effective teachers there are on the schools' roll, the more positive the climate is likely to be. Given this finding, schools should employ deliberate retention strategies that stymie the annual exodus of teachers from some low performing schools. The constant introduction of inexperienced teachers in an otherwise challenging environment is counterproductive to achieving the academic gains needed to elevate schools from the low-performing status.

Effective leadership has a positive effect on teacher turnover (Kraft et al., 2016; Ronfeldt et al., 2013; Wang \& Degol, 2016). However, a noteworthy point of divergence presented by the highly effective teacher group and the teacher-colleagues group in this study was that leadership only influenced whether highly effective veteran teachers remained teaching in their current schools when the principals were themselves perceived as highly effective. Participants in this study expressed displeasure with the quality of 
leadership in their schools and were quick to point out that it was their motivation to see the students succeed that kept them in place at the school. This finding is consistent the framework which proposes that transformational leadership directly influences state engagement and indirectly mediates the relationship between state and behavioral engagement. This raises an important question about principal selection in leading the schools and the importance of developing a team that can work together to achieve the outcomes. Transformational leaders are those who can facilitate change and inspire others to excel (Bass \& Riggio, 2006; Griffith, 2004; Rao, 2014). Therefore, a holistic study about effective teaching, learning, and leadership will explicate more factors about effective turnaround methods.

The highly effective teachers were unanimous in identifying one main source of job dissatisfaction. It was the time spent completing excessive paperwork. Highly effective veteran teachers opined that excessive paperwork was an unnecessary waste of time that would be better spent devising and implementing ways of improving their students' success. This however, was not presented as a reason for teachers to leave their jobs. Most of the participants affirmed that there were no existing factors that would make them leave their current assignments at low-performing schools. Only two participants indicated that there are factors that might cause them to leave. One person was concerned about the long distance she had to travel to school and the other indicated that ineffective leadership which I addressed in the previous paragraph was her main concern.

The third research question: "How do highly effective veteran teachers perceive their engagement as contributing to their commitment to remain teaching in low- 
performing schools?" was targeted at highly effective veteran teachers only. This question is focused on explicating the factors that influence highly effective veteran teachers to remain teaching in low-performing schools. Two main themes emerged in the findings: School Climate and Relationships with the School's Administration. I explicated the findings in the following paragraphs.

Highly effective veteran teachers gave mixed responses about their school climates. The majority of the participants commented that positive influencers in their schools were supportive administrators and family-like relationships with their colleagues. However, some participants were dissatisfied and frustration with some leaders their schools and the conditions of the school climates. Overall, collegiality was the more important factor that influenced highly effective veteran teachers to remain teaching in low-performing schools (Kraft et al., 2016; Pogodzinski et al., 2012).

The findings in this chapter also indicated intrinsic motivation as factor that influence highly effective veteran teacher to remain. Highly effective veteran teachers stated that they were there for the students and the positive influence they had on their students' lives. The teachers also indicated that they remained teaching because they were satisfied with their jobs (Ashiedu \& Scott-Ladd, 2012; Perrachione et al., 2008; Petty et al., 2011). However, Trait Engagement appears to be a significant factor that influenced highly effective veteran teachers to remain teaching in low-performing schools.

\section{Connection to Theory}

There were several points of convergence between the findings in this study and the theory identified in Chapter 1. The finding from this study indicated that building 
relationships with students, evidence of engagement-Trait engagement in particular, collegiality and a positive school climate were significant factors in retaining highly effective veteran teachers. Observers of the highly effective veteran teachers ably articulated attributes that were consistent with teacher effectiveness as proposed in the literature (Darling-Hammond \& Baratz-Snowden, 2007; Goe et al., 2008; Popp et al., 2011; Stronge, 2007).

All of the participants agree that building positive, strong relationships with their students is paramount to the success of highly effective veteran teachers. The teacher/student relationships are important in creating a positive classroom climate and facilitating structure in the classroom. Current literature indicate that teachers remain teaching in low-performing schools due to their satisfaction with their job role and the positive influence they felt they had on children's lives (Ashiedu \& Scott-Ladd, 2012; Perrachione et al., 2008; Petty et al., 2011). The students trust that the teachers support them; therefore, the students support the teachers' efforts to instruct and to guide them. This finding is in keeping with the literature. Darling-Hammond and Baratz-Snowden (2007) highlighted that highly effective teachers build relationships with their students. Thus, creating a mutually respectful classroom environment where students were consistently held to high standards.

Conversely, this finding diverges from Macey and Schneider's (2008) framework which does not specifically account for the teacher-student relationship which is a significant factor in the teachers' level of engagement. The framework proposes that work conditions directly and indirectly influence the teachers' feelings (State Engagement) and attitude (Behavioral Engagement) to teaching. Work conditions are 
defined as: the nature of the job, intellectual stimulation evoked by the job, and the amount of autonomy afforded by the job.

A second finding was that highly effective veteran teachers were intrinsically motivated and they displayed a high degree of Trait Engagement. Previous literature highlighted that teachers were intrinsically motivated due to personal teacher efficacy, that is the teachers are confident that they could promote student learning (Bandura, 1994), displayed a high degree of job satisfaction, and optimistic about the positive influence they had on students' lives (Ashiedu \& Scott-Ladd, 2012; Hughes, 2012; Perrachione et al., 2008; Petty et al., 2011). It is noteworthy that the teachers had either achieved national board status or were identified by their supervisors as exemplary teachers. Their colleagues also spoke very highly about their competence and commitment to their work.

The intrinsic motivation disposition is closely linked with Trait Engagement which is a psychological concept. Teachers with Trait Engagement are said to have a positive mindset or disposition, they are conscientiousness or commitment to teaching. The teachers are not motivated by rewards or external gratification. Rather, highly effective veteran teachers teach because they find meaning and purpose in teaching (Kahn, 1990; Macey \& Schneider, 2008). Erikson (2005) explicated that engagement goes "above and beyond simple satisfaction with the employment arrangement or basic loyalty to the employer." The researcher stated that engagement is about passion and commitment - the willingness to invest oneself and expend one's discretionary effort to help the employer succeed" (p.14). This finding is in congruence with Macey and Schneider's (2008) framework. The framework highlights that positive mindsets (Trait 
Engagement) influence the teachers' feelings about teaching (State Engagement).

Teachers' personal dispositions and their feelings about their job influence their attitude and on-the-job behavior (Behavioral Engagement). That is the amount of effort, time and energy they are willing to exert. A third finding was that the majority of highly effective veteran teachers in this study had generally good relationships with their administrators and their colleagues. The teachers depended on their administrators to ensure a safe, positive school climate. They also wanted their administrators to provide feedback and to listen to them.

This finding is corroborated by the engagement framework and by findings by Kahn (1990). Kahn (1990) in his needs-satisfying theory expressed that employees are more willing to invest time, emotional and physical energy in a job when they find the job safe, meaningful and if they have the resources to do the job effectively. It also aligns with Macey and Schneider's (2008) framework which indicates that work conditions have a direct influence on State Engagement and an indirect influence of Trait Engagement. This means that the schools' climate might not influence a highly effective veteran teacher's already formed mindset. A negative school climate might influence how the teacher feels about the effectiveness of the schools' leaders. However, neither the teacher's mindset nor feeling would influence if the teacher remains at the school.

The framework also shows that trust is important in the employee/employer relationship. That is, teachers who trust their administrators to support them are more likely to exert on-the-job discretionary effort. However, a divergent finding from the framework was that collegiality rather than leadership had a greater influence on whether highly effective veteran teachers in this study would remain teaching in low-performing 
schools (Christian et al. 2011; Kraft et al., 2016; Ronfeldt et al., 2013). In reference to findings to comments that teachers made about each other in the previous chapter, it was evident that there was a high degree of inter-dependence. This is exemplified in several ways. One teacher remarked that in her early years teaching at the school she tended to want to do her work on her own but she soon found out the value of collaborating when she observed how the quality of her work increased. Other teachers talked about the joy of coming to work in a place where the climate had improved over the years and that there was a corporate commitment to serving the students.

In comparison, despite the general commitment to relationship with leadership, there was some room for continued growth with some of the veteran teachers. One teacher referred to the loss of a dynamic leader who was replaced by someone who she hoped would live up to the same billing as the previous leader. Another referred to the ways in which her leader "talked down to her." Understanding that leaders do affect the levels of engagement of teachers, the school district should provide the development necessary that helps leaders to understand how they can positively influence teachers' engagement thereby helping to retain them at greater levels in the schools where they serve. Transformational leadership influences State Engagement and Behavioral Engagement. That is, the school administrators influence how teachers feel about their jobs. The teacher's on-the job behavior is influenced by the level of trust the teacher has in the school administrator.

\section{Limitations to the Study}

In the process of executing this research project, I encountered some challenges that limited its scope. There were limitations with the sampling and the schools that I was 
able to access due to restrictions by WPS district IRB committee. In the initial design I anticipated sampling from an equal number of middle schools and high schools, but the schools that I was permitted to access were mainly high schools. Thus, there was an imbalance between the number of middle and high schools from which information was drawn in my study.

A second consideration is the fact that I limited the selection of highly effective veteran teachers to people who have been teaching in the roles for five or more years but did not place a tenure limit on the principals under whom they served. Considering that the effect of leadership is a factor in the Macey and Schneider (2008) model, an opportunity to measure the leadership effect over the same time period may have yielded different results. All of the six principal participants and the one assistant principal participant had been in their current jobs for fewer than five years. Feedback on the growth of the veteran teachers over the five-year period would have been helpful in establishing patterns that led to their growth and effectiveness.

Third, the feedback from the colleagues of highly effective veteran teachers was limited to planning and activities outside the classroom. Considering that the teachers are on the same teaching schedules, there were no opportunities for the teacher-colleagues to observe the classroom instruction of the veteran teachers. Therefore, they had a limited perspective of what made the veteran teachers "highly effective."

Fourth, time and weather affected data collection. It was my intention to schedule face to face interviews with each of the participants. However, with the data collection phase occurring at the height of the winter, many teachers became unavailable for face to face interviews due to road conditions and school closings. Therefore, several interviews, 
especially with the teacher-colleagues of the highly effective veteran teachers were telephone interviews. The telephone interviews created a disadvantage of not being able to observe the participants' facial expressions and body language which help to contextualize some of the emotions that support what they were saying in response to the interview questions. In contrast, I observe the facial expressions and hand gestures of the other participants when they were giving feedback. I was able to capture the genuineness of Participant 10's account of her interaction with her students in my field notes. There was a smile of satisfaction on her face and she enthusiastically she moved her hands to mimic the activity in her classroom during the "academic enrichment sessions."

Finally, there was a high degree of confidence amongst the teachers and principals that the veteran teachers were indeed making a positive impact on the lives of the students. A more rounded perspective would have been garnered had past or present student of the teachers been interviewed also. This should therefore be considered for future study as we work to measure effectiveness and engagement.

\section{Implications for Policy}

Retaining teachers in low-performing school is a challenge on all levels. Current literature shows that although adequate numbers of teachers are being certified and hired, an even larger number vacate their professions every year for reasons other than retirement (Ingersoll, 2001, 2003). The schools that are impacted most by teacher attrition are low-performing schools that serve low SES, minority students. However, there is a cohort of highly effective veteran teachers who remain teaching in lowperforming schools despite the situational challenges. This study was inspired by the paucity of information regarding the factors that influence some highly effective veteran 
teachers to remain teaching at their current low-performing schools despite the challenging working conditions. The study is important because it helps to explicate main factors that help keep a cadre of highly effective veteran teachers in low-performing schools in WPS, a large southeastern school district.

The findings from this research indicated that a few factors influence the retention of highly effective veteran teachers. First, Trait Engagement appears to be a significant factor that influenced highly effective veteran teachers to remain teaching in lowperforming schools (Macey \& Schneider, 2008). The teachers in the study had positive mindsets despite the challenging conditions associated with low-performing schools. Highly effective veteran teachers are intrinsically motivated by wanting their students to be successful. The teachers enjoyed being there for their students and seeing them learn. Highly effective veteran teachers feel they make a positive impact on the lives of their students (Ashiedu \& Scott-Ladd, 2012; Hughes, 2012; Perrachione et al., 2008; Petty et al., 2011. These findings have implications for WPS district policy.

One might focus on district policy when considering the question: "To what extent is the school district recruiting and matching teachers with the schools where they are most likely to succeed?" It is evident from the high degree of teacher turnover in these schools that not all teachers will thrive in such environments. This therefore presents an opportunity for the school district to specifically recruit and select teachers who have the dispositions of "selflessness" to serve in these schools. Jackson (2013) points out that poor person-job match may predict teacher migration. It would require some change in the hiring policies and processes but will likely yield more significant results in the fight to retain the best teachers in the schools where they are most needed. 
Another policy issue to consider is the level of preparation offered to beginning and less effective teachers in low-performing schools. Despite some efforts to connect teachers through professional learning communities, there was limited evidence to suggest that there were attempts to connect the effective veteran teachers with their less effective colleagues for the purpose of role modeling or mentorship. Given that the veteran teachers in this study enjoy the admiration and high regard of their supervisors and colleagues, the principals of the schools might seek to engage them in the ongoing professional development and nurturing of other teachers with promise. These would be teachers who are inclined to be as engaged as highly effective veteran teachers and motivated to help the school in its turnaround efforts.

Highly effective veteran teachers should be offered the opportunity to participate in a highly structured mentoring program where mentors/mentees will receive scheduled time during the day to meet (Ingersoll \& Strong, 2011). Ingersoll et al. (2014) recommends such a program, as highly effective veteran teachers are well versed in working through student behavior issues and often know how to work with a culturally diverse student population. Additionally, veteran teachers have experience with interacting and communicating with parents, encouraging self-efficacy, and inspiring a good work ethic in students. Young teachers will be paired with highly effective veteran teachers as a part of their on-boarding process. Mentors should be properly recruited to ensure that they and their mentees are a fit and vice-versa. There should be mile-stones during the program to evaluate its success. The program should be incentivized based on recommendations from the highly effective veteran teachers. Each school should ensure mentors are a part of the leadership structure. 
Another finding indicated that the leaders had some, but limited influence on retention of highly effective veteran teachers in low-performing schools. The teachers appreciated the leaders' support in creating positive, safe, and structured school environments. They also appreciated feedback from leadership. However, for the majority of the participants leadership did not influence whether highly effective veteran remained at their current schools. Principals could learn from the teachers and their colleagues about the factors that endear them to each other. There is some opportunity for leaders to work more to becoming genuine members of the team rather than be viewed as administrators who remain outside the teams. There is evidence from this research that where principals engage the teachers in the planning and decision processes, the teachers are likely to be happier and willing to contribute more of their time to advancing the school (Kraft et al., 2016; Ronfeldt et al., 2013; Wang \& Degol, 2016).

The school district might also work with the teacher training college or develop a program to prepare teachers to be the agents of change in the low-performing schools. A concentration in a degree program or a certification that is targeted at developing the knowledge, skills and behaviors required to thrive and contribute at high levels in the low-performing schools would serve the school district well. The information from this study can help to develop components of the curriculum by drawing from these success stories and others like them. To confirm such a need, one participant in the study (teacher-colleague) who had 20 years of teaching experience but had been teaching at her school for six months commented that she did not know what she could have done differently to prepare herself for student behavior issues and classroom challenges at her school. She had come from a more conservative school district where the behavior 
challenges were less intense. It would therefore add value to include some kind of internship in the specialized training that teachers would receive.

Another recommendation is that low-performing schools intentionally focus on improving the school climate. For example, develop and consistently adhere to schoolwide behavior programs. One veteran teacher (Participant 3) expressed appreciation that her colleagues were now consistently adhering to the school's behavior guidelines. She compared this school year to the previous school year when there was a lack of consistency in enforcing the school's behavior expectations. This participant emphasized that teachers need to model the right behaviors to students and explain to the students the rationale for adhering to the school's guidelines and expectations.

Teachers and leaders could also work as a team to cultivate a positive and caring school climate by creating and sustaining supportive environments in which students have an "I can do it" attitude. This attitude could be nurtured by teachers consistently engaging in supportive practices such as intentionally providing positive feedback and praise for hard work and converting mistakes into opportunities for students to learn and grow. A strong presence of highly effective veteran teachers along with effective leadership is more likely to produce a positive school climate (Ingersoll \& Merrill, 2013). Improved school climates may lead to higher teacher satisfaction and the increased probability that highly effective veteran teachers will remain teaching in low-performing schools (Ghavifekr \& Pillai, 2016). There is also a probability that younger teachers will remain in teaching. Beginning teachers who remain will have a chance to gain skills and experience needed to be highly effective veteran teachers (Ghavifekr \& Pillai, 2016). 


\section{Implications for Practice}

Findings indicated that highly effective veteran teachers spend significant time developing positive, strong, and lasting relationships with their students (DarlingHammond \& Baratz-Snowden, 2007). This study found that relationship-building was fundamental in facilitating the success of highly effective veteran teachers their schools. Participant 7 aptly rationalized:

You know you hear the old clichés about "students don't care how much you know until they know how much you care", and that truly goes here... our students are so used to having adults come in and out of their lives, that's what they expect their adults to do here. Once they see that the adults are here for them, and the adults are going to stay and they're [the students] not going to be able to run that adult off, it changes the whole perception and the relationship. (Participant 7)

This appears to be an important ingredient that teachers in low-performing schools must include in their interaction with their students.

The findings from this study indicated that collegiality was another factor that influenced whether or not some highly effective veteran teachers would remain teaching in low-performing schools (Kraft et al., 2016; Pogodzinski et al., 2012). Reports from the participants indicated that teachers enjoyed working with each other in professional learning communities. Some teachers also indicated they enjoyed social interaction with their colleagues. Teachers and leaders may consider organizing a variety of school and social events to consolidate these relationships. This would allow teachers to engage with each other at professional and social levels.

Moreover, the results from the study indicated that highly effective veteran teachers value leadership support. For example, this is evident in ensuring a safe, positive school environment. The teachers also appreciate feedback and the fact that their leaders 
gave them latitude to voice their concerns. This finding is important to leaders as it informs them on how to cater to the needs of teachers. Maintaining an open-door policy and nurturing positive relationships with teachers would be beneficial in sustaining positive school climates in low-performing schools.

\section{Implications for Future Research}

There are a few areas of interest that will be considered for future research. Research suggests that some teachers more than others are predisposed to be more engaged than other teachers (Kahn, 1990). Trait Engagement is explicated as an individual's mindset or worldview, State Engagement is one's feelings or emotions, and Behavioral Engagement is one's on-the-job attitude or discretionary effort (Macey \& Schneider, 2008). School leaders by themselves cannot influence teachers to be engaged, and they have minimal influence on changing one's Trait Engagement since this is more an individual's mindset or world view. However, results of this study indicate that highly effective veteran teachers remain teaching in low-performing schools mainly due to Trait Engagement. Therefore, there might be further study that examines the psychological factors that influence some teachers to have higher Trait Engagement than other teachers. This would equip leaders who are involved in the teacher selection processes and the day to day management of teachers with additional knowledge about how to get the best from the teachers under their charge. This information would also greatly enhance teacher training and development programs.

A second study might be an examination of the effectiveness of teacher recruitment and selection processes. A study of this nature was recently proposed by the National Education Association (NEA). In its White Paper publication: "Teacher 
Assessment and Evaluation: The National Education Association's Framework for Transforming Education Systems to Support Effective Teaching and Improve Student Learning" the association emphasized that initial teacher training is critical in the recruitment and hiring process (NEA, 2010). The association stressed that teachers who are hired must show proficiency in teaching, they "should demonstrate subject-area knowledge, pedagogical knowledge, and professional teaching ability" (NEA, 2010, p. 2). They therefore recommended that school districts consider using teacher evaluation tools in the recruitment and selection processes. The argument is that if teachers are going to be assessed on a set of criteria, they should be hired based on similar criteria.

The demographic information for participants in this research shows a predominantly White, female sample. This finding is in keeping with previous research (Henke et al., 2000; Ingersoll et al., 2014). The literature suggests that the schools most affected by turnover of minority teachers are public schools whilst there is evidence of increasing numbers of minority students enrolling in the same schools (Ingersoll et al., 2014). A third study might focus on how to increase the number of highly effective veteran minority females and male teachers in low-performing schools in order to create a balance between the number of minority students and minority teachers.

\section{Summary}

The teacher turnover rate is higher than that of other highly regarded professions such as engineering, nursing, architecture, and academia (Ingersoll \& Perda, 2012). Whilst an adequate number of teachers are being recruited and hired, even larger numbers continue to exit the profession for reasons other than retirement (Ingersoll, 2001, 2003). Both veteran and beginning teachers are leaving, but the problem is particularly 
challenging amongst beginning teachers (Ingersoll \& Merrill, 2013). Teachers either leave the profession all together or they leave to teach in higher performing less challenging schools (Ingersoll, 2001, 2011; Ingersoll \& Merrill, 2013). The schools that need the most qualified teachers are the most vulnerable to teacher attrition (Clotfelter et al., 2004; Ingersoll, 2011). However, there is remnant of highly qualified veteran teachers who continue to teach in low-performing schools despite the challenges associated with such schools.

Ingersoll and Merrill (2013) assert that the presence of highly effective experienced teachers may positively influence student learning and their overall development. Further, there is evidence to support that highly effective veteran teachers have the skills and knowledge needed to work with students from diverse backgrounds (Ingersoll et al., 2014; Ingersoll \& Strong, 2011). The presence of highly effective veteran teachers in low-performing schools could only have a positive impact on student learning (Ingersoll \& Merrill, 2013). The findings from this study may highlight ways to retain highly effective veteran teachers and thus help in the turnaround process in lowperforming schools. The research examined individual teacher engagement and school climate characteristics that influence highly effective veteran teachers to continue teaching in low-performing schools in WPS.

This study utilized the concept employee engagement (EE) as a proxy for teacher engagement (TE). In recent work, Shuck et al. (2017) and Shuck et al. (2016) defined EE as an active, work-related positive psychological state operationalized by the intensity and direction of cognitive, emotional, and behavioral energy. Macey and Schneider's (2008) engagement framework was used to examine teacher engagement. The framework 
proffers three tenets of engagement: Trait Engagement (mindset), State Engagement (emotions/feelings), Behavioral Engagement (attitude to work/discretionary effort).

The research was a qualitative case study. Semi-structured interviews using openended questions were used to collect data from three groups of participants: principals, highly effective veteran teachers, and teacher-colleagues of highly effective veteran teachers. The findings from the first research question indicated that highly effective veteran teachers were proactive by nature. This was evidence of Trait Engagement and Behavioral Engagement. The teachers spent considerable time building strong, positive with their students and planning instruction for their students. All participants confirmed that relationship-building was critical to the success of highly effective teachers.

Highly effective veteran teachers were also engaged in their jobs. Although there was evidence of intrinsic motivation that influenced highly effective veteran teachers to continue teaching in low-performing schools, Trait Engagement appeared to be the stronger influencer of teacher retention. The teachers confirmed that they were committed to their students' well-being and found satisfaction knowing they were making a positive impact in the lives of their students. Highly effective veteran teachers were also found to consistently maintain a positive and optimistic disposition despite daily challenges endemic to low-performing schools that influence the exit of other teachers. The teachers appeared not to be only satisfied with being teachers, they were also passionate and committed to teaching.

Another finding was that most of the highly effective veteran teacher participants had positive relationships with their school administrators and colleagues. Leadership was important to the extent that highly effective veteran teachers depended on school 
leaders to support them. They also relied on leaders to provide a safe, positive work environment. Most of the participants confirmed that collegiality was a factor that influenced them to remain teaching in their current schools.

In conclusion, school leaders might intentionally focus on improving their schools' climate to attract highly effective veteran teachers to their schools. Further, since highly effective veteran teachers seem mainly influenced to remain teaching in lowperforming schools due to Trait Engagement, this presents opportunity for schools to examine their teacher recruitment and hiring processes. Trait Engagement is a "disposition" or "mindset" therefore some attention might be given to devising a process to evaluate teacher applicants' disposition and teaching aptitude before the individuals are formally considered as teachers. Also, teacher colleges and universities might consider changing their teacher training programs to include or intensify components that prepare teachers to teach in low-performing schools. Finally, highly effective veteran teachers may be further utilized to lead formally structured mentorship programs in their schools.

Further studies might be carried out examining psychological factors that influence some teachers to have higher Trait Engagement than other teachers. Another study may be a critical examination of the teacher recruitment and hiring process using an instrument similar to the one used to evaluate active teachers. A final study may research ways to attract and retain highly effective minority male and female highly effective veteran teachers to low-performing school 


\section{REFERENCES}

Achinstein, B., Ogawa, R. T., \& Sexton, D. (2010). Retaining teachers of color: A pressing problem and a potential strategy for "hard-to-staff" schools. Review of Educational Research, 80(1), 71-107.

Adams, G. J. (1996). Using a Cox Regression Model to examine voluntary teacher turnover. Journal of Experimental Education, 649(3), 267-285.

AERA (2015). AERA statement on use of value-added models (VAM) for the evaluation of educators and educator preparation programs. (2015). Educational Researcher, $44(8), 448-452$.

Alliance for Excellent Education. (2014, July 17). Teacher attrition costs United States up to $\$ 2.2$ billion annually [Press Release]. Retrieved from http://all4ed.org/press/teacher-attrition-costs-united-states-up-to-2-2-billionannually-says-new-alliance-report/

Altheide, D., \& Johnson, J. (1994). Criteria for assessing interpretive validity in qualitative research. In N. Denzin and Y. Lincoln (Eds.), Handbook of Qualitative Research (pp. 485-499). Thousand Oaks, CA: Sage.

American Association of Colleges for Teacher Education (AACTE). (2013, March 20). The changing teacher preparation profession [Press release]. Retrieved from www.https://aacte.org/news-room/13-press-releases-statements/145-aactereleases-first-national-data-report-on-teacher-preparation-profession 
Aquilino, W. (1994). Interview mode effects in surveys of drug and alcohol use: A field experiment. Public Opinion Quarterly, 58, 210-240.

Ashiedu, J. A., \& Scott-Ladd, B. D. (2012). Understanding teacher attrition and retention drivers: Addressing teacher shortages. Australian Journal of Teacher Education, $37(11), 17-35$.

Attridge, M. (2009). Measuring and managing employee work engagement: A review of the research and business literature. Journal of Workplace Behavioral Health, 24, $383-398$.

Ballou, D., \& Springer, M. G. (2015). Using student test scores to measure teacher performance: Some problems in the design and implementation of education systems. Educational Researcher, 44(2), 77-86.

Bandura, A. (1994). Self-efficacy. In V. S. Ramachaudran (Ed.), Encyclopedia of human behavior. Retrieved from https://www.uky.edu/ eushe2/Bandura/Bandura1994EHB.pdf

Barnwell, P. (2015, May 27). The ongoing struggle of teacher retention. The Atlantic. Retrieved from https://www.theatlantic.com/education/archive/2015/05/theongoing-struggle-of-teacher-retention/394211/

Bass, B. M. (1999). Two decades of research and development in transformational leadership. European Journal of Work and Organizational Psychology, 8, 9-32.

Bass, B. M., \& Riggio, R. E. (2006). Transformational leadership. (2nd ed.). Mahwah, NJ: Lawrence Erlbaum Associates.

Becker, H. S. (1998). Tricks of the trade: How to think about your research while you're doing it. Chicago, IL: University of Chicago Press. 
Berliner, D. (2005). Describing the behavior and documenting the accomplishments of expert teachers. Bulletin of Science, Technology, and Society, 24(3), 200-212.

Berry, B. (2008). Staffing high-needs schools: Insights from the nation's best teachers. Phi Delta Kappan, 89(10), 766-771.

Bidwell, A. (2014, April 09). Most teachers are not engaged in their jobs, Gallup finds. US News \& World Report. Retrieved from http://www.usnews.com/news/articles/2014/04/09/most-teachers-are-notengaged-in-their-jobs-gallup-finds

Billingsley, B. S., \& Cross, L. H. (1992). Predictors of commitment, job satisfaction, and intent to stay in teaching; A comparison of general and special educators. The Journal of Special Education, 25(4), 453-471.

Bogdan, R. C., \& Biklen, S. K. (1992). Qualitative research for education: An introduction to theory and methods. Boston, MA: Allyn \& Bacon.

Bogler, R. (2002). Two profiles of schoolteachers: A discriminant analysis of job satisfaction. Teaching and Teacher Education, 18, 665-673.

Borman, G. D., \& Dowling, N.M. (2008). Teacher attrition and retention: A metaanalytic and narrative review of the research. Review of Educational Research, 78(3), 367-409.

Boser, U. (2014). Return on education investment 2014: A district-by-district evaluation of U.S. education productivity. Retrieved from https://cdn.americanprogress.org/up-content /uploads/2014/07/RQI-report.pdf 
Broughman, S., \& Rollefson, M. (2000). Teacher supply in the United States: Sounds of newly hired teachers in public and private schools (1987-88 to 1993-94). Education Statistics Quarterly, 2(3), 28-32.

Boyd, D., Grossman, P., Ing, M., Lankford, H., Loeb, S., \& Wyckoff, J. (2011). The influence of school administrators on teacher retention decisions. American Educational Research Journal, 48(2), 303-333.

Boyd, D., Langford, H., Loeb, S., \& Wyckoff, J. (2005). Exploring the short careers of high-achieving teachers in low-performing schools. The American Economic Review, 95(2), 166-171.

Boyd, D., Langford, H., Loeb, S., \& Wyckoff, J. (2008). The impact of assessment and accountability on teacher recruitment and retention: Are there unintended consequences? Public Finance Review, 36(1), 88-111.

Burke, L., \& Miller, M. (2001). Phone interviewing as a means of data collection: Lessons learned and practical recommendations. Forum: Qualitative Social Research, 2(2), Art (7), 1-8. Retrieved from http://www.qualitativeresearch.net/index.php/fqs/article/view/959/2095

Chang, M. L., \& Davis, H. A. (2009). Understanding the role of teacher appraisals in shaping the dynamics of their relationships with students: Deconstructing teachers' judgements of disruptive behavior/students. In P. A. Schultz \& M. Zembylas (Eds.), Advances in teacher emotion research: The impact on teachers' lives (pp. 95-127). New York, NY: Springer. 
Chase, S. (2005). Narrative inquiry: Multiple lenses, approaches, voices. In N. K. Denzin \& Y. S. Lincoln (Eds.), The Sage handbook of qualitative research (3rd ed.) (pp. 651-680), Thousand Oaks, CA: Sage.

Cherng, H. Y., \& Halpin, P. F. (2016). The importance of minority teacher: Student perceptions of minority versus white teachers. American Educational Research Association, 47(7), 407-420.

Chetty, R., Friedman, J. N., \& Rockoff, J. E. (2014). Measuring the impacts off teachers II: Teacher value-added and student outcomes in adulthood. American Economic Review, 104(9), 2633-2679.

Christian, M. S., Garza, A. S., \& Slaughter, J. E. (2011). Work engagement: A quantitative review and test of its relations with task and contextual performance. Personnel Psychology, 64, 89-136.

Clotfelter, C. T., Ladd, H. F., Vigdor, J. L., \& Aliago-Diaz, R. (2004). Do school accountability systems make it more difficult for low-performing schools to attract and retain high-quality teachers? Journal of Policy Analysis and Management, 23(2), 251-271.

Clotfelter, C. T., Ladd, H. F., \& Vigdor, J. L. (2007). Teacher credentials and student achievement: Longitudinal analysis with student fixed effects. Economics of Education Review, 26, 673-682.

Clotfelter, C. T., Ladd, H. F., \& Vigdor, J. L. (2011). Teacher mobility, school segregation, and pay-based policies to level the playing field. Education Finance and Policy, 6(3), 399-438. 
Clotfelter, C. T., Ladd, H. F., Vigdor, J. L., \& Wheeler, J. (2007). High-poverty schools and the distribution of teachers and principals. North Carolina Law Review, 85, 1348-1379.

Cowan, J., \& Goldhaber, D. (2015, February 11). National board certification and teacher effectiveness: Evidence from Washington. Center for Education Data \& Research. Retrieved from http://www.cedr.us/papers/working/CEDR\%20WP\%202015-

3_NBPTS\%20Cert.pdf

Cowan, J., Goldhaber, D., Hayes, K., \& Theobald, R. (2016). Missing elements in the discussion of teacher shortage. Educational Researcher, 45(8), 460-462.

Creswell, J. W. (2013). Qualitative inquiry \& research design: Choosing among five approaches (3rd ed.). Thousand Oaks: CA: Sage Publications, Inc.

Croninger, R. G., Rice, J. K., Rathbun, A., \& Nishio, M. (2007). Teacher qualifications and earlier learning: Effects of certification degree and experience in first-grade student achievement. Economics of Education Review, 26(3), 312-324.

Darling-Hammond, L. (1997, November). Doing what matters most: Investing in quality teaching. National Commission on Teaching and America's Future (NCTAF). Retrieved from http://nctaf.org/wp-content/uploads/DoingWhatMattersMost.pdf Darling-Hammond, L. (2003). Keeping good teachers: Why it matters, what leaders can do. Educational Leadership, 60(8), 6-13.

Darling-Hammond, L., \& Baratz-Snowden, J. (2007). A good teacher in every classroom: Preparing the highly qualified teachers our children deserve. Educational Horizons, 85(2), 111-132. 
Darling-Hammond, L., Dilworth, M. E., \& Bullmaster, M. L. (1996, January). Educators of color. Paper presented at the meeting of Invitational Conference Recruiting, Preparing, and Retaining Persons of Color in the Teaching Profession, Washington, DC. Retrieved from http://files.eric.ed.gov/fulltext/ED474898.pdf

Darling-Hammond, L., \& Sykes, G. (2003). Wanted: A national teacher supply policy for education: The right way to meet the "Highly Qualified Teacher" challenge. Education Policy Analysis Archives, 11(3), 1-55. Retrieved from https:/epaa.asu.edu/ojs/article/view/261/387

De Stercke, J., Goyette, N., \& Robertson, J. E. (2015). Happiness in the classroom: Strategies for teacher retention and development. Prospects, 45, 421-427. doi:10.1007/s11125-015-9372-z

Dillard, C. B. (2000). The substance of things hoped for, the evidence of things not seen; Examining an endarkened feminist epistemology in educational research and leadership. International Journal of Qualitative Studies, 13(6), 661-681.

Dreyfus, S. E. (2004). The five-stage model of adult skill acquisition. Bulletin of Science, Technology and Society, 24(3), 177-181. doi:10.1177/0270467604264992. Retrieved from http://www.bumc.bu.edu/facdev-medicine/files/2012/03/Dreyfusskill-level.pdf

Erikson, T. J. (2005). Testimony submitted before the U.S. Senate Committee on health, education, labor, and pensions. May 26.

Erickson, F. (1986). Qualitative methods in researching teaching. In M. C. Whittrock (Ed.), Handbook of research on teaching (3rd ed.) (pp. 119-161). New York: McMillan. 
Eckert, S. A. (2012). What do teaching qualifications mean in urban schools? A mixedmethods study of teacher preparation and qualification. Journal of Teacher Education, 64(1), 75-89.

Feng, L. (2009). Opportunity wages, classroom characteristics, and teacher mobility. Southern Economic Journal, 75(4), 1165-1190.

Fideler, E., \& Haselkorn, D. (1999). Learning the ropes: Urban teacher induction programs and practices in the United States. Belmont, MA: Recruiting New Teachers.

Freebody, P. (2003). Qualitative research in education: Interaction and practice. Thousand Oaks, CA: SAGE.

Fuller, E., Williams, S., Nash, A. M., \& Young, M. D. (2016). Equity, diversity, and the ISLLC and PSEL standards. UCEA Review, 57(1), 19-22)

Futernick, K. (2007). A possible dream: Retaining California teachers so all students learn. Retrieved from https://www.wested.org/wpcontent/uploads/2016/11/139941242532061.TeacherRetention_Futernick07-3.pdf

Ghavifekr, S., \& Pillai, N. S. (2016). The relationship between school's organizational climate and teacher's job satisfaction: Malaysian experience. Asia Pacific Educational Review, 17, 87-106.

Glesne, C. (2016). Qualitative researchers: An introduction (5th ed.). Boston, MA: Pearson.

Goe, L., Bell, C., \& Little, O. (2008, June). Approaches to evaluating teacher effectiveness: A research synthesis. Retrieved from https://gtlcenter.org/sites/default/files/docs/EvaluatingTeachEffectiveness.pdf 
Goetz, J. P., \& LeCompte, M. D. (1984). Ethnography and qualitative design in educational research. Orlando, FL: Academic Press.

Goffman, E. (1961). Encounters: Two studies in the sociology of interaction. Indianapolis, IN: Bobbs-Merrill Co.

Goldhaber, D. (2015). Exploring the potential of value-added performance measures to affect the quality of the teacher workforce. Educational Researcher, 44(2), 87-95.

Goldhaber, D., Gross, B., \& Player, D. (2007). Are public schools really losing their best? Assessing the career transitions of teachers and their implications for the quality of the teacher workforce. National Center for Analysis of Longitudinal Data in Education Research. Retrieved from http://files.eric.ed.gov/fulltext/ED509666.pdf

Goldhaber, D., \& Hansen, M. (2010). Race, gender, and teacher testing: How informative a tool is teacher licensure testing? American Research Journal, 47(1), 218-251.

Goodlad, J. I. (1984). A place called school. New York, NY: McGraw-Hill.

Gray, L., \& Taie, S. (2015). Public school attrition and mobility in the first five years: Results from the first through five waves of the 2007-08 beginning teacher longitudinal study. National Center for Education Statistics. Retrieved from https://nces.ed.gov/pubs2015/2015337.pdf

Griffith, J. (2004). Relation of principal transformational leadership to school staff, job satisfaction, staff turnover, and school performance. Journal of Educational Administration, 42(3), 333-356.

Grissmer, D., \& Kirby, S. (1987). Teacher attrition: The uphill climb to staff the nation's schools. Santa Monica, CA: RAND. 
Grissmer, D., \& Kirby, S. (1997). Teacher turnover and teacher quality. Teacher College Record, 99(1), 45-56.

Grissmer D. W., \& Kirby, S. N. (1994). Teacher retention: Linking research and policy. Santa Monica, CA: RAND.

Grissom, J. A., \& Strunk, K. O. (2012). How should school districts shape teacher salary schedule? Linking school performance to pay structure in traditional compensation. Education Policy, 26(5), 663-695.

Gritz, R. M., \& Theobald, N. D. (1996). The effects of school district spending priorities on length of stay in teaching. Journal of Human Resources, 31(3), 477-512.

Guarino, C., Santibañez, L., \& Daley, G. (2011). Teacher recruitment and retention: Review of recent empirical literature. Review of Educational Research, 76, 173208.

Guba, E. G., \& Lincoln, Y. S. (1981). Effective evaluation. San Francisco, CA: JosseyBass.

Guglielmi, D., Bruni, I., Simbula, S., Fraccaroli, F., \& Depolo, M. (2016). What drives teacher engagement: A study of different age cohorts. European Journal of Psychology of Education, 31, 323-340. doi:10. 1007/s10212-015-1263-8

Hakanen, J. J., Bakker, A. B., \& Schaufeli, W. B. (2006). Burnout and work engagement among teachers. Journal of School Psychology, 43, 495-513. doi:10.1016/j.jsp.2005.11.001

Hanushek, E., Kain, J., \& Rivkin, S. G. (2004). Why do public schools lose teachers? Journal of Human Resources, 39(2), 326-354. 
Hanushek, E., \& Raymond, M. (2005). Does school accountability lead to improved student performance? Journal of Policy Analysis and Management, 24(2), 297327.

Hanushek, E., \& Rivkin, S. (2007). Pay, working conditions, and teacher quality. Future of Children, 17(1), 69-86.

Hanushek, E. A., Kain, J. F., O’Brien, D. M., \& Rivkin, S. G. (2005). The market of teacher quality. (Working Paper No. 11154). National Bureau of Economic Research. Retrieved from https://hanushek.stanford.edu.sites/default/files/publications/Hanushek+Kain+O' Brien+rivkin\%202005\%20NBER\%20w11154.pdf

Hanushek, E. A., Kain, J. F., \& Rivkin, S. G. (1999). Do higher salaries buy better teachers? (Working Paper No. 7082). National Bureau of Economic Research. Retrieved from http://www.nber.org/papers/w7082

Harris, D. N., Ingle, W. K., \& Rutledge, S. A. (2014). How teacher evaluation methods matter for accountability: A comparative analysis of teacher effectiveness ratings by principals and teacher value-added measures. American Educational Research Journal, 51(1), 73-112.

Harter, J. K., Schmidt, F. L., \& Hayes, T. L. (2002). Business-unit-level relationship between employee satisfaction, employee engagement, and business outcomes: A meta-analysis. Journal of Applied Psychology, 87(2), 268-279.

Harwell, M., \& LeBeau, B. (2010). Student eligibility for free lunch as an SES measure in education research. Education Researcher, 39(2), 120-131. 
Henke, R., Chen, X., Geis, S., \& Knepper, P. (2000). Progress through the teacher pipeline: 1992-93 college graduates and elementary/secondary teaching as of 1997 (Report No. NCES 2000-152). Retrieved from National Center for Education Statistics: http://nces.ed.gov/pubs2000/2000152.pdf

Henry, G., Fortner, K., \& Bastian, K. (2012). The effects of experience and attrition for novice high school science and mathematics teachers. Science, 335, 1118-1121.

Heyns, B. (1988). Educational defectors: A first look at teacher attrition in the NLS-72. Educational Researcher, 17(3), 24-32.

Hirsch E., \& Emerick, S., Church, K., \& Fuller, E. (2007). Teacher working conditions are student learning conditions: A report on the 2006 North Carolina teacher working conditions survey. Center for Teaching Quality. Retrieved from https://files.eric.ed.gov/fulltext/ED498770.pdf

Hughes, G. D. (2012). Teacher retention: Teacher characteristics, school characteristics, organizational characteristics, and teacher efficacy. The Journal of Educational Research, 105(4), 245-255.

Imazeki, R. M. (2005). Teacher salaries and teacher attrition. Economics of Education Review, 24(4), 431-449.

Ingersoll, R. M. (2011). Do we produce enough mathematics and science teachers? Phi Delta Kappan, 92(6), 37-41.

Ingersoll, R. M., \& Absalam, N. (1997). Teacher professionalism and teacher commitment: A multi-level analysis. National Center for Education Statistics. Retrieved from www.http://nces.ed.gov/pubs/97069.pdf 
Ingersoll, R., \& May, H. (2011). The magnitude, destinations, and determinants of mathematics and science teacher turnover. Education Evaluation and Policy Analysis, 34(4), 435-464.

Ingersoll, R., \& Merrill, L. (2013). Seven trends: The transformation of the teaching force. Philadelphia, PA: Consortium for Policy Research in Education.

Ingersoll, R., Merrill, L., \& Stuckey, D. (2014). Seven trends: the transformation of the teaching force. Philadelphia, PA: Consortium for Policy Research in Education.

Ingersoll, R., \& Perda, D. (2012). How high is teacher turnover and is it a problem? Consortium for Policy Research in Education. University of Pensilvania.

Ingersoll, R., \& Strong, M. (2011). The impact of induction and mentoring programs for beginning teachers: A critical review of the research. Review of Education Research, 81(2), 201-233.

Ingersoll, R.M. (2001). Teacher turnover and teacher shortages: An organizational analysis. American Educational Research Journal, 38(3), 499-534.

Ingersoll, R. M. (2003, September). Is there really a teacher shortage? Retrieved from https://repository.upenn.edu/cgi/viewcontent.cgi?article=1133\&context=gse_pubs

Ingersoll, R. M., \& Kralik, J. M. (2004, February). The impact of mentoring on teacher retention: What the research says. Retrieved from http://www.gse.upenn.edu/pdf/rmi/ECS-RMI-2004.pdf

Ingersoll, R. M., \& Smith, T. M. (2003). The wrong solution to the teacher shortage. Educational Leadership, 60(8), 30-33.

Ingersoll, R. M., \& Strong, M. (2011). The impact of induction and mentoring programs for beginning teachers. Review of Educational Research, 81(2), 201-233. 
Ingle, W. K. (2009). Teacher quality and attrition in a U.S. school district. Journal of Educational Administration, 47(5), 557-585.

Jackson, C.K. (2013). Match quality, worker productivity, and worker mobility: Direct evidence from teachers. Review of Economics and Statistics. 95(4), 1096-1116.

Kahlenberg, R. D. (2015). Tenure: How due process protects teachers and students. Retrieved from https:/www.aft.org/ae/summer2015/kahlenberg

Kahn, W. A. (1990). Psychological conditions of personal engagement and disengagement at work. Academy of Management, 33(4), 692-724.

Kahn, W. A. (1992). To be fully there: Psychological presence at work. Human Relations, 45, 321-349.

Karge, B. D. (1993). Beginning teachers: In danger of attrition. Paper presented at the Annual Meeting of the American Educational Research Association, Atlanta, GA. Retrieved from http://files.eric.ed.gov/fulltext/ED360281.pdf

Kirby, S. N., Berends, M., \& Naftel, S. (1999). Supply and demand of minority teachers in Texas: Problems and prospects. Educational Evaluation and Policy Analysis, 21(1), 47-66.

Kraft, M. A., Marinell, W. H., \& Yee, D. (2016). School organizational contexts, teacher turnover, and student achievement: Evidence from panel data. American Educational Research Journal, 53(5), 1411-1449.

Krieg, J. M. (2006). Teacher quality and attrition. Economics of Education Review, 25(1), $13-27$.

Kyriacou, C., \& Sutcliffe, J. (1978). Teacher stress: Prevalence, sources, and symptoms. Journal of Educational Psychology, 48, 159-167. 
Ladd, H. F., \& Sorensen, L. C. (2017). Returns to teacher experience: Student achievement and motivation in middle school. Education Finance and Policy, $12(2), 241-279$

Lankford, M., Loeb, S., \& Wyckoff, J. (2002). Teacher sorting and the plight of urban schools: A descriptive analysis. Educational Evaluation and Policy Analysis, 24(1), 37-62.

Lee, J., \& Orfield, G. (2006, June). Tracking achievement gaps and assessing the Impact of NCLB on the gaps: An in-depth look at national and state reading and math outcome trends. Retrieved from http://civilrightsproject.ucla.edu/research/k-12education/integration-and-diversity/tracking-achievement-gaps-and-assessing-theimpact-of-nclb-on-the-gaps/lee-tracking-achievement-gaps-2006.pdf

Leithwood, K., Louis, K. S., Anderson, S., \& Wahlstrom, K. (2004). How leadership influences student learning. Center for Applied Research and Educational Improvement. Retrieved from http://www.wallacefoundation.org/knowledgecenter/Documents/How-Leadership-Influences-Student-Learning.pdf

Lincoln, Y. S. \& Guba, E. G. (1985). Naturalistic Inquiry. Newbury Park, CA: Sage Publication.

Loeb, S., Darling-Hammond, L., \& Luczak, J. (2005). How teaching conditions predict teacher turnover in California schools. Peabody Journal of Education, 80(3), 4470.

Loeb, S., \& Page, M. (2000). Examining the link between teacher wages and outcomes: The importance of alternative labor market opportunities and non-pecuniary variations. Review of Economics and Statistics, 82(3), 393-408. 
Lopez, O. (2007). Classroom diversification: An alternative paradigm for research in educational productivity. Review of Educational Research, 77(1), 128-180.

Lortie, D. C. (1975). School teacher: A sociological study. Chicago, IL: University of Chicago Press.

Ma, X., \& MacMillan, R. B. (1999). Influences of workplace conditions on teachers' job satisfaction. The Journal of Educational Research, 93(1), 39-47.

Macey, W. H., \& Schneider, B. (2008). The meaning of employee engagement. Industrial and Organizational Psychology, 1, 3-30.

Marinell, W. H., \& Coca, V. M. (2013). Who stays and who leaves? Findings from a three-part study of teacher turnover in NYC middle schools. Retrieved from https://steinhardt.nyu.edu/scmsAdmin/media/users/sg158/PDFs/ttp_synthesis/TTP Synthesis_ExecutiveSummary_March2013.pdf

Maslach, C., Schaufeli, W. B., \& Leiter, M. P. (2001). Job burnout. Annual Review of Psychology, 52(1), 397-422.

McCarthy, C. J., Lambert, R. G., Fitchell, P., \& Baddouh, P. G. (2016). Assess teacher appraisals and stress in the classroom: Review of the classroom appraisal of resources and demands. Educational Psychology Review, 28(3), 577-603.

McCarthy, C. J., Lambert, R. G., \& Reiser, J. (2014). Vocational concerns of elementary teachers: Stress, job satisfaction, and occupational commitment. Journal of Employment Counseling, 51(2), 59-74. doi:10.1002/j.2161-1920.2014.00042.x

McMillan, J., \& Schumacher, S. (2001). Research in education: A conceptual introduction. New York, NY: Addison Wesley Longman. 
Merriam, S. B. (1988). Case study research in education: A qualitative approach. San Francisco, CA: Jossey-Bass Publishers.

Meyer, J. P., \& Gagné, M. (2008). Employee engagement from self-determination theory perspective. Industrial and Organizational Psychology, 1, 60-62.

Metlife. (2012). The Metlife survey of the American teacher: Teachers, parents and the economy. Retrieved from http://files.eric.ed.gov/fulltext/ED530021.pdf

Miles, M. B., Huberman, M., \& Saldaña, J. (2014). Qualitative data analysis: A methods sourcebook (3rd ed.). Los Angeles, CA: Sage.

Milner, H, R., IV (2007). Race, culture, and researcher positionality: Working through the dangers see, unseen, and unforeseen. American Educational Research Association, 36(7), 388-400.

Mont, D., \& Rees, D. I. (1996). The influence of classroom characteristics on high school teacher turnover. Economic Inquiry, 34, 152-167.

Moustakas, C. (1994). Phenomenological research methods. Thousand Oaks, CA: Sage. Murnane, R., Singer, J., \& Willett, J. (1988). The career paths of teachers: Implications for teacher supply and methodological lessons for research. Educational Researcher, 17(5), 22-30.

Murnane, R. J. (1984). Selection and survival in the teacher labor market. The Review of Economics and Statistics, 66(3), 513-518.

Murnane, R. J., Singer, J.D., \& Willett, J. B. (1989). The influences of salaries “opportunity costs” on teachers' career choices: Evidence from North Carolina. Harvard Educational Review, 59(3), 325-346. 
Murnane, R. J., Singer, J. D., Willett, J. B., Kemple, J. J., \& Olsen, R. J. (1991). Who will teach? Cambridge, MA: Harvard University Press.

National Board for Professional Teaching Standards. (2018). National board certification. Retrieved from http://www.nbpts.org/national-board-certification/

National Commission on Teaching and America's Future (NCTAF). (2003, January). No dream denied: A pledge to America's children. Retrieved from http://nctaf.org/wp-content/uploads/no-dream-denied_summary_report.pdf National Education Association (NEA). (2010, December) Teacher assessment and evaluation: The National Education Association's framework for transforming education systems to support effective teaching and improve student learning. Retrieved from http://www.nea.org/assets/docs/HE/TeachrAssmntWhtPaperTransform10_2.pdf National Strategic Planning Analysis Research Center. (2017, May). The impact of national board certified teachers on the literacy outcomes of Mississippi kindergarteners and third graders. Retrieved from http://www.nbpts.org/wpcontent/uploads/NBCT_MS_Report.pdf

Nienaber, H., \& Martins, N. (2014). An employee engagement instrument and framework building on existing research. Mediterranean Journal of Social Sciences, 5(20), 485-496.

Novick, G. (2008). Is there a bias against telephone interviews in qualitative research? Research in Nursing \& Health, 31, 391-398.

Okas, A., Van der Schaaf, M., \& Krull, E. (2014). Novice and experienced teachers’ views on professionalism. Trames, 18(4), 327-344. 
Palinkas, L. A., Horwitz, S. M., Green, C. A., Wisdom, J. P., Duan. N., \& Hoagwood, K. (2013). Purposeful sampling for qualitative data collection and analysis in mixedmethod implementation research. Administration and policy in Mental Health and Mental Health Services Research, 42(5), 533-544.

Patton, M. (2002). Qualitative research \& evaluation methods (3rd ed.). Thousand Oaks, CA: Sage.

Perda, D. (2013). Transitions into and out of teaching: A longitudinal analysis of early career teacher turnover. Retrieved from ProQuest Digital Dissertations. (AAI 3594959)

Perrachione, A. B., Rosser, V. J., \& Petersen, G.J. (2008). Why do they stay? Elementary teachers' perceptions of job satisfaction and retention. The Professional Educator, $32(2), 24-41$.

Petty, T. M., O’Connor, K. A., \& Dagenhart, D. B. (2011). Staffing high-need middle schools: North Carolina teachers' perspectives. North Carolina Middle School Association Journal, 26(1). Retrieved from http://www.ncmle.org/journal/

Pogodzinski, B., Youngs, P., Frank, K. A., \& Belman, D. (2012). Administrative climate and novices' intent to remain in teaching. The Elementary School Journal, 113(2), $252-275$.

Popp, P. A., Grant, L. W., \& Stronge, J. H. (2011). Effective teachers for at-risk or highly mobile students: What are the dispositions and behaviors of award-winning teachers? Journal for Students Places At-Risk, 16, 275-291. doi:1080/10824669.2011.610236 
RAND Education. (2015). Evaluating teaching effectiveness: The intensive partnership for effective teaching initiative. RAND Corporation. Retrieved from http://rand.org/education/projects/evaluating-teaching-effectiveness.html

Rao, M. S. (2014). Transformational leadership: An academic case study. Industrial and Commercial Training, 46(3), 150-154.

Redding, C., \& Smith, T. M. (2016). Easy in, easy out: Are alternatively certified teachers turning over at increased rates? American Educations Research Journal, 53(4), 1086-1125.

Rich, B. L., LePine, J. A., \& Crawford, E. R. (2010). Job engagement: Antecedent and effects on job performance. Academy of Management Journal, 53(3), 617-635.

Rivkin, S. G., Hanushek, E. A., \& Kain, J. F. (2005). Teachers, schools, and academic achievement. Econometrica, 73(2), 417-458.

Ronfeldt, M., Loeb, S., \& Wyckoff, J. (2013). How teacher turnover harms student achievement. American Educational Research Journal, 50(1), 4-36.

Rubin, H. J., \& Rubin, I. S. (2011). Qualitative interviewing: The art of hearing data (3rd ed.). Thousand Oaks, CA: Sage.

Saks, A. M. (2006). Antecedents and consequences of employee engagement. Journal of Managerial Psychology, 21(7), 600-619.

Saldaña, J. (2013). The coding manual for qualitative researchers (2nd ed.). London: Sage.

Sawchuk, S. (2015, March 25). New studies find that, for teachers, experience really matter. Education Week. Retrieved from 
http://edweek.org/ew/articles/2015/03/25/new-studies-find-that-for-teachersexperience.html

Schaufeli, W. B., Bakker, A. B., \& Salanova, M. (2006). The measurement of work engagement with a short questionnaire. Educational and Psychological Measurement, 66(4), 701-716.

Schaufeli, W. B., Salanova, M., González-Roma, V., \& Bakker, A. B. (2002). The measurement of engagement and burnout: A two sample confirmatory factor analysis approach. Journal of Happiness Studies, 3, 71-92.

Shirom, A. (2003). Feeling vigorous at work? The construct of vigor and the study of positive affect in organizations. In D, Ganster \& P. L. Perrewe (Eds.), Research in organizational stress and well-being (pp. 135-165). Greenwich, CT: JAI. doi:10.1016/S1479-3555(03)03004-X

Shuck, B. (2011). Four emerging perspectives of employee engagement: An integrative literature review. Human Resource Development Review, 10(3), 304-328.

Shuck, B., Adelson, J. L., \& Reio, T. G. (2016). The employee engagement scale: Initial evidence for construct validity and implications for theory and practice. Human Resource Management, 56(6), pp. 953-977. doi:10.1002/hrm.21811

Shuck, B., Nimon, K., \& Zigarmi, D. (2017). Untangling the predictive nomological validity of employee engagement: Participating variance in employee engagement using job attitude measures. Group and Organizational Management, 42(1), 79112. 
Shuck, B., Reio, T., \& Rocco, T. (2011). Employee engagement: An antecedent and outcome approach to model development. Human Resource Development International, 14, 427-445, doi:10.1080/13678868.2011.601587

Shuck, B., \& Wollard, K. (2010). Employee engagement \& HRD: A seminal review of the foundations. Human Resource Development Review, 9(1), 89-110.

Simon, N. S., \& Johnson, S. M. (2015). Teacher turnover in high-poverty schools: What we know and can do. Teacher College Record, 117, 030308.

Smith, T., \& Ingersoll, R. (2004). What are the effects of induction and mentoring on beginning teacher turnover? American Educational Research Journal, 41(3), 687 714.

Spadley, J. P. (1979). The ethnographic interview. New York, NY: Harcourt Brace Jovanich College Publisher.

Spillane, J. P. (2005). Distributed leadership. The Education Forum, 69(2), 143-150.

Stinebrickner, T. R. (1999). Estimation of a duration model in the presence of missing data. Review of Economics and Statistics, 81(3), 529-542.

Strauss, A., \& Corbin, J. (1998). Basics of qualitative research: Techniques and procedures for developing grounded theory (2nd ed.). Thousand Oaks, CA: Sage.

Strecher, B. M., Garet, M. S., Hamilton, L. S., Steiner, E. D., Robyn, A., Poirier, \& J De los Reyes, I. B. (2016). Taking stock: The intensive partnerships for effective teaching through 2013-2014. RAND Corporation. Retrieved from http://www.rand.org/pubs/research_briefs/RB9908-1.html

Strong, M. (2011). The highly qualified teacher: What is teacher quality and how do we measure it? Journal of Educational Administration, 51(2), 242-244. 
Stronge, J. H. (2007). Qualities of effective teachers (2nd ed.). Alexandria: VA: Association for Supervision and Curriculum Development.

Suitts, S. (2015). A new majority research bulletin: Low income students now a majority in the nation's public schools. Retrieved from http://www.southerneducation.org/Our-Strategies/Research-andPublications/New-Majority-Diverse-Majority-Report-Series/A-New-Majority2015-Update-Low-Income-Students-Now

Tye, B. B., \& O'Brien, L. (2002). The teacher shortage: Why are experienced teachers leaving the profession? Phi Delta Kappan, 84(1), 24-32.

U.S. Department of Education (1997, February). Teacher professionalization and teacher commitment: A multi-level analysis. (Report No. NCES 97-069). National Center for Education Statistics. Retrieved from www.http//nces.ed.gov/pubs/97069.pdf

Wang, M. T., \& Degol, J. L. (2016). School climate: A review of the construct, a measurement, and impact on student outcome. Educational Psychological Review, 28, 315-352.

Wollard, K. K., \& Shuck, B. (2011). Antecedents to employee engagement: A structured review of the literature. Sage Journals, 13(4), 429-446.

Wu, J. (2012). Behavioral engagement: How can you measure it? Retrieved from http://forms.gradsch.psu.edu/diversity/monair/mcnair_jrnl2011/files/Wu.pdf

Yin, R. K. (2014). Case study research: Design and methods (5th ed.). Los Angeles, CA: Sage. 
APPENDIX A

SUMMATIVE TEACHER EVALUATION (FORM D) 
NAME: SCHOOL/LOCATION:

ID \#:

SUBJ./ GRADE

LEVEL:

DATES OF

OBSERVATION:
YEARS OF SERVICE:
PRINCIPAL/COST CENTER HEAD:

DATE:

A comprehensive evaluation will be made by the evaluator using multiple sources of evidence as specified in the Certified Evaluation Plan. A narrative is required for any teacher domain rating that is marked "ineffective" or "developing", and the evaluator and teacher must initial all additional pages. The evaluator may choose to write a narrative for "accomplished" or "exemplary".

PROFESSIONAL PRACTICE

RATING

$+\begin{aligned} & \text { STUDENT GROWTH } \\ & \text { RATING }\end{aligned}=\begin{aligned} & \text { OVERALL } \\ & \text { PERFORMANCE } \\ & \text { CATEGORY }\end{aligned}$

\begin{tabular}{|l|l|l|l|l|}
\hline \multicolumn{1}{|c|}{ Domains } & Ineffective & Developing & Accomplished & Exemplary \\
\hline 1.Planning and & & & & \\
Preparation & & & & \\
\hline 2.Classroom & & & & \\
Environment & & & & \\
\hline 3. Instruction & & & & \\
\hline 4.Professional & & & & \\
Responsibilities & & & & \\
\hline
\end{tabular}

The overall professional practice rating is a holistic rating of performance, combining data

from multiple sources of evidence across each domain of the Framework for Teaching. 


\begin{tabular}{|c|l|l|l|l|}
\hline $\begin{array}{c}\text { Professional } \\
\text { Practice } \\
\text { Rating }\end{array}$ & Ineffective & Developing & Accomplished & Exemplary \\
\cline { 2 - 5 } & & & & \\
\hline
\end{tabular}

\begin{tabular}{|c|c|c|c|}
\hline Overall Student Growth & Low & Expected & High \\
\cline { 2 - 3 } Rating & & & \\
\hline
\end{tabular}

\begin{tabular}{|c|l|l|l|l|}
\hline $\begin{array}{c}\text { Overall } \\
\text { Performance } \\
\text { Category }\end{array}$ & Ineffective & Developing & Accomplished & Exemplary \\
\cline { 2 - 5 } & & & & \\
\hline
\end{tabular}




\section{PROFESSIONAL GROWTH PLAN AND SUMMATIVE CYCLE FOR TEACHERS AND OTHER PROFESSIONALS}

A one-year directed growth plan and summative cycle will apply for all non-tenured teachers. *

\begin{tabular}{|c|c|c|c|}
\hline $\begin{array}{l}\text { If professional } \\
\text { practice rating } \\
\text { is this: }\end{array}$ & $\begin{array}{l}\text { And, if } \\
\text { student } \\
\text { growth rating } \\
\text { is this: }\end{array}$ & Then: & And then this: \\
\hline \multirow[t]{2}{*}{$\begin{array}{l}\text { Exemplary or } \\
\text { Accomplished }\end{array}$} & $\begin{array}{l}\text { High or } \\
\text { Expected }\end{array}$ & $\begin{array}{l}\text { 3-year self- } \\
\text { directed cycle }\end{array}$ & $\begin{array}{l}\text { - Goals set by teacher with } \\
\text { evaluator input. } \\
\text { - Plan activities are teacher } \\
\text { directed and implemented with } \\
\text { colleagues. } \\
\text { - Formative review annually. } \\
\text { - Summative occurs at the end of } \\
\text { year } 3 .\end{array}$ \\
\hline & Low & $\begin{array}{l}\text { 3-year self- } \\
\text { directed cycle }\end{array}$ & $\begin{array}{l}\text { - Goal set by teacher with } \\
\text { evaluator input. } \\
\text { - One goal must focus on low } \\
\text { student growth outcome. } \\
\text { - } \quad \text { Formative review annually. }\end{array}$ \\
\hline \multirow{3}{*}{ Developing } & High & $\begin{array}{l}\text { 3-year self- } \\
\text { directed cycle }\end{array}$ & $\begin{array}{l}\text { - Goal(s) set by educator with } \\
\text { evaluator input. } \\
\text { - Formative review annually. }\end{array}$ \\
\hline & Expected & $\begin{array}{l}\text { 3-year self- } \\
\text { directed cycle }\end{array}$ & $\begin{array}{l}\text { - Goal(s) set by teacher with } \\
\text { evaluator input; one must } \\
\text { address professional practice or } \\
\text { student growth. } \\
\text { - } \quad \text { Formative review annually. }\end{array}$ \\
\hline & Low & $\begin{array}{l}1 \text { year } \\
\text { directed cycle }\end{array}$ & $\begin{array}{l}\text { - Goal(s) determined by } \\
\text { evaluator. } \\
\text { - Goals focus on professional } \\
\text { practice and student growth. } \\
\text { - Plan activities designed by } \\
\text { evaluator with teacher input. } \\
\text { - Summative review annually. }\end{array}$ \\
\hline \multirow[t]{2}{*}{ Ineffective } & $\begin{array}{l}\text { High or } \\
\text { Expected }\end{array}$ & $\begin{array}{l}1 \text { year } \\
\text { directed cycle }\end{array}$ & $\begin{array}{l}\text { - Goal determined by evaluator. } \\
\text { - } \text { Goals focused on low } \\
\text { - Performance/outcome area. } \\
\text { - evaluativities designed by } \\
\text { - } \text { Formative review at midpoint. } \\
\text { - Summative at end of plan. }\end{array}$ \\
\hline & Low & $\begin{array}{l}\text { Up to } 12- \\
\text { month } \\
\text { improvement } \\
\text { plan }\end{array}$ & $\begin{array}{l}\text { - Goal(s) determined by } \\
\text { evaluator. } \\
\text { - } \quad \text { Focus on low performance area. } \\
\text { - Summative at end of plan. } \\
\end{array}$ \\
\hline
\end{tabular}


Next Steps for Professional Growth Plan and Summative Cycle:

\begin{tabular}{|l|l|}
\hline ( ) 3 Year Self-Directed & Next Steps: \\
Cycle & \\
\hline $\begin{array}{ll}\text { ( }) 1 \text { Year Directed Cycle } \\
\text { (All non-tenured teachers } \\
\text { not on Improvement Plan) }\end{array}$ \\
\cline { 1 - 1 } ( ) Improvement Plan \\
$3 \quad 6 \quad 9 \quad 12$ months \\
\hline
\end{tabular}

Optional Comments by Evaluator and/or Teacher:

(May be attached to this form provided the evaluator and teacher have initialed all additional pages.)

The teacher may submit a written response within ten (10) days to be sent to Employee Relations for inclusion in the teacher's personnel file with a copy to the evaluator. Certified personnel have the right to appeal to a WPS Local Evaluation Appeals Panel (LEAP) within fourteen (14) calendar days after receiving a summative evaluation. Appeals must be submitted in writing to the superintendent/designee using the WPS Certified Evaluation Appeals Form. Appeals to a LEAP may be based upon evaluation process or evaluation content concerns.
DATE EVALUATOR DATE EMPLOYEE

PRINCIPAL/COST CENTER

Distribution: Personnel File

$$
\begin{aligned}
& \text { Principal } \\
& \text { Employee }
\end{aligned}
$$

\section{Domain 1: Planning and Preparation}

1A: Demonstrating Knowledge of Content and Pedagogy

1B: Demonstrating Knowledge of Students

1C: Setting Instructional Outcomes 
1D: Demonstrating Knowledge of Resources

1E: Designing Coherent Instruction

1F: Designing Student Assessment

\section{Summary statement:}

\section{Domain 2: Classroom Environment}

2A: Creating an Environment of Respect and Rapport

2B: Establishing a Culture for Learning

2C: Managing Classroom Procedures

2D: Managing Student Behavior

2E: Organizing Physical Space 


\section{Summary statement:}

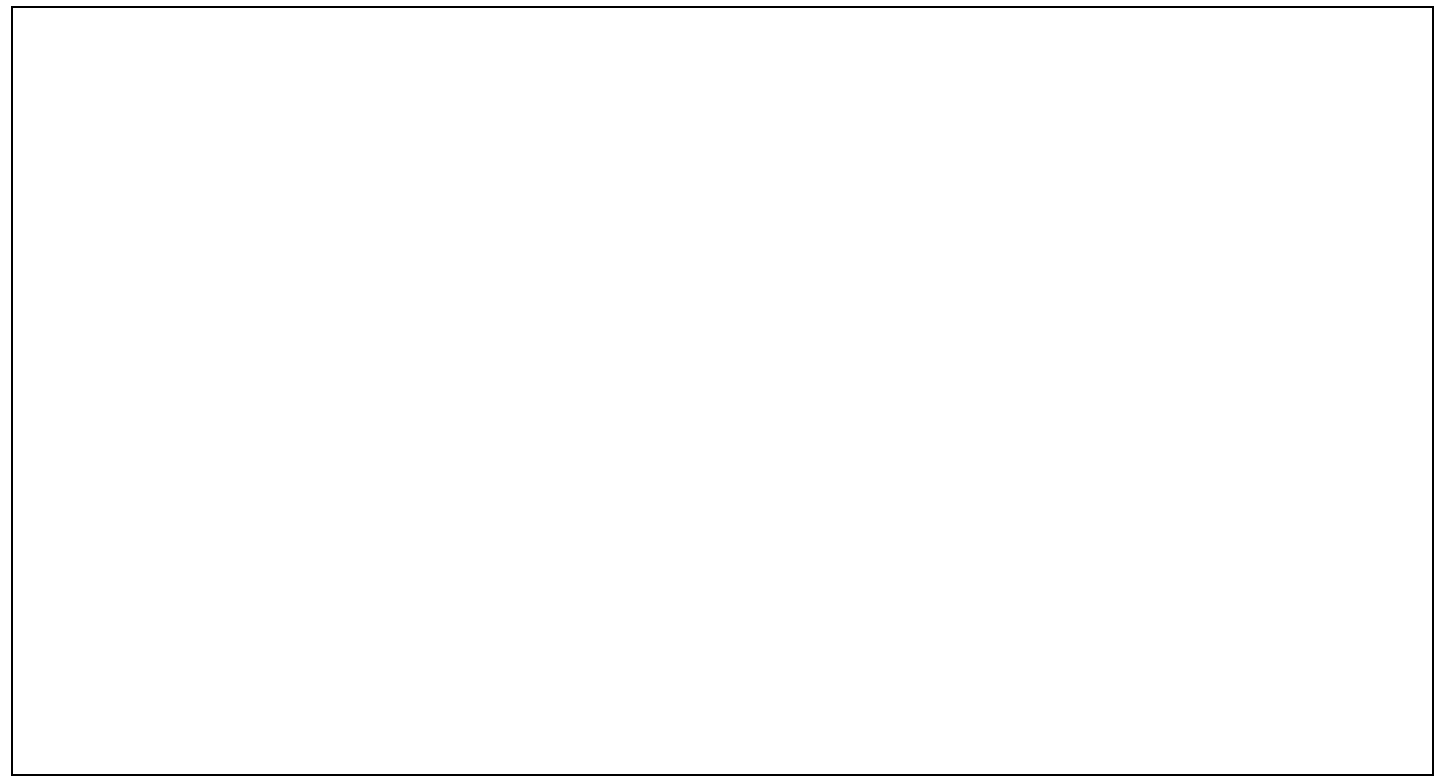

Domain 3: Instruction

3A: Communicating with Students

3B: Questioning and Discussion Techniques

3C: Engaging Students in Learning

3D: Using Assessment in Instruction

3E: Demonstrating Flexibility and Responsiveness

\section{Summary statement:}




\section{Domain 4: Professional Responsibilities}

4A: Reflecting on Teaching

4B: Maintaining Accurate Records

4C: Communicating with Families

4D: Participating in a School Community

4E: Growing and Developing Professionally

4F: Demonstrating Professionalism

\section{Summary statement:}


APPENDIX B

RETENTION OF HIGHLY EFFECTIVE VETERAN TEACHERS:

SUBJECT INFORMED CONSENT DOCUMENT 


\title{
Retention of Highly Effective Veteran Teachers: Subject Informed Consent Document
}

\author{
Principal Investigator name \& address: $\quad$ W. Kyle Ingle, Ph.D. \\ Associate Professor \\ Educational Leadership, Evaluation, \& \\ Organizational Development \\ University of Louisville \\ 1905 South 1st Street \\ Louisville, Kentucky 40292 \\ Site(s) where study is to be conducted: University of Louisville \\ Phone number for subjects to call for questions: (502) 852-6097
}

\section{Introduction and Background Information}

You are invited to participate in a research study. The study is being conducted Dr. W. Kyle Ingle, Dr. Brad Shuck, and Terrie Blackman. The study is sponsored by the University of Louisville, Department of Educational Leadership, Evaluation and Organizational Development. The study will take place at the University of Louisville campus.

\section{Purpose}

This study seeks to examine individual teacher engagement and school climate characteristics that influence highly effective veteran teachers to remain teaching in lowperforming schools in a large urban school district. I propose that if highly effective teachers can be retained in high numbers in low-performing schools, their presence, positive perceptions, and instructional examples may be instrumental in helping to retain other teachers who would otherwise leave. By leaving prematurely, some non-veteran teachers miss opportunities to gain teaching skills and knowledge needed to become quality, experienced teachers. Quality experienced teachers are essential to raising student scores thereby helping to close the achievement gap.

\section{Procedures}

In this study, you will be asked to answer interview questions about your perceptions (whether principal or teacher) of teacher engagement characteristics and school climate characteristics that influence highly effective veteran teachers to remain teaching in lowperforming schools. This study should be completed in Spring 2018. The interviewing process for the purpose of data collection will take approximately 60 minutes per interview. Interviews will be audio recorded. The recording is to accurately store the information you provide and will be used for transcription purposes only. Participant files will be kept on a password-protected computer and voice recording will be store in a locked cabinet. Each participant has the option to decline to answer any questions that 
makes him or her feel uncomfortable and may stop the interview at any time. The minimum number of respondents is 18 .

\section{Potential Risks}

There are no foreseeable risks other than possible discomfort in answering personal questions.

\section{Benefits}

There are no known risks for your participation in this research study. The information collected may not benefit you directly, but the information learned in this study may be helpful to others. I believe that this study will provide valuable insights that may assist in the retention of veteran teachers in low performing schools. Extensive research indicates that veteran teachers are more effective teachers who can influence the turn-around in low performing schools.

\section{Payment}

You will not be compensated for your time, inconvenience, or expenses while you are in this study.

\section{Confidentiality}

Total privacy cannot be guaranteed. We will protect your privacy to the extent permitted by law. If the results from this study are published, your name will not be made public. Once your information leaves our institution, we cannot promise that others will keep it private.

Your information may be shared with the following:

- The sponsor University of Louisville and others hired by the sponsor to oversee the research

- $\quad$ Organizations that provide funding at any time for the conduct of the research.

- $\quad$ The University of Louisville Institutional Review Board, Human Subjects Protection Program Office, Privacy Office, others involved in research administration and compliance at the University, and others contracted by the University for ensuring human subjects safety or research compliance

- $\quad$ The local research team

- Researchers at other sites participating in the study (if applicable)

- $\quad$ People who are responsible for research, compliance and HIPAA oversight at the institutions where the research is conducted

- $\quad$ People responsible for billing, sending and receiving payments related to your participation in the study

- Government agencies, such as:

- Office for Human Research Protections

- Office of Civil Rights 


\section{Conflict of Interest}

There is no conflict of interest associated with this study. The investigator is not being compensated for undertaking this study.

\section{Security}

The researcher will assign identifiers such as Participant 1,2, and so on, and pseudonyms to protect the names of work locations. Research will be conducted in a completely private location where others will not walk in on the interview or hear respondents' responses. Respondents will be advised not to use real names or locations at any time during the interview. If real names are mentioned in any recording, the real names will not be typed into the transcription (pseudonyms will be used). Consent forms (which have participant names) will not be attached to any of the data collected from specific individuals. Consent forms and data will be locked in a file cabinet and password protected computer.

\section{Voluntary Participation}

Taking part in this study is voluntary. You may choose not to take part at all. If you decide to be in this study you may stop taking part at any time. If you decide not to be in this study or if you stop taking part at any time, you will not lose any benefits for which you may qualify.

\section{Contact Persons, Research Subject's Rights, Questions, Concerns, and Complaints}

If you have any concerns or complaints about the study or the study staff, you have three options.

You may contact the principal investigators, Dr. W. Kyle Ingle (502) 852-6097 or william.ingle@louisville.edu and Dr. Brad Shuck at (502) 852-7396 or brad.shuck@louisville.edu. You may also contact the co-investigator assisting with the study, Terrie Blackman at (502) 271-7765 or terrie.blackman@jefferson.kyschools.us.

If you have any questions about your rights as a study subject, questions, concerns, or complaints, you may call the Human Subjects Protection Program Office (HSPPO) (502) 852-5188. You may discuss any questions about your rights as a subject, in secret, with a member of the Institutional Review Board (IRB) or the HSPPO staff. The IRB is an independent committee composed of members of the University community, staff of the institutions, as well as lay members of the community not connected with these institutions. The IRB has reviewed this study.

If you want to speak to a person outside the University, you may call 1-877-8521167. You will be given the chance to talk about any questions, concerns, or 
complaints in secret. This is a 24-hour hot line answered by people who do not work at the University of Louisville.

\section{Acknowledgment and Signatures}

This informed consent document is not a contract. This document tells you what will happen during the study if you choose to take part. Your signature indicates that this study has been explained to you, that your questions have been answered, and that you agree to take part in the study. You are not giving up any legal rights to which you are entitled by signing this informed consent document. You will be given a copy of this consent form to keep for your records.

\begin{tabular}{|c|c|c|}
\hline Subject Name (Please Print) & Signature of Subject & Date Signed \\
\hline $\begin{array}{l}\text { Printed Name of Legally } \\
\text { Authorized Representative } \\
\text { (if applicable) }\end{array}$ & $\begin{array}{c}\text { Signature of Legally } \\
\text { Authorized Representative }\end{array}$ & Date Signed \\
\hline
\end{tabular}

Authority of Legally Authorized Representative to act on behalf of Subject

*Authority to act on behalf of another includes, but is not limited to parent, guardian, or durable power of attorney for health care.

\begin{tabular}{ccc}
\hline $\begin{array}{c}\text { Printed Name of Person Explaining } \\
\text { Consent Form }\end{array}$ & $\begin{array}{c}\text { Signature of Person Explaining } \\
\text { Consent form (if other than } \\
\text { Investigator) }\end{array}$ \\
\hline $\begin{array}{c}\text { Printed Name of } \\
\text { Investigator }\end{array}$ & Signature of Investigator & Date Signed
\end{tabular}

\section{List of Investigators:}

Dr. W. Kyle Ingle

Dr. Brad Shuck

Terrie Blackman

\section{Phone Numbers:}

(502) 852-6097

(502) 852-7396

(502) 271-7765 


\begin{abstract}
APPENDIX C
INTERVIEW PROTOCOL FOR DISSERTATION STUDY

INTERVIEWEES: HIGHLY EFFECTIVE VETERAN TEACHERS
\end{abstract}


Terrie Blackman, M. Ed.

Candidate for Doctor of Education (Ed. D.)

Interview Protocol for Dissertation Study

Interviewees: Highly Effective Veteran Teachers

Topic

An examination of individual teacher engagement and school climate characteristics that

influence highly effective veteran teacher to remain teaching in low performing schools.

\section{Brief description of the study:}

The nation faces the challenge of teacher shortage. This is a problem particularly in lowperforming urban schools. However, there is a cohort of highly effective veteran teachers who continue to teach in these schools despite the challenges typically associated with such schools. The purpose of this study to examine individual teacher engagement and school climate characteristics that influence highly effective veteran teachers to continue teaching in low-performing schools.

Therefore, you will be asked questions about your perception of teacher engagement characteristics and school climate characteristics that influence highly effective veteran teachers to remain teaching in low-performing schools. In this interview, I will identify myself as "The Researcher." You will be identified as "Participant number 1, 2, 3, and so on." The interview should last approximately 60 mins. This interview will be audiotaped and later transcribed. Recorded interviews and transcriptions will be stored in a secure place. You may decline to answer any questions that make you feel uncomfortable or stop the interview at any time.

\section{Definition of highly effective veteran teacher:}

In this study, a veteran teacher is a teacher who has been teaching for over five years. Highly effective teachers plan and prepare appropriate instruction, is knowledgeable about content and pedagogy. They find multiple ways to assess and actively encourage students to reflect and engage in self-reflection. Highly effective teachers ensure a safe, positive, and culturally competent learning environment with high expectations that are clearly articulated to all students, provide instruction that is rigorous and they actively engage students in learning. They assist students in connecting personal experiences and current events to the learning from text. Highly effective teachers engage in professional responsibilities. They communicate with families and maintain a high degree of professionalism.

Today's date: 


\section{Participant Demographic Information}

Name:

Ethnicity:

Gender:

Age: $27-35 ; 36-45 ; 46-55$; Over 55

Years of Teaching:

School/Level:

Number of years at current school:

Grade level:

Subject/s taught by participant: Interview questions to explicate each research question

Research Question 1: What are the characteristics of highly effective veteran teachers who remain teaching in low-performing schools?

\section{CLASSROOM INSTRUCTION}

1. Describe your classroom environment and how you create and communicate expectations to students

Prompt: Creating a positive learning environment

Artifacts and activities that sets the mood for the day 
2. Describe how you go about planning and preparing for classroom instruction.

$\begin{array}{ll}\text { Prompts: } & \text { Amount of time spent planning } \\ \text { Collaboration with others } \\ \text { Accessing resources to enhance learning }\end{array}$

3. Describe the instructional strategies you use in the classroom.

Prompts: Teaching tools

Differentiation of instruction

Activities

Assessments

\section{BEHAVIOR MANAGEMENT}

4. Describe how and when you communicate expectations of student behavior to students. 
5. How do you manage student behavior against the expectations you outlined to students?

6. How do students respond to your management guidelines?

\section{STUDENT ENGAGEMENT AND DEVELOPMENT}

7. Describe the ways in which you build relationships with students.

Prompt: How do you engage students?

Check on students' well-being

Connect with parents to engage in student development 


\section{PROFESSIONAL RESPONSIBILITIES}

8. The following are included in the list of professional responsibilities of all teachers. Describe the ways in which you carry-out each of these responsibilities:

a. Self-reflection

b. Record- keeping

c. Communicating with internal and external constituents (students, other teachers, administrators, parents, community leaders, school district representatives)

\section{Research Question 2: In what ways are highly effective veteran teachers engaged in low-performing schools?}

1. Why did you choose teaching as a profession? 
2. Given your experiences to date, what is it about your job that allows you to persist in the teaching profession?

3. Describe any safety concerns that you have about your current school.

a. What do you do to remain focused on your job despite these concerns?

4. Describe the adequacy of time and resources you need to do a good job.

a. How does the adequacy (or lack of) time and resources affect your attitude to your work?

b. How does the adequacy of time and resources affect your work output and performance?

i. What feedback do you receive from administrators and your peers about your performance? 
5. Describe the ways in which your work contributes to the advancement of the school.

\section{Prompts: Work climate}

Meeting AYP requirements

Student development

Stakeholder engagement

Extracurricular activities

SBDM or other committees 
6. To what extent do you enjoy your work? Please explain.

7. To what extent do you find your work to be challenging? Please explain.

8. To what extent do you feel obligated to effectively complete your work assignments? Explain.

Research Question 3: How do highly effective veteran teachers perceive their engagement as contributing to their commitment to remain teaching in the lowperforming schools?

1. How would you describe the climate at your school? 
a. What aspects of the school's climate positively influence your willingness to remain at your current school?

b. What aspects of the school's climate cause you to consider leaving your current school?

2. Describe your relationship with your peers and the extent to which those relationships influence your desire to remain at your current school.

3. Describe your relationship with the school's administration and the extent to which these relationships influence your decision to remain at the current school.

4. Describe your relationship with students and the extent to which these relationships influence your decision to remain at the current school. 
5. What other significant relationships influence your desire to remain at the current school?

6. Reflecting on your work, what would you change about your job if you had the power to change it?

7. Are you likely to consider leaving this school over the next two to three years?

a. If yes, will you go to another school or leave the teaching profession?

b. What factors are causing you to consider a possible move? 


\begin{abstract}
APPENDIX D
INTERVIEW PROTOCOL FOR DISSERTATION STUDY

INTERVIEWEES: PRINCIPALS AND TEACHER COLLEAGUES
\end{abstract}


Terrie Blackman, M. Ed.

Candidate for Doctor of Education (Ed. D.)

Interview Protocol for Dissertation Study

Interviewees: Principals and Teacher Colleagues

Topic

An examination of individual teacher engagement and school climate characteristics that

influence highly effective veteran teacher to remain teaching in low performing schools.

\section{Brief description of the study:}

Th nation faces the challenge of teacher shortage. This is a problem particularly in lowperforming urban schools. However, there is a cohort of highly effective veteran teachers who continue to teach in these schools despite the challenges typically associated with such schools. The purpose of this study to examine individual teacher engagement and school climate characteristics that influence highly effective veteran teachers to continue teaching in low-performing schools. Therefore, you will be asked questions about your perception of teacher engagement characteristics and school climate characteristics that influence highly effective veteran teachers to remain teaching in low-performing schools. In this interview, I will identify myself as "The Researcher." You will be identified as "Participant number 1, 2, 3, and so on." The interview should last approximately 60 mins. This interview will be audiotaped and later transcribed. Recorded interviews and transcriptions will be stored in a secure place. You may decline to answer any questions that make you feel uncomfortable or stop the interview at any time.

\section{Definition of highly effective veteran teacher:}

In this study, a veteran teacher is a teacher who has been teaching for over five years. Highly effective teachers plan and prepare appropriate instruction, is knowledgeable about content and pedagogy. They find multiple ways to assess and actively encourage students to reflect and engage in self-reflection. Highly effective teachers ensure a safe, positive, and culturally competent learning environment with high expectations that are clearly articulated to all students, provide instruction that is rigorous and they actively engage students in learning. They assist students in connecting personal experiences and current events to the learning from text. Highly effective teachers engage in professional responsibilities. They communicate with families and maintain a high degree of professionalism. 
Today's date:

$$
\text { Participant Demographic Information }
$$

Name:

Ethnicity:

Gender:

Age: $27-35 ; 36-45 ; 46-55$; Over 55

Role: (Teacher or Administrator)

Years of Teaching or as Administrator:

School/Level:

Number of years at current school:

For Teachers:

Grade level:

Subjects taught by participant:

Interview questions to explicate each research question

Research Question 1: What are the characteristics of highly effective veteran teachers who remain teaching in low-performing schools?

1. What is your perception of how highly effective veteran teachers exemplify the following?

\section{CLASSROOM INSTRUCTION}

2. Creating a positive classroom environment and communicating expectations to students

Prompt: Artifacts and activities that sets the mood for the day 
3. Planning and preparing for classroom instruction.

Prompts: Amount of time spent planning

Collaboration with others

Accessing resources to enhance learning

4. Use of instructional strategies in the classroom.

Prompts: Teaching tools

Differentiation of instruction

Activities

Assessments

\section{BEHAVIOR MANAGEMENT}

5. Communicate expectations of student behavior to students.

6. Manage student behavior against the expectations you outlined to students? 


\section{STUDENT ENGAGEMENT AND DEVELOPMENT}

7. Build relationships with students.

Prompt: How to directly engage students

Check on students' well-being

Connect with parents to engage in student development

\section{PROFESSIONAL RESPONSIBILITIES}

8. Carry-out each of the following professional responsibilities:

a. Self-reflection

b. Record keeping

c. Communicating with internal and external constituents (students, other teachers, administrators, parents, community leaders, school district representatives)

\section{Research Question 2: In what ways are highly effective veteran teachers engaged in low-performing schools?}

1. Based on your knowledge of teachers in the building, can you identify three or four teachers who you would consider to be highly effective? What are their names? 
2. What is your perception of how they exemplify the following:

a. Management of safety concerns that arise in the school.

b. Positive attitude despite limited time and resources to do the job

c. Work output and overall performance.

3. What are the ways in which they contribute to the advancement of the school?

Prompts: Meeting AYP requirements

Student development

Stakeholder engagement

Involved in extracurricular activities

Serve on the SBDM or other committees 
4. What is your perception of whether they enjoy their work and how is that exemplified?

Research Question 3: How do highly effective veteran teachers perceive their engagement as contributing to their commitment to remain teaching in lowperforming schools?

1. How would you describe the climate at your school?

Prompts: What are the positive and negative aspects of the school's climate?

2. How do the highly effective veteran teachers you identified contribute to the school's work climate?

3. Describe their relationships with their peers.

4. Describe their relationships with the school's administration. 
5. Describe their relationships with students.

6. Describe their relationships with other stakeholders. 
Terrie E. Blackman

9916 Spring Gate Drive, Louisville

Kentucky, 40241

Tel. (502) 271-7765

Email: terrie.blackman@jefferson.kyschools.us

\section{PROFESSIONAL WORK HISTORY}

2015 to Present Teacher, Barret Traditional Middle School

2011 to 2015 Teacher, Stuart Middle School.

2009 to 2011 Teacher, Ballard High School.

2004 to 2009 Teacher, Westport Traditional Middle School.

2003 to 2004 Teacher, Western Middle School

1995 to 2003 Teacher, Alleyne High School

1994 to 1995 Teacher, Coleridge and Parry High School

1980 to 1992 Bank Officer, promoted from clerk to Supervisor, $1980-1992$.

\section{EDUCATION}

2014 - Present University of Louisville Doctor of Education - Educational Leadership and Organizational Development (Doctoral Candidate)

2012 Kentucky Teacher Internship Program (KTIP)/ Teacher Performance Assessment (TPA) Certificate

2012 Principal Certification Level II and Supervisor Certification Levels I and II

2012 Partially completed ESL Endorsement. Opted to pursue a doctorate in education with the intent of completing ESL Endorsement at a later date

2008 Kentucky Principal Eligibility Certification - School Leaders Licensure

2007 University of Louisville

Masters of Education - Educational Administration

2003 Erdiston Teacher's Training College

Diploma in Education, (History/ Social Studies)

2000 Education Sector Enhancement Program Intermediate Computer Training

1994 University of the West Indies 
Bachelor of Arts (Hons.) History and Sociology

\section{LEADERSHIP EXPERIENCE}

\section{7 to Present}

Elected to be Member of the School Based Decision Making (SBDM) Council at Barret Traditional Middle School

2016 to Present

Homeroom Teacher and FCA Volunteer

2013 to 2015

KTIP Resource Teacher

2014 to 2015

FCA Leader

2011 to 2015 - Sixth Grade Team Leader

2011 to 2015 - Instructional Leadership team (ILT)

This committee meets once monthly to discuss student performance, analyze data and create school improvement strategies.

2011 Elected to be teacher representative on the School Based Decision Making (SBDM) Council at Ballard High school but returned to middle school the same year.

2007 to 2009 - Eighth Grade Team Leader

2006 to 2007 - Sixth Grade Team Leader

Supervised a team of 5 teachers.

Developed a pilot mentorship program for "At-risk" sixth grade boys focusing on improving learning, conduct, self-esteem, and relationship building.

Planned a Culture Week featuring six countries in Latin America. The exhibition was featured in the school's newspaper.

2005 to 2006 - Safe School Coordinator

Liaised regularly with over 20 active school clubs to ensure their smooth and effective running.

2005 to 2007 - CHAMPS Leader

CHAMPS is the acronym for a Jefferson County Public Schools behavior management program that offers directions on student behavior expectations in the school environment: $\mathrm{C}$ - Conversation; $\mathrm{H}$ - Help; $\mathrm{A}$ - Activities; $\mathrm{M}$ Movement; P - Participation; S - Success.

Classroom Behavior Management Leader and member of the CHAMPS Committee. 
Nominated CHAMPS ALL STAR presenter for Westport Traditional Middle School.

Presenter at the Jefferson County Schools CHAMPS ALL STAR Conference in August 2006.

2006, 2007, 2011 to 2015 - Student Teacher Mentor/Coach

Mentor in-training student teachers from University of Louisville, Bellarmine University and Jefferson County Community College

\section{5 to 2003 - Club Leader}

Successfully led the Interschool Christian Fellowship for eight years. The students led school assemblies and initiated annual community programs for the mentally and physically disabled.

\section{9 to 2000 - Homeroom Teacher}

Homeroom teacher for an experimental class of female students for five years at the Alleyne School in Barbados. The class gained the best overall results in the school for their high school examinations.

2000 to 2003 - School Assembly Coordinator

Served on the Curriculum Reform Committee at the Alleyne School. Worked with the Committee to review, upgrade and implement the school's curriculum.

\section{PROFESSIONAL DEVELOPMENT SEMINARS}

2017

Deeper Learning Symposium: Project-Based Learning

Facing History: Holocaust and Human Behavior

2015, 2016

Youth Mental Health First Aid Training

2016 Diversity Training - Multicultural Summit

2016 Middle School Advance Program Differentiation

2015 PBIS Summer PD Institute

2014 Professional Learning Communities (PLCS) Training

2013 Teambuilding/ Team Effectiveness - Transforming One Year at a Time

2012 Magic in the Middle Conference

2011 Workshop on using the Smart Board.

Workshops on Cultural Competency in the classroom. 
2010 Trained to teach Advance Placement World History (College Board Certified History Course).

\section{3 to 2010}

Workshop on developing skills in integrating technology in classroom teaching.

2008 to 2009

Developing Open Response and Multiple-Choice questions for Social Studies.

2006 Technical Integration Program (TIP) Training in usage of the personal computer (PC) in the classroom.

2005 Teaching Life Skills to Middle School students.

2005 Workshop in differentiated learning (teaching students with different learning

2004, 2005

$$
\text { styles) }
$$

Literacy - Developing reading skills in Middle School.

\section{AWARDS/RECOGNITION}

2012 Selected by students as the Teacher of the Month for the month of February

2011 Selected by Ballard High School to represent the school in a televised documentary on teacher evaluation.

\section{6 to 2009}

Selected as the teacher representative featured in the Westport Traditional Middle School magazine.

Selected as the teacher representative for the Jefferson County Public Schools (JCPS) featured on the homepage of the JCPS website.

2006

Nominated for the Disney Teacher of the Year Award.

Selected by peers as the Teacher of the Month for the month of March.

Member of Golden Key International Academic Society.

Was selected as a member of a team of teachers and administrators from

Kentucky to represent the state in the establishment of international partnerships with schools in Dijon, France.

Selected to represent Westport Traditional Middle School at the National Middle School Conference in Philadelphia.

Recipient of a GE Grant to represent Westport Traditional Middle School at the Keystone Foundation Key Issues Institute in Silverthorne, Colorado. 


\section{SERVICE}

2017

Serving in a Christian High School Summer Camp

\section{5 to Present}

Outreach to College-Age Students at the University of Louisville

\section{1 to 2012}

Member of Worship Team at Southeast Christian Church

\section{9 to 2013}

Parent volunteer with Du Pont Manual High School sports teams specifically involved in fundraising and student development.

\section{PROFESSIONAL REFERENCES}

Mr. Tom Wortham

Principal

Barret Traditional Middle School

2561 Grinstead Drive,

Louisville, KY. 40206

tom.wortham@jefferson.kyschools.us

Mr. Tim Campbell

Assistant Principal

Barret Traditional Middle School

2561 Grinstead Drive

Louisville, KY. 40206

tim.campbell@jefferson.kyschools.us

Mr. Titus Exum

Retired Assistant Principal

2606 Springbud Court

Louisville, KY. 40220

Tel: 502 499-5615

E-Mail: thexbossoo@,bellsouth.net

Ms. Lesa May

Counselor

Barret Traditional Middle School

2561 Grinstead Drive

Louisville, KY. 40206

Lesa.may@jefferson.kyschools.us 
Ms. Dana Wimsatt

Teacher

Barret Traditional Middle School

2561 Grinstead Drive

Louisville, KY. 40206

dana.wimsatt@jefferson.kyschools.us 